Illinois State University

ISU ReD: Research and eData

Theses and Dissertations

4-2-2019

\title{
Effects Of Electrical Stimulation On Glioma Cells In Vitro With Implications For Treating Chronic Pain: Development Of A Model System
}

David C. Platt

Illinois State University, dcplatt26@gmail.com

Follow this and additional works at: https://ir.library.illinoisstate.edu/etd

Part of the Biochemistry Commons, Biology Commons, and the Chemistry Commons

\section{Recommended Citation}

Platt, David C., "Effects Of Electrical Stimulation On Glioma Cells In Vitro With Implications For Treating Chronic Pain: Development Of A Model System" (2019). Theses and Dissertations. 1092.

https://ir.library.illinoisstate.edu/etd/1092

This Thesis is brought to you for free and open access by ISU ReD: Research and eData. It has been accepted for inclusion in Theses and Dissertations by an authorized administrator of ISU ReD: Research and eData. For more information, please contact ISUReD@ilstu.edu. 


\section{EFFECTS OF ELECTRICAL STIMULATION ON GLIOMA CELLS IN VITRO WITH IMPLICATIONS FOR TREATING CHRONIC PAIN: \\ DEVELOPMENT OF A MODEL SYSTEM}

\section{DAVID C. PLATT}

\section{Pages}

Glial cells comprise over $70 \%$ of the central nervous system cells and exhibit diverse functions including regulation of synaptic transmission, neuron protection/repair, maintenance of neuronal metabolism, and are implicated in the development of persistent neuropathic pain. In addition, a perturbation in the concentration of intracellular reactive oxygen species (ROS) and reactive nitrogen species (RNS) has likewise been associated with the development of a chronic pain state. This perturbation in ROS and RNS creates an environment of oxidative stress. However, the mechanism by which the pain signal transmission is modulated, and the roles ROS play in the perpetuation of the pain state are poorly understood processes. Although treatments using electrical stimulation (ES) have been shown to be effective in providing clinical pain relief, their mechanism of action is likewise poorly understood. Traditional explanations propose that the applied electric field is affecting a specific population of neurons; however, it has been previously demonstrated in vivo that ES of rat neuronal tissue modulates the genes expressed in the surrounding glial cells. Thus experiments have been designed to examine the potential effect of ES on ROS generation, RNS generation, and the gene expression of cultured Rattus norvegicus C6 glioma cells. This work has led to the development of a non-animal model system to evaluate the role(s) of glial cells. 
KEYWORDS: electrical stimulation; glial cells; fluorescence; QPCR; reactive oxygen species 


\title{
EFFECTS OF ELECTRICAL STIMULATION ON GLIOMA CELLS IN VITRO WITH IMPLICATIONS FOR TREATING CHRONIC PAIN: \\ DEVELOPMENT OF A MODEL SYSTEM
}

DAVID C. PLATT

\author{
A Thesis Submitted in Partial \\ Fulfillment of the Requirements \\ for the Degree of \\ MASTER OF SCIENCE \\ Department of Chemistry \\ ILLINOIS STATE UNIVERSITY
}


Copyright 2019 David C. Platt 


\section{EFFECTS OF ELECTRICAL STIMULATION ON GLIOMA CELLS IN VITRO WITH IMPLICATIONS FOR TREATING CHRONIC PAIN: \\ DEVELOPMENT OF A MODEL SYSTEM}

DAVID C. PLATT

COMMITTEE MEMBERS:

Marjorie A. Jones, Chair

Jon A. Friesen

Jun-Hyun Kim 


\section{ACKNOWLEDGMENTS}

Here I would like to take the opportunity to acknowledge the Illinois State University Department of Chemistry for graciously admitting me into their programs, and for their continued support and encouragement throughout my many years there. Also, I would like to thank Dr. David Cedeño and all our collaborators at the Millennium Pain Center, specifically Jon Rink, for their hard work on this project. I must also acknowledge my family and friends who, for as long as I can remember, have been unwavering in their belief in my abilities and future successes. Thank you all for your innumerable contributions to this work.

D.C.P. 


\section{CONTENTS}

Page

ACKNOWLEDGMENTS

TABLES $\quad$ V

FIGURES

CHAPTER I: INTRODUCTION 1

CHAPTER II: MATERIALS AND METHODS 4

$\begin{array}{ll}\text { Glutamate } & 4\end{array}$

$\begin{array}{ll}\text { Cell Culture } & 4\end{array}$

MTT Cell Viability Assay $\quad 5$

$\begin{array}{ll}\text { Light Microscopy } & 5\end{array}$

Fluorescent Probe Assays $\quad 5$

$\begin{array}{ll}\text { Electrical Stimulation } & 6\end{array}$

Quantitative Polymerase Chain Reaction (QPCR) 10

CHAPTER III: RESULTS AND DISCUSSION 12

$\begin{array}{ll}\text { MTT Assay Results } & 12\end{array}$

Use of Light Microscopy to Asses Cells Exposed to Electrical Stimulation 14

Quantitative Polymerase Chain Reaction (QPCR) Results 15

BAG3 Results (I) 17

$\begin{array}{ll}\text { BAG3 Results (II) } & 18\end{array}$

BAG3 Results (III) 19

$\begin{array}{ll}\text { GFAP Results (I) } & 20\end{array}$

GFAP Results (II) $\quad 21$ 
Anodic Passive Recharge Results 49

Anodic Passive Recharge Results cont.

Cathodic Monophasic Results 53

Cathodic Monophasic Results cont.

Anodic Monophasic Results $\quad 58$

$\begin{array}{ll}\text { Anodic Monophasic Results cont. } & 60\end{array}$

Asymmetric Biphasic 1-2 Results $\quad 62$

Asymmetric Biphasic 1-2 Results cont. 64

Asymmetric Biphasic 2-1 Results 66

$\begin{array}{ll}\text { Asymmetric Biphasic 2-1 Results cont. } & 68\end{array}$

$\begin{array}{ll}\text { Symmetric Biphasic Results } & 70\end{array}$

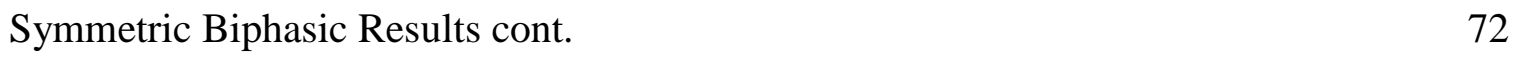

Fluorescent Probe Assay Summary $\quad 74$

CHAPTER IV: CONCLUSION

$\begin{array}{ll}\text { Conclusions } & 76\end{array}$

$\begin{array}{ll}\text { CHAPTER V: FUTURE WORK } & 78\end{array}$

$\begin{array}{ll}\text { Mitosox Optimization } & 78\end{array}$

$\begin{array}{ll}\text { Temperature Effects Experiment } & 78\end{array}$

$\begin{array}{ll}\text { Dimethylfumarate Experiment } & 78\end{array}$

$\begin{array}{ll}\text { WORKS CITED } & 79\end{array}$

APPENDIX A: SUPPLIMENTRY MATERIALS 83 


\section{TABLES}

Table

Page

1. Table 1: Panel of genes selected for testing in the QPCR analysis and their reported roles

2. Table 2: Tabulated summary of the QPCR results

3. Table 3: A) Tabulated summary of the effect of each waveform on the gene panel as a

whole. B) Tabulated summary of the modulation of the gene panel tested

5. Table 4: Tabulated summary of the fluorescent probe trend results at the first time point

6. Table 5: Tabulated summary of the fluorescent probe trend results 


\section{FIGURES}

Figure

$\begin{array}{lr}\text { 1. Waveform representations } & 8\end{array}$

2. Digital representation of the electrode holder (right) and stimulation apparatus (left) 8

3. Electrical stimulation example $\quad 9$

4. Example plate setup for ES experiments 10

5. Results (mean $\pm \mathrm{SD} ; \mathrm{n}=4$ ) from the serial dilution of a glial cell pool experiment 13

6. Light microscopy images (40x) of dilution experiment 14

7. Light microscopy images (40x) of the same cell population before cathodic PR ES (left) and after ES (right)

8. Comparison of BAG3 normalized gene expression with the $7 \mathrm{ES}$ waveforms to the BAG3 normalized gene expression without ES

9. Comparison of BAG3 normalized gene expression with the 7 ES waveforms and glutamate to the BAG3 normalized gene expression with only glutamate

10. Comparison of BAG3 normalized gene expression with the 7 ES waveforms and the $7 \mathrm{ES}$ waveforms with glutamate to the BAG3 normalized gene expression control groups without ES

11. Comparison of GFAP normalized gene expression with the 7 ES waveforms to the GFAP normalized gene expression without ES

12. Comparison of GFAP normalized gene expression with the 7 ES waveforms and glutamate to the GFAP normalized gene expression with only glutamate 
13. Comparison of GFAP normalized gene expression with the 7 ES waveforms and the 7 ES waveforms with glutamate to the GFAP normalized gene expression control groups without ES

14. Comparison of GS normalized gene expression with the 7 ES waveforms to the GS normalized gene expression without ES

15. Comparison of GS normalized gene expression with the $7 \mathrm{ES}$ waveforms and glutamate to the GS normalized gene expression with only glutamate

16. Comparison of GS normalized gene expression with the $7 \mathrm{ES}$ waveforms and the 7 ES waveforms with glutamate to the GS normalized gene expression control groups without ES

17. Comparison of GSR normalized gene expression with the 7 ES waveforms to the GSR normalized gene expression without ES

18. Comparison of GSR normalized gene expression with the 7 ES waveforms and glutamate to the GSR normalized gene expression with only glutamate

19. Comparison of GSR normalized gene expression with the 7 ES waveforms and the 7 ES waveforms with glutamate to the GSR normalized gene expression control groups without ES

20. Comparison of HMOX1 normalized gene expression with the 7 ES waveforms to the HMOX1 normalized gene expression without ES

21. Comparison of HMOX1 normalized gene expression with the $7 \mathrm{ES}$ waveforms and glutamate to the HMOX1 normalized gene expression with only glutamate 
22. Comparison of HMOX1 normalized gene expression with the 7 ES waveforms and the 7 ES waveforms with glutamate to the HMOX1 normalized gene expression control groups without ES

23. Comparison of MT2A normalized gene expression with the 7 ES waveforms to the MT2A normalized gene expression without ES

24. Comparison of MT2A normalized gene expression with the 7 ES waveforms and glutamate to the MT2A normalized gene expression with only glutamate

25. Comparison of MT2A normalized gene expression with the 7 ES waveforms and the 7 ES waveforms with glutamate to the MT2A normalized gene expression control groups without ES

26. Comparison of S100A4 normalized gene expression with the 7 ES waveforms to the S100A4 normalized gene expression without ES

27. Comparison of S100A4 normalized gene expression with the 7 ES waveforms and glutamate to the S100A4 normalized gene expression with only glutamate

28. Comparison of S100A4 normalized gene expression with the 7 ES waveforms and the 7 ES waveforms with glutamate to the S100A4 normalized gene expression control groups without ES

29. Comparison of SLC7A11 normalized gene expression with the 7 ES waveforms to the SLC7A11 normalized gene expression without ES

30. Comparison of SLC7A11 normalized gene expression with the 7 ES waveforms and glutamate to the SLC7A11 normalized gene expression with only glutamate 
31. Comparison of SLC7A11 normalized gene expression with the 7 ES waveforms and the 7 ES waveforms with glutamate to the SLC7A11 normalized gene expression control groups without ES.

32. (A) Graphical representation of the normalized DAF-FM signal at the initial reading as a result of cathodic PR ES with or without glutamate treatment. (B) Graphical representation of the normalized DAF-FM signal changing with time as a result of cathodic PR ES with or without glutamate treatment

33. (A) Graphical representation of the normalized Mitosox signal at the initial reading as a result of cathodic PR ES with or without glutamate treatment. (B) Graphical representation of the normalized Mitosox signal changing with time as a result of cathodic PR ES with or without glutamate treatment

34. (A) Graphical representation of the normalized DAF-FM signal at the initial reading as a result of anodic PR ES with or without glutamate treatment. (B) Graphical representation of the normalized DAF-FM signal changing with time as a result of anodic PR ES with or without glutamate treatment

35. (A) Graphical representation of the normalized Mitosox signal at the initial reading as a result of anodic PR ES with or without glutamate treatment. (B) Graphical representation of the normalized Mitosox signal changing with time as a result of anodic PR ES with or without glutamate treatment

36. (A) Graphical representation of the normalized DAF-FM signal at the initial reading as a result of cathodic monophasic ES with or without glutamate treatment. (B) Graphical representation of the normalized DAF-FM signal changing with time as a result of cathodic monophasic ES with or without glutamate treatment 
37. (A) Graphical representation of the normalized Mitosox signal at the initial reading as a result of cathodic monophasic ES with or without glutamate treatment. (B) Graphical representation of the normalized Mitosox signal changing with time as a result of cathodic monophasic ES with or without glutamate treatment

38. (A) Graphical representation of the normalized DAF-FM signal at the initial reading as a result of anodic monophasic ES with or without glutamate treatment. (B) Graphical representation of the normalized DAF-FM signal changing with time as a result of anodic monophasic ES with or without glutamate treatment

39. (A) Graphical representation of the normalized Mitosox signal at the initial reading as a result of anodic monophasic ES with or without glutamate treatment. (B) Graphical representation of the normalized Mitosox signal changing with time as a result of anodic monophasic ES with or without glutamate treatment

40. (A) Graphical representation of the normalized DAF-FM signal at the initial reading as a result of asymmetric biphasic 1-2 ES with or without glutamate treatment. (B) Graphical representation of the normalized DAF-FM signal changing with time as a result of asymmetric biphasic 1-2 ES with or without glutamate treatment

41. (A) Graphical representation of the normalized Mitosox signal at the initial reading as a result of asymmetric biphasic 1-2 ES with or without glutamate treatment. (B) Graphical representation of the normalized Mitosox signal changing with time as a result of asymmetric biphasic 1-2 ES with or without glutamate treatment 
42. (A) Graphical representation of the normalized DAF-FM signal at the initial reading as a result of asymmetric biphasic 2-1 ES with or without glutamate treatment. (B) Graphical representation of the normalized DAF-FM signal changing with time as a result of asymmetric biphasic 2-1 ES with or without glutamate treatment

43. (A) Graphical representation of the normalized Mitosox signal at the initial reading as a result of asymmetric biphasic 2-1 ES with or without glutamate treatment. (B) Graphical representation of the normalized Mitosox signal changing with time as a result of asymmetric biphasic 2-1 ES with or without glutamate treatment

44. (A) Graphical representation of the normalized DAF-FM signal at the initial reading as a result of symmetric biphasic ES with or without glutamate treatment. (B) Graphical representation of the normalized DAF-FM signal changing with time as a result of symmetric biphasic ES with or without glutamate treatment

45. (A) Graphical representation of the normalized Mitosox signal at the initial reading as a result of symmetric biphasic ES with or without glutamate treatment. (B) Graphical representation of the normalized Mitosox signal changing with time as a result of symmetric biphasic ES with or without glutamate treatment 


\section{CHAPTER I: INTRODUCTION}

The initiation, propagation, and perception of acute pain has been traditionally described in terms of the excitation of neuronal transmission pathways (Verkhratsky \& Kirchhoff, 2007a). Although these pathways represent an integral process responsible for the organism's perception of pain, they are unable to adequately explain the mechanism by which acute pain develops into chronic pain. It has been demonstrated that, in response to injury, neurons and glial cells sustain nociceptive signals via a variety of neurotransmitters, cytokines, and neuropeptides (Salvemini et al., 2011). The initiating event in these signaling processes was reported by Grace et al. to involve the production of reactive oxygen species (ROS) and reactive nitrogen species (RNS) by both enzymatic and non-enzymatic processes (Matés et al., 2006; Salvemini et al., 2011; Grace et al., 2016). The production of ROS and RNS results in hypersensitivity of neurons by altering the neuronal and biochemical processing within the synapses. When the neurons become sensitized, the acute nociceptive signals can persist initiating a chronic pain state (Grace et al., 2016). A recent explanation of this progression from acute to chronic pain implicates the activation of glial cells adjacent to the site of injury or inflammation in addition to sensitization of neurons (Kung et al., 2013). In a healthy individual, glial cells function as housekeeping cells for neurons; however, once activated the glia will undertake an immunoresponsive role characterized by the release of chemical signals such as cytokines and chemokines that induce neuronal hyperexcitability, necrosis, and inflammation (Verkhratsky \& Kettenmann, 1996). This process would seem to exacerbate the symptomology of the chronic pain state, but it has been shown that the activated glia also release anti-inflammatory modulators indicative of a neuroprotective role (Milligan \& Watkins, 2009). Mechanistically speaking this process is very poorly understood and in need of description. Our collaborators at Millennium Pain Center (MPC; Bloomington, 
IL) have previously performed a study that indicated chronic back pain can be attenuated via the application of electrical stimulation (ES) (Tiede et al., 2013). Other clinical reports indicate a similar effect of ES in alleviating chronic pain in humans (Sdrulla et al., 2018). In a separate study the chronic pain attenuation by ES seen in the rodent model was attributed to the modulation of gene expression for genes associated with nociceptive regulatory pathways (Vallejo et al., 2016). These results, taken in conjunction with the reports of neuroprotective activity in glial cells, suggest that pain relief in response to electrical stimulation is potentially due, in part, to the differential expression of genes in the activated glial cells. To investigate this in an animal cell culture system, in collaboration with MPC, experiments were designed to measure axenic glial cell gene expression, with or without the presence of the neurotransmitter glutamate, for a panel of genes reported to be associated with either oxidative stress or glial activation. Further, the production of reactive oxygen species by the glial cells, with or without the presence of the neurotransmitter glutamate, was also studied utilizing two fluorescent probes sensitive to the presence of superoxide radical (a potent ROS) and nitric oxide radical (RNS) species.

Glutamate is an excitatory neurotransmitter which acts as a neuronal-glial signal activating glial cells via one of three types of glutamate receptors (Verkhratsky \& Kirchhoff, 2007b). Kainite, $\alpha$-amino-3-hydroxy-5-methyl-4-isoxazolepropionic acid, and N-methyl-Daspartic acid - type glutamate receptors are ionophore channels that, in the presence of glutamate, allow $\mathrm{Ca}^{2+}$ levels to change. This glutamate signaling results in release of $\mathrm{Ca}^{2+}$ from the endoplasmic reticulum into the cytoplasm and propagation of an interglial $\mathrm{Ca}^{2+}$ wave. This $\mathrm{Ca}^{2+}$ signal will activate NO synthase producing RNS in addition to propagating through gap junctions to adjacent glia or neurons (Verkhratsky \& Kirchhoff, 2007b; Grace et al., 2016). 
Additionally, gliotransmitters such as taurine and D-serine can also be released in response to changes in cytosolic $\mathrm{Ca}^{2+}$ (Verkhratsky \& Kettenmann, 1996). Also, glutamate is reported to induce the production of ROS thereby resulting in oxidative stress (Liu et al., 2009). Taurine, in contrast, has been reported to elicit protective effects against ROS, and inflammation associated with oxidative stress (Niu et al., 2018). Given these various mechanisms reported to be involved with pain signaling and the clinical reports of ES attenuating pain, a series of experiments were conducted to 1) grow axenic glial cells in culture 2) measure changes in glial gene expression in response to glutamate with and without ES and 3) measure the production of glial ROS and RNS in response to glutamate with and without ES. 


\section{CHAPTER II: MATERIALS AND METHODS}

Glutamate - Glutamate was obtained from Sigma Aldrich (St. Louis, MO) and used as provided, at biologically relevant concentrations to stress the cultured glioma cells. It was first dissolved in $\mathrm{H}_{2} \mathrm{O}$ preparing a $100 \mathrm{mM}$ stock solution. This solution was loaded into a syringe and filter sterilized with a MILLEX® GP $0.22 \mu \mathrm{m}$ syringe driven filter unit from Millipore (Cork, Ireland).

Cell Culture - Axenic Rattus norvegicus C6 glioma cells (ATCC CCL-107) were grown in sterile 6-well plates using high glucose Dulbecco's Modified Eagle's Medium (incomplete DMEM) (Sigma Life Sciences D6429; St. Louis, MO) supplemented with 15\% (v/v) horse serum (ATCC; Manassas, VA) and 5\% (v/v) heat treated fetal bovine serum (GIBCO; Waltham, MA) designated as 'complete medium' (Cookson et al., 1995). Cells were grown at $37^{\circ} \mathrm{C}$ under a $5 \% \mathrm{CO}_{2}$ atmosphere in the presence of an open vessel of $\mathrm{H}_{2} \mathrm{O}$ to maintain relative humidity. To transfer the adherent cells, trypsin (Sigma Life Sciences T4049; St. Louis, MO) was used to release cells from the bottom of the plate in accordance with the manufacturer's instructions. The trypsin was subsequently neutralized upon addition of complete medium by the $\alpha-1$ antitrypsin present from the serum supplementation of the complete DMEM. This cell preparation was then centrifuged (Labnet Hermle Z 400K) at $2000 \mathrm{rpm}$ for 10 minutes at $7^{\circ} \mathrm{C}$. The supernatant was discarded and the resultant cell pellet was re-suspended in complete DMEM and plated as required. Large cultures of cells were maintained in CELLSTAR ${ }^{\circledR}$ TC sterile 6-well plates (Greiner Bio-one). For experimentation, cells were harvested, as previously described, resuspended in complete DMEM, and applied to tissue culture treated sterile 96-well cell culture plates (Falcon ${ }^{\circledR}$ ) in a total volume of $100 \mu \mathrm{L}$ per well. Experiments began when the cells in the 96-well plates were deemed confluent. All cell culturing was performed in a UV sterilized hood 
(Thermo Electron Corporation Forma Class II Biological Safety Cabinet) for maintaining sterile conditions. Surfaces contacted within the hood were treated with $70 \%$ ethanol solution to disinfect these surfaces.

MTT Cell Viability Assay - The 3-(4,5-dimethylthiazol-2-yl)-2,5-diphenyltetrazolium bromide (MTT) assay was utilized as described in the literature with slight modifications to assess glioma cell viability (Cookson et al., 1995). MTT incubation occurred at room temperature for a duration of 45 minutes. Absorbance was measured at $595 \mathrm{~nm}$ using a Bio-Rad iMark Microplate Reader. The experimental groups were conducted in quadruplicate and results reported as a mean \pm standard deviation. This value was corrected by subtracting the average absorbance value of four medium only (negative control) wells. These assays were carried out in 96 well plates in which the complete DMEM was replaced with incomplete DMEM diluted 1:10 with filter sterilized saline.

Light Microscopy - Visual assessment of the morphology and distribution of the glioma cells was performed using an inverted light microscope (JENCO USA) under 40x magnification. Images were captured with an Asus ZOOM3 digital camera.

Fluorescent Probe Assays - Mitosox Red Superoxide indicator (Invitrogen), an analog of dihydroethidium, was prepared according to manufacturer's instruction and implemented with a modification of the manufacturer's directions. This probe was utilized to assess the presence of superoxide radical species (Robinson et al., 2006). Another probe, 2'-7'-dichlorofluorescin diacetate (DAF-FM), obtained from EDM Millipore Corp., was prepared according to manufacturer's instructions and implemented with a modified procedure of the manufacturer's directions. DAF-FM is employed to assess the presence of nitric oxide radical species (Tjalkens et al., 2011). For these assays, the medium was changed to a Modified Dulbecco's Modified 
Eagle's Medium (MDMEM) made in house as shown in Appendix A. As the name suggests, this medium is of similar composition as DMEM, but lacks the phenol red $\mathrm{pH}$ indicator, and did not contain sera as the experiments, utilizing this medium, were short in duration. This medium was sterilized in a CORNING® $250 \mathrm{~mL}$ filter system with a $0.22 \mu \mathrm{m}$ cellulose acetate, low protein binding membrane (Sigma Aldrich; St. Louis, MO). Cells were incubated with the fluorescent probes with and without glutamate at $37^{\circ} \mathrm{C}$ for 1 hour. Fluorescence measurements were collected utilizing a Thermo Electron Corporation Fluoroskan Ascent FL microplate fluorimeter at appropriate excitation and emission wavelengths depending on the probe. Fluorescent signals of Mitosox Red wells were assessed by a 544/590 nm excitation/emission couple. Fluorescent signals of DAF-FM wells were assessed by a 485/538 nm excitation/emission couple. Data were collected in quadruplicate and Grubb's tested (Grubbs, 1950) to eliminate outlier signals. The average signal of the no cell control was then subtracted from each signal to correct for background fluorescence. The corrected signals were then averaged and subsequently normalized by dividing by the corrected average signal of the no treatment (e.g. no ES and/or no glutamate) glioma cells, but with the fluorescent probe. By doing these corrections and normalization a comparison can be made of the effect of ES and/or glutamate on the cells' ROS and RNS probe signal relative to the ROS and RNS probe signal of a no treatment cell population without these perturbations. Fluorescent data were collected as a function of time.

Electrical Stimulation - The electrical stimulation (ES) was accomplished using four concentric bipolar electrodes (FHC Microelectrodes; Bowdoin, ME) arranged in parallel, a current isolator (WPI A365; Sarasota, FL), and an arbitrary waveform generator (Siglent SDG1025; Shenzen, China). ES was applied at $50 \mathrm{~Hz}$ for 30 minutes using one of seven different 
waveforms: cathodic (monophasic) or anodic (monophasic) (50 $\mu$ sec pulse width), biphasic symmetric (SymBi) (50 $\mu \mathrm{sec}$ pulse width), biphasic asymmetric 1-2 (AsymBi 1-2) (50 $\mu \mathrm{sec}$ cathodic pulse width and $100 \mu$ sec anodic pulse width), biphasic asymmetric 2-1 (AsymBi 2-1) (50 $\mu$ sec cathodic pulse width and $25 \mu$ sec anodic pulse width), and passively balanced cathodic (Cathodic PR) or anodic (Anodic PR) (60 $\mu$ sec pulse width). Artistic representations of each of the waveforms are depicted in Figure 1. The C6 glial cells (ATCC) were grown in 96-well plates with $100 \mu \mathrm{L}$ complete DMEM medium per well. Two hours prior to stimulation, the medium was changed to high glucose DMEM with no sera (incomplete DMEM). A custom simulation apparatus, pictured in Figures 2 and 3, houses the concentric bipolar electrodes, and situates them in an appropriate orientation such that the electrode tip is submerged in the medium, but elevated above the bottom of the plate. A post stimulation incubation was carried out for two hours at $37^{\circ} \mathrm{C}$ in $5 \% \mathrm{CO}_{2}$ atmosphere. Four replicate wells for each treatment condition then underwent RNA extraction using Tri-Reagent (Sigma Aldrich; St. Louis, MO) following manufacturer's instructions. The four replicate wells were pooled during this extraction creating a single sample with sufficient RNA for analysis. Twelve replicate wells were thus pooled into three samples giving an $n=3$ for each condition. An example plate set-up is depicted in Figure 4 . For each experiment two 96-well plates were seeded using a single pool of glioma cells in complete DMEM. One plate had no glutamate addition while another plate, seeded using the same cell pool, and also contained an additional $10 \mathrm{mM}$ glutamate. Additionally, each plate had four wells of cells designated for MTT cell viability assay. Cells were added to plates a minimum of 12 hours before the experiments were conducted to allow cells to adhere and spread to indicate normal glial cell morphology. ES was done at room temperature in ambient atmosphere for 30 minutes with the 4 replicate wells to be pooled treated simultaneously. 


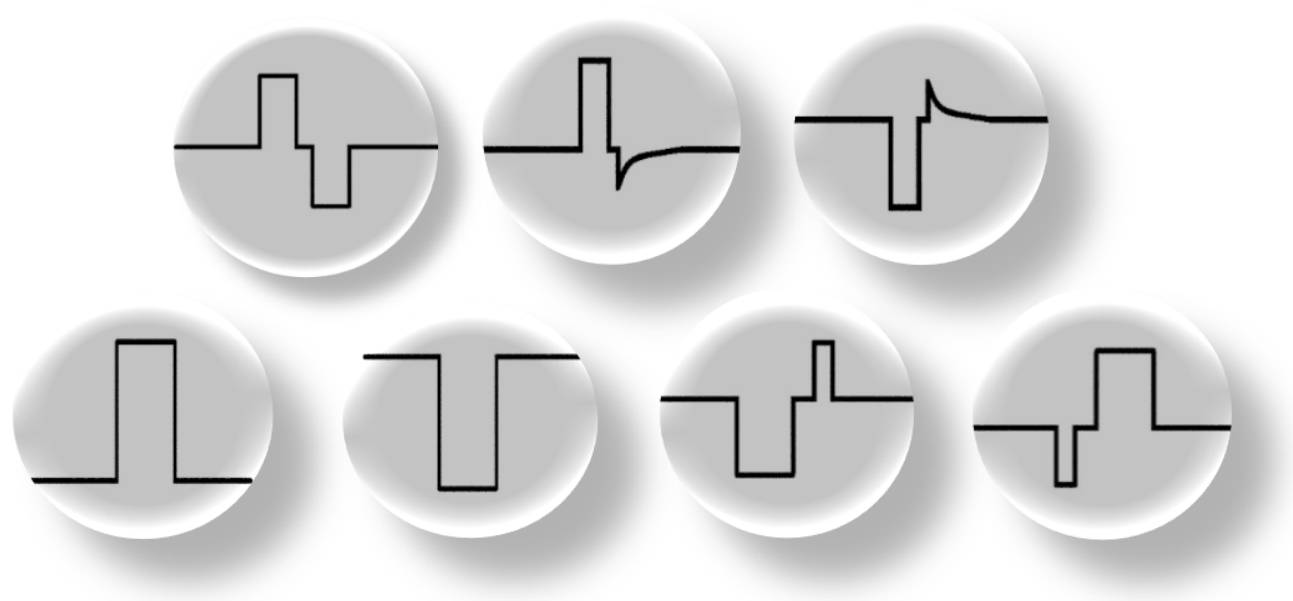

Figure 1: Waveform representations. Balanced waveforms: symmetric biphasic*, anodic $\mathrm{PR}^{*}$, cathodic PR* (Top row; left to right). Unbalanced waveforms: anodic monophasic, cathodic monophasic*, asymmetric biphasic 2-1, and asymmetric biphasic 1-2 (Bottom row; left to right). *Waveforms used clinically (Tiede et al., 2013).
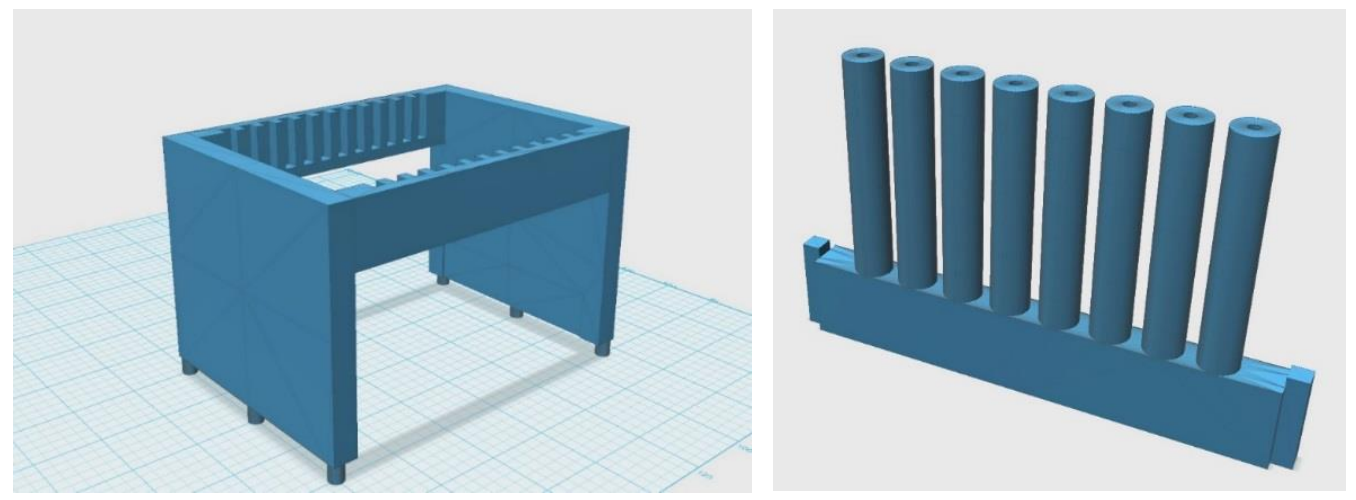

Figure 2: Digital representation of the electrode holder (right) and stimulation apparatus (left). The grooves in the apparatus guide the holder into an ideal position for stimulating any given well on a 96-well plate. 


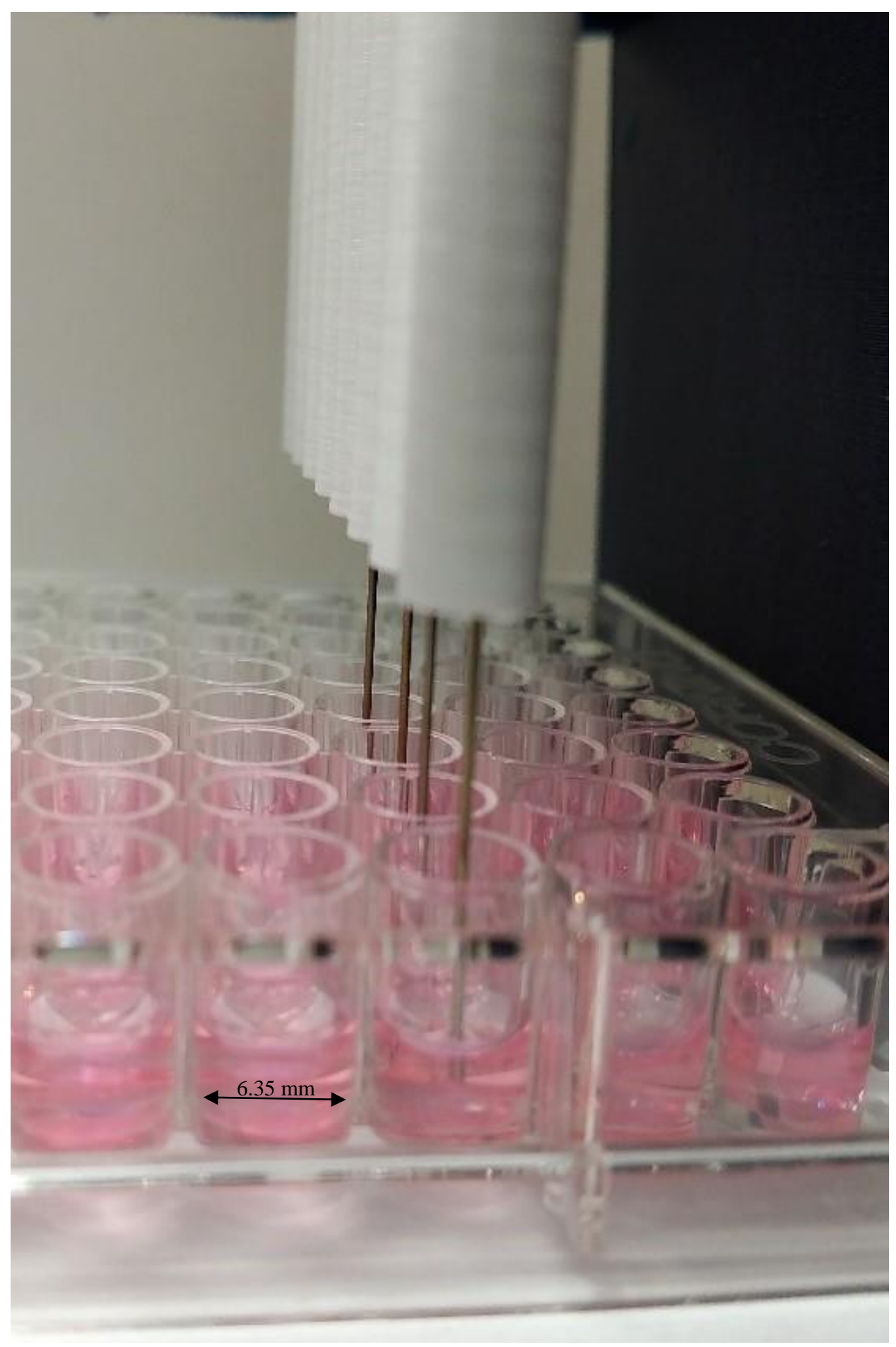

Figure 3: Electrical stimulation example. Concentric bipolar electrodes housed within the electrode guide stimulating row 3 on of a 96-well plate. The four electrodes are pictured with submerged tips that are suspended in $100 \mu \mathrm{L}$ volume. 


\begin{tabular}{|l|c|c|c|c|c|c|c|c|c|c|}
\hline & 1 & 2 & 3 & 4 & 5 & 6 & 7 & 8 & 9 & 10 \\
\hline & $\begin{array}{c}100 \mu \mathrm{L} \\
\text { cells } \\
\text { No ES }\end{array}$ & $\begin{array}{c}100 \mu \mathrm{L} \\
\text { cells } \\
\text { No ES }\end{array}$ & $\begin{array}{c}100 \mu \mathrm{L} \\
\text { cells } \\
\text { No ES }\end{array}$ & $\begin{array}{c}100 \mu \mathrm{L} \\
\text { cells ES } \\
30 \mathrm{~min}\end{array}$ & $\begin{array}{c}100 \mu \mathrm{L} \\
\text { cells ES } \\
30 \mathrm{~min}\end{array}$ & $\begin{array}{c}100 \mu \mathrm{L} \\
\text { cells ES } \\
30 \mathrm{~min}\end{array}$ & $\begin{array}{c}100 \mu \mathrm{L} \\
\text { cells } \\
\text { for MTT }\end{array}$ & $\begin{array}{c}100 \mu \mathrm{L} \\
\text { medium } \\
\text { for MTT }\end{array}$ & \\
\hline A & & & & & & & & & & \\
\hline B & & & & & & & & & & \\
\hline C & & & & & & & & & & \\
\hline D & & & & & & & & & \\
\hline
\end{tabular}

Figure 4: Example plate set up for ES experiments. RNA extracted from rows A-D are pooled for each condition, giving 3 total samples from 12 wells. For columns 7 and 8 , the complete DMEM was replaced with incomplete DMEM 1:10 diluted in sterile saline prior to MTT analysis.

Quantitative Polymerase Chain Reaction (QPCR) - After the post-stimulation incubation, the incomplete DMEM was removed and the glioma cell RNA extracted using TriReagent (Sigma Aldrich; St. Louis, MO) following the manufacturer's instructions. The isolated RNA samples were stored in $75 \%$ ethanol at $-80^{\circ} \mathrm{C}$. To remove any contaminating DNA or protein, the RNA was then processed using a GeneJET RNA Cleanup and Concentration Microkit obtained from ThermoFisher Scientific (Waltham, MA) and used in accordance with the manufacturer's instructions. An MJ Instruments Peltier Thermocycler 200 (Reno, NV) was used to transcribe the RNA sequences to cDNA. Agilent AriaMx Real-Time PCR system (Santa Clara, CA) and a panel of DNA primers were then utilized to amplify and quantitate the cDNA sequences of selected genes. Expression data were normalized using the house-keeping gene GAPDH (Mori et al., 2008). Comparison of normalized gene expression post treatment to unstimulated control glioma cells yielded differential expression attributable to ES alone, glutamate addition alone, or both ES and glutamate. The panel of genes tested can be found in Table 1. 
Table 1: Panel of genes selected for testing in the QPCR analysis and their reported roles.

\begin{tabular}{|c|c|}
\hline Gene & References \\
\hline $\begin{array}{l}\text { GAPDH: (Glyceraldehyde 3-phosphate dehydrogenase; enzyme in } \\
\text { glycolysis pathway) }\end{array}$ & (Mori, et al., 2008) \\
\hline $\begin{array}{l}\text { GFAP: (Glial Fibrillary Acidic Protein; intermediate filament protein } \\
\text { involved in communication and cell proliferation) }\end{array}$ & (Weinstein, 1991) \\
\hline $\begin{array}{l}\text { GSR: (Glutathione-disulfide (GSSG) Reductase; regenerates GSSG for } \\
\text { resisting oxidative stress) }\end{array}$ & (Deponte, 2013) \\
\hline SLC7A11: (cystine/glutamate transporter) & (Bridges et al., 2012) \\
\hline BAG3: (involved in chaperone-assisted selective autophagy) & (Arndt et al., 2010) \\
\hline $\begin{array}{l}\text { HMOX1: (Heme Oxygenase, degrades heme producing CO in response to } \\
\text { oxidative stress) }\end{array}$ & (Loboda et al., 2016) \\
\hline $\begin{array}{l}\text { MT2A: (Metallothionein-2; antioxidant protects against hydroxyl free } \\
\text { radicals) }\end{array}$ & (Ling et al., 2016) \\
\hline $\begin{array}{l}\text { S100a4: (Calcium binding protein functions in motility, invasion, and } \\
\text { tubulin polymerization) }\end{array}$ & (Helfman et al., 2005) \\
\hline $\begin{array}{l}\text { GS: (Glutamine Synthetase; converts glutamate to glutamine in response } \\
\text { to elevated glutamate levels) }\end{array}$ & $\begin{array}{l}\text { (Tiburcio-Félix et al., } \\
\text { 2018) }\end{array}$ \\
\hline
\end{tabular}




\section{CHAPTER III: RESULTS AND DISCUSSION}

MTT Assay Results - Due to the adherent behavior of this cell type there were initially concerns about the cells clumping together hindering the ability to evenly divide the cells into sub-cultures. To see if this was going to prove problematic, the MTT cell viability assay was used to establish whether or not aliquots of a single cell pool, delivered via an 8 channel pipettman, yielded sub-cultures in a reproducible fashion. The experiment began with a single, confluent well of glioma cells from a 6-well plate of cell. This population was trypsinized as previously described and then suspended in complete DMEM creating a single pool of cells. Aliquots ranging from $0-100 \mu \mathrm{L}$ were seeded, in replicates of four, into a 96-well plate.

Complete DMEM was then added to the wells such that each well had a final volume of $100 \mu \mathrm{L}$ of medium. Plates were then incubated for $24 \mathrm{hrs}$. Next, the MTT cell viability assay was performed on the plate. The absorbance at $595 \mathrm{~nm}$ of the four replicates was averaged and then corrected by subtracting the average absorbance of the no cell (medium only) control yielding the data plotted in Figure 5. These data cleanly show that the glioma cells can be delivered with reproducibility and that the consistency of the MTT value from experiment to experiment is a first approximation of use of same cell number and/or cell viability. 


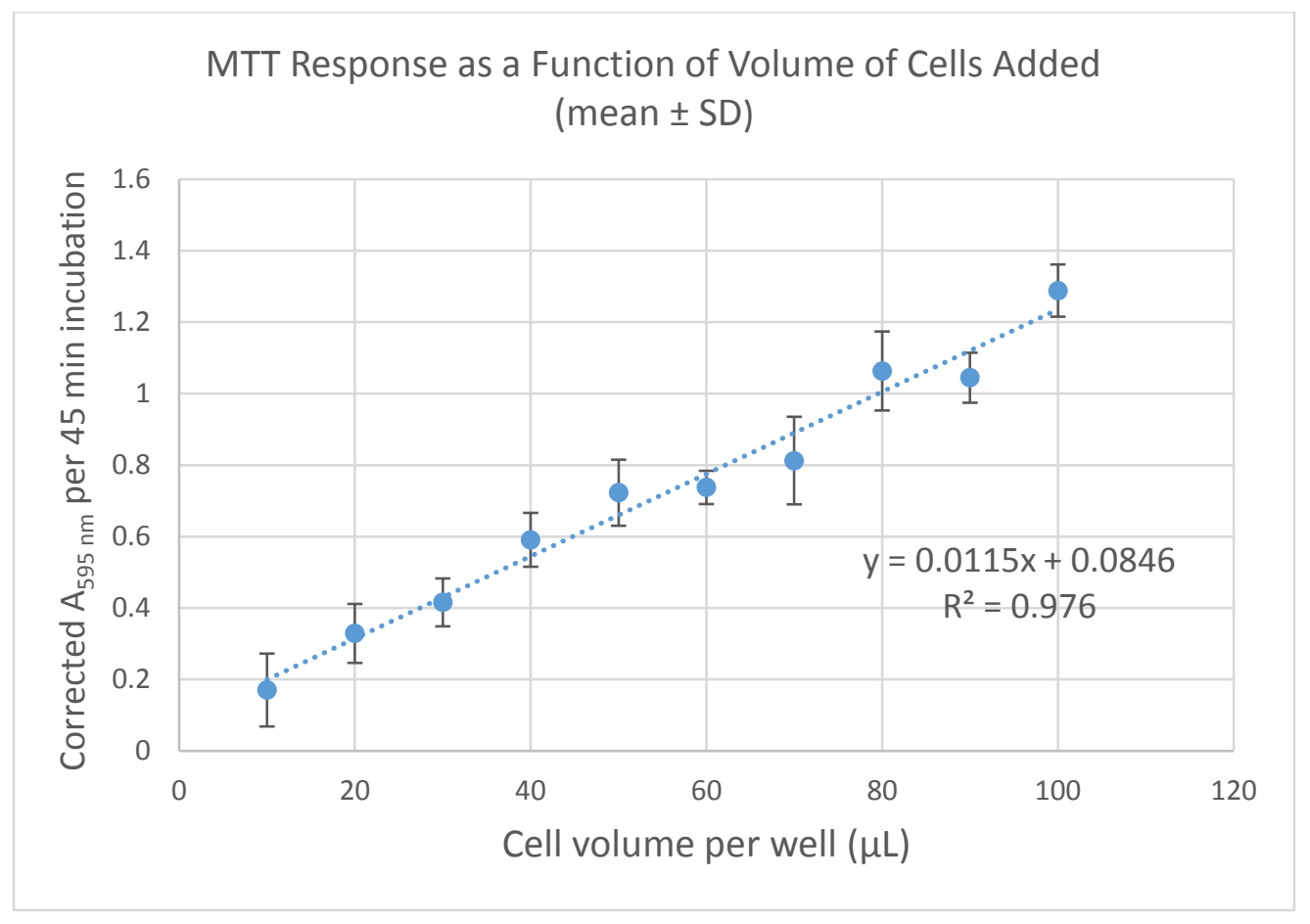

Figure 5: Results (mean $\pm \mathrm{SD} ; \mathrm{n}=4$ ) from the serial dilution of a glial cell pool experiment. Data are shown by plotting the corrected $\mathrm{A}_{595 \mathrm{~nm}}$ per 45 minutes value as a function of volume of cell pool added to the well (with the volume of complete DMEM also added to yield a final volume of $100 \mu \mathrm{L}$; for example, if $20 \mu \mathrm{L}$ of cell pool was seeded then $80 \mu \mathrm{L}$ of medium was also added).

The linear regression analysis of these data indicate that the absorbance at $595 \mathrm{~nm}$ responds linearly in comparison to the cell pool volume aliquots under the conditions tested. This result suggests that the pipette and operator are capable of populating 96-well plates with reproducible sub-cultures of glioma cells. Light microscopy images taken of this experiment are depicted in Figure 6 below and suggest a similar conclusion. 

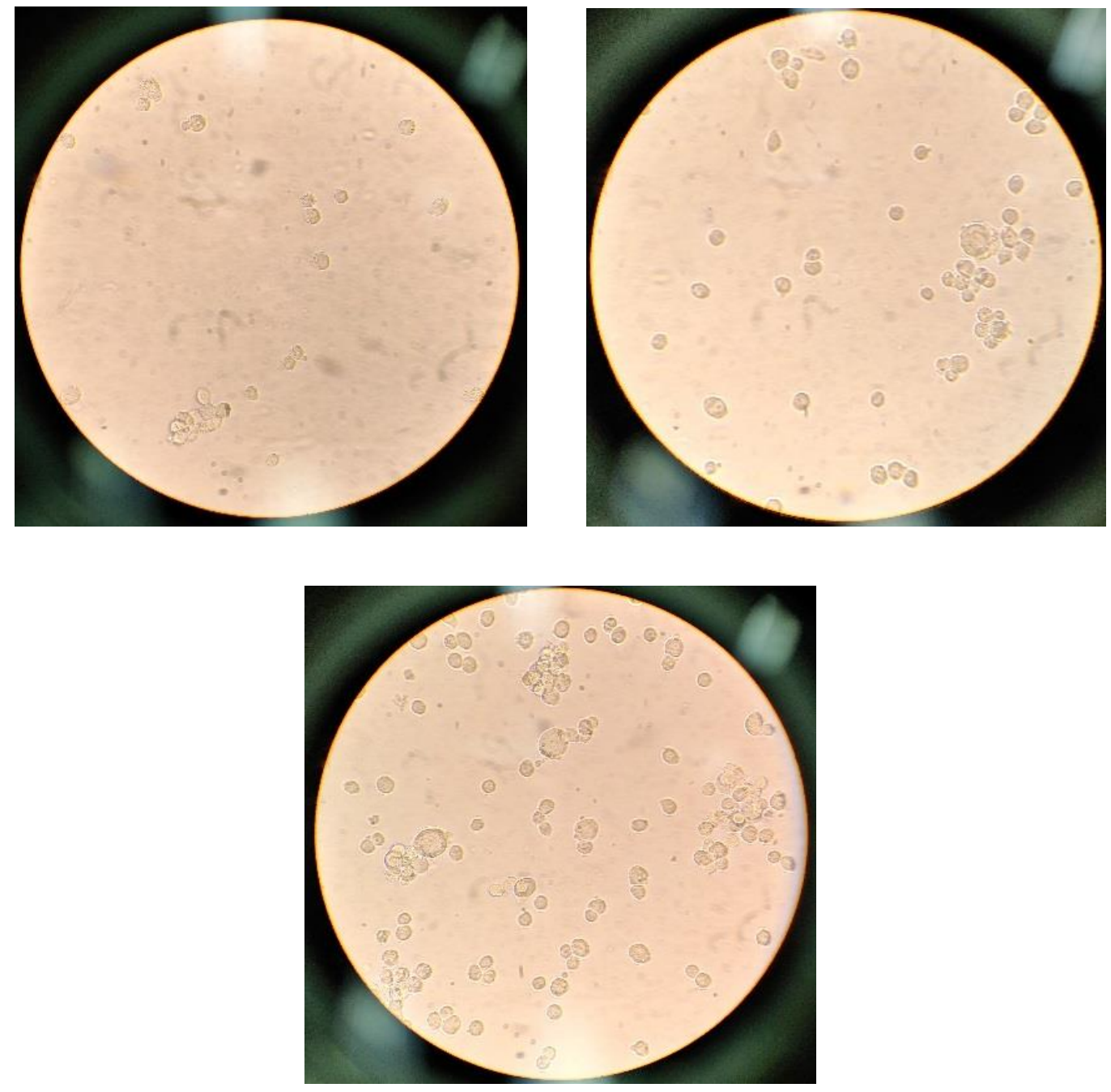

Figure 6: Light microscopy images (40x) of dilution experiment. Volumes aliquoted were $10 \mu \mathrm{L}$ (top left), $20 \mu \mathrm{L}$ (top right), and $50 \mu \mathrm{L}$ (bottom).

Use of Light Microscopy to Asses Cells Exposed to Electrical Stimulation - Cells that are exposed to electrical fields of appropriate strength can be destroyed by electricity. If the cell populations are greatly decreased by the ES parameters utilized during these experiments, differences in RNA expression levels between the experimental group and control group, that 
received no ES, could be attributed to a difference in the population. To establish that the parameters of the electrical field applied during these experiments were not killing large swaths of the cells, light microscopy was used to visualize the cell population before and after ES. Some representative images are presented in Figure 7. It can be seen that our ES waveform parameters cause very little change to cell morphology or distribution of cells on the plate.

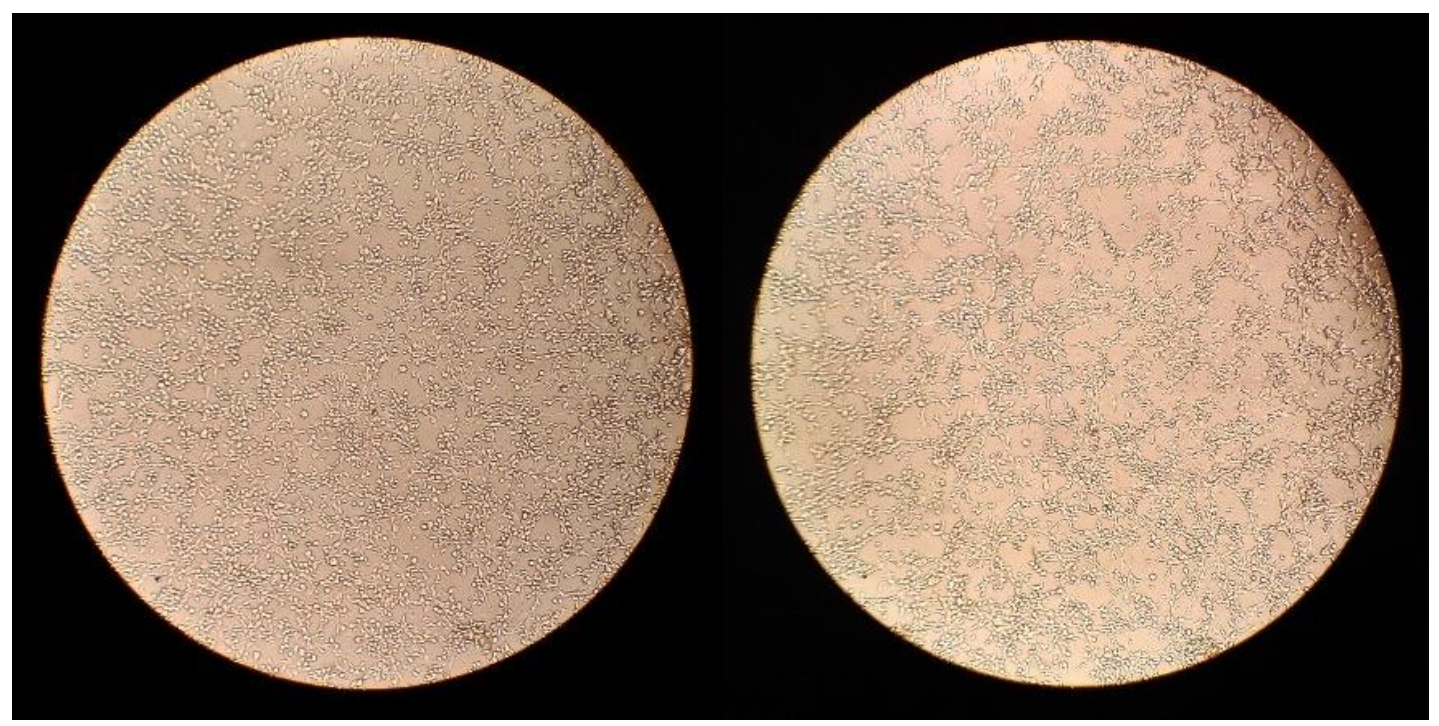

Figure 7: Light microscopy images $(40 x)$ of the same cell population before cathodic PR ES (left) and after ES (right).

Quantitative Polymerase Chain Reaction (QPCR) Results - The relative gene expression data gleaned from the QPCR analysis is overwhelming when represented on a single graph so the data for each gene were separated into three graphs. For each gene, the first graph (I) compares the normalized gene expression of a cell population exposed to ES to the normalized gene expression of a replicate cell population that received no ES. For the first graph of each gene, the shaded exclusionary zone encompasses the mean \pm SD of all of the unstimulated control populations $(n=3)$ for all the waveforms. Relative gene expression levels falling outside the shaded region on these graphs will be interpreted as alterations in gene expression attributable to the ES waveform alone. The second graph (II) is a comparison of 
normalized gene expression of cells in the presence of $10 \mathrm{mM}$ glutamate $(n=3)$ to the normalized gene expression of cells with ES and $10 \mathrm{mM}$ glutamate added $(\mathrm{n}=3)$. For the second graph of each gene, the shaded exclusionary zone encompasses the mean \pm SD of all of the unstimulated control populations in the presence of glutamate for all the waveforms. Relative gene expression levels falling outside the shaded region on these graphs will be interpreted as alterations in gene expression attributable to the effect of ES in the presence of added glutamate. The third graph (III) compares the normalized gene expression of cells with ES and with the addition of $10 \mathrm{mM}$ glutamate $(\mathrm{n}=3)$ to the normalized gene expression of cells with ES and no glutamate added $(n=3)$. Relative gene expression levels falling outside the shaded region on these graphs are different than the mean and standard deviation of both the no ES and no ES with $10 \mathrm{mM}$ glutamate added and will be interpreted as alterations in gene expression attributable ES alone or ES with the addition of $10 \mathrm{mM}$ glutamate. Note: the no ES control groups' normalized expression levels, which delineate the grey region, are omitted in the interest of clarity on the third graphs for each gene. 
BAG3 Results (I) - With no glutamate added the GAPDH normalized BAG3 expression with and without the 7 waveforms of ES are shown in Figure 8. The anodic PR waveform results in an increase of approximately $30 \%$ in the normalized expression level of this gene relative to the no ES control normalized expression levels. All other groups fall within the mean and standard deviation of the control groups.

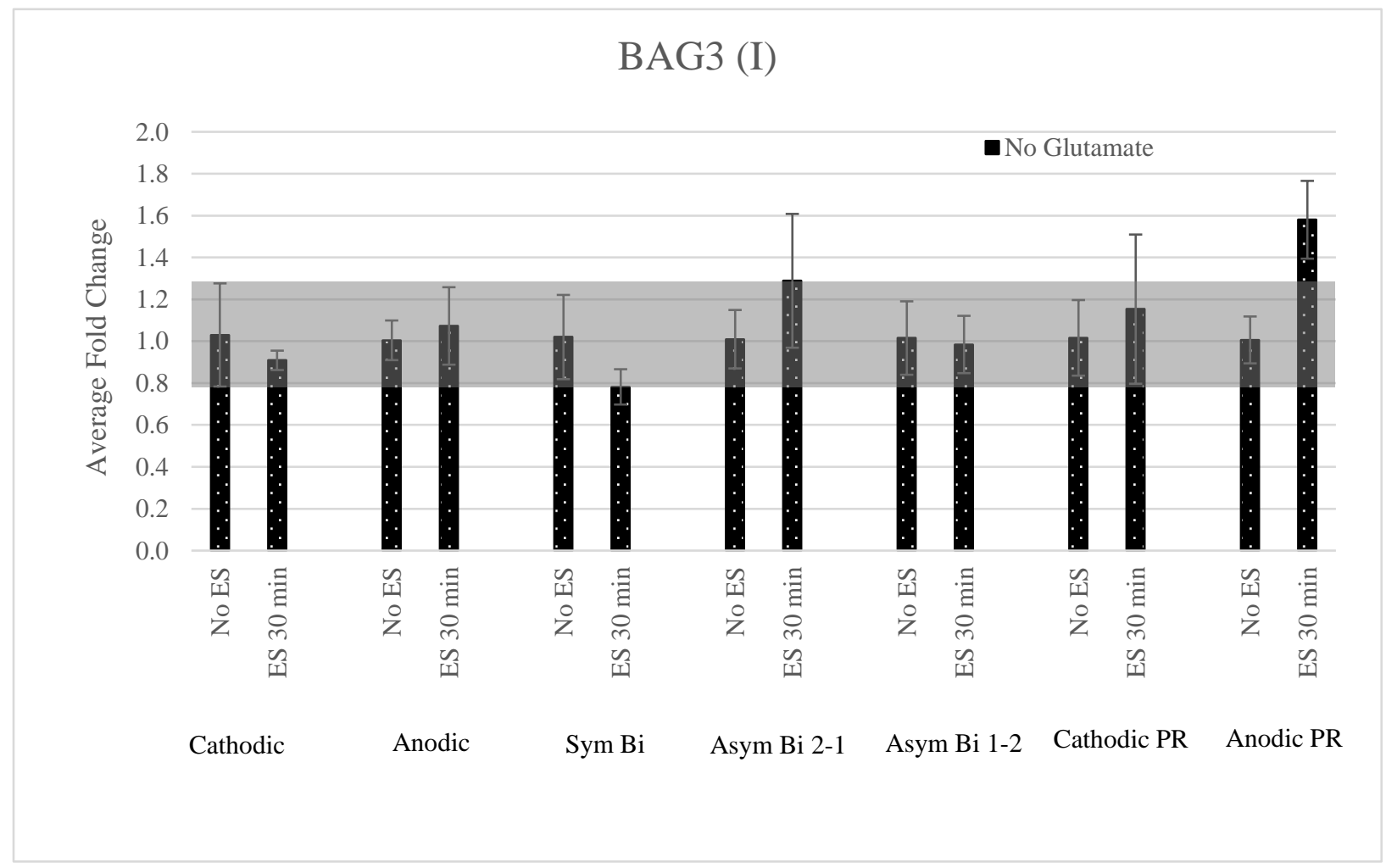

Figure 8: Comparison of BAG3 normalized gene expression with the 7 ES waveforms to the BAG3 normalized gene expression without ES. Values are mean \pm SD for $n=3$ independent replicates. 
BAG3 Results (II) - The normalized BAG3 expression in the presence of added glutamate with and without ES is shown in Figure 9. When added glutamate is present, the anodic monophasic waveform results in an increase by approximately $10 \%$ in the normalized expression level of this gene relative to the normalized expression level of the no ES control. All other groups fall within the mean and standard deviation of the control groups.

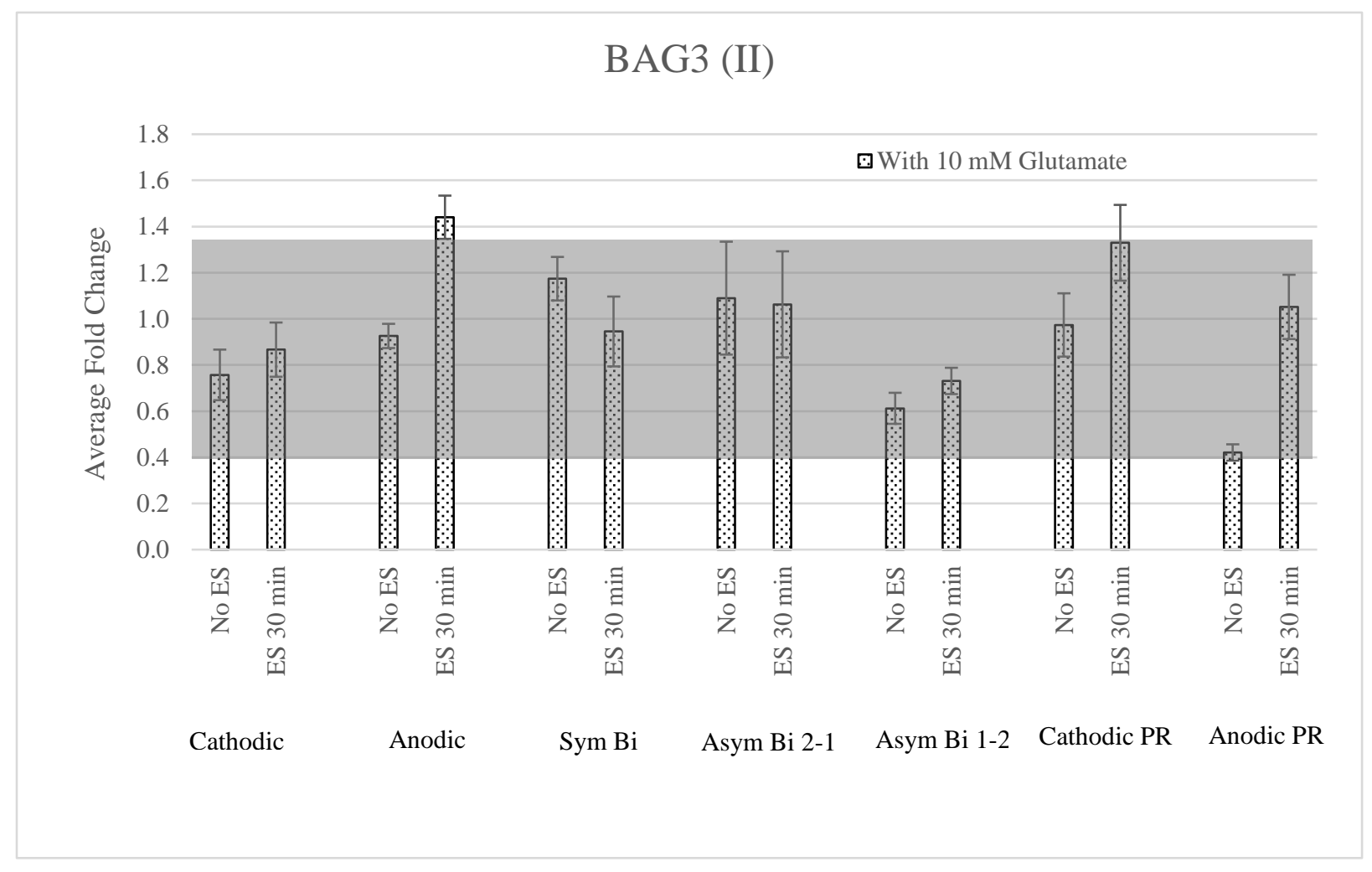

Figure 9: Comparison of BAG3 normalized gene expression with the $7 \mathrm{ES}$ waveforms and glutamate to the BAG3 normalized gene expression with only glutamate. Values are mean \pm $\mathrm{SD}$ for $\mathrm{n}=3$ independent replicates. 
BAG3 Results (III) - The normalized BAG3 expression with and without added glutamate in the presence of the 7 waveforms of ES is shown in Figure 10. The anodic PR waveform, in the absence of added glutamate, results in an increase by approximately $20 \%$ in the normalized expression level of this gene relative to the no ES control groups' normalized expression levels. However, application of ES and glutamate appears to return normalized expression to control levels. The anodic monophasic waveform, in the presence of added glutamate, results in an increase by approximately $10 \%$ in the normalized expression level of this gene relative to the no ES control groups' normalized expression levels. All other groups fall within the mean and standard deviation of the control groups.

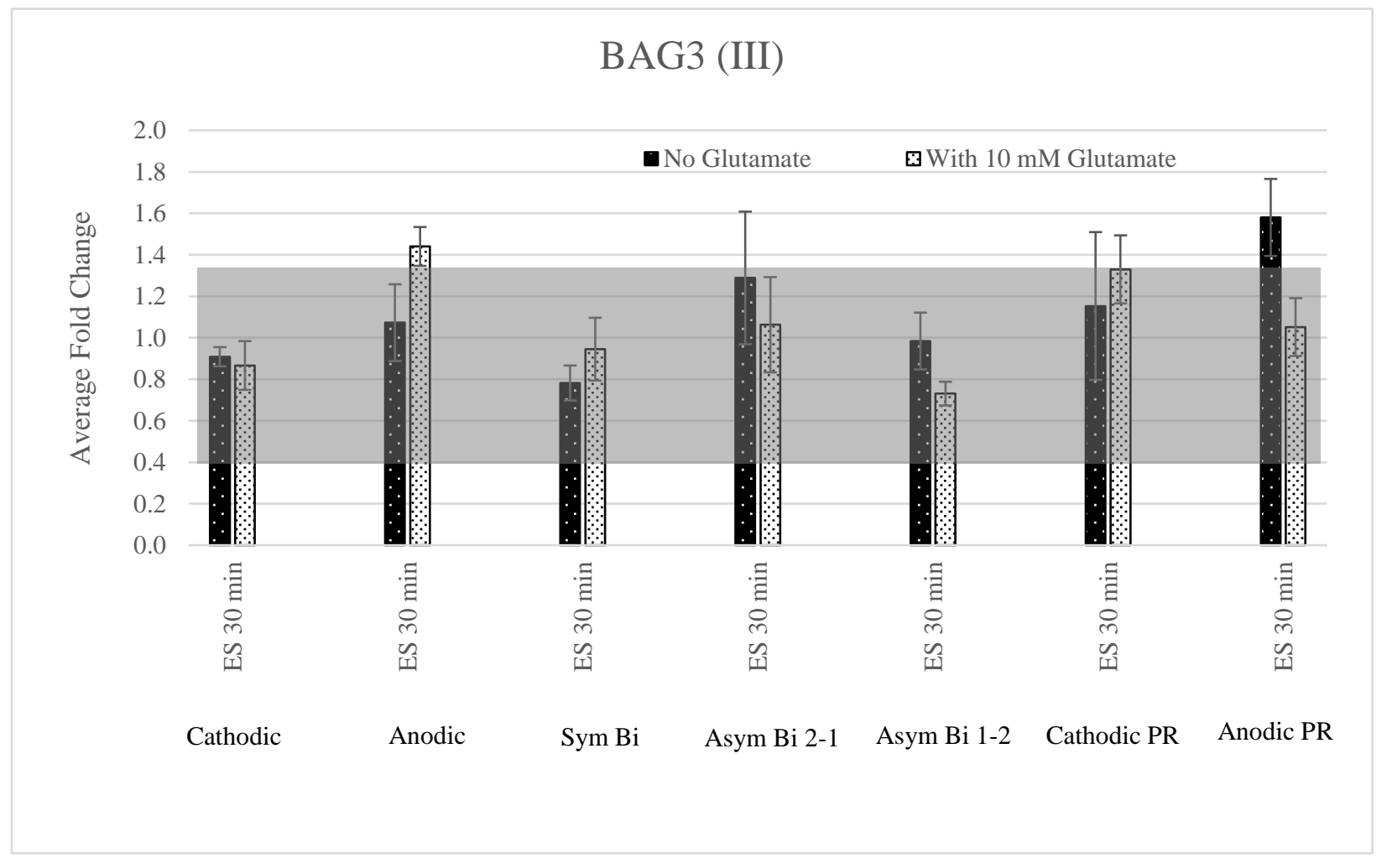

Figure 10: Comparison of BAG3 normalized gene expression with the 7 ES waveforms and the $7 \mathrm{ES}$ waveforms with glutamate to the BAG3 normalized gene expression control groups without ES. Values are mean $\pm \mathrm{SD}$ for $\mathrm{n}=3$ independent replicates. 
GFAP Results (I) - With no glutamate added the GAPDH normalized GFAP expression with and without the 7 waveforms of ES are shown in Figure 11. The cathodic monophasic waveform results in a decrease by approximately $15 \%$ in the normalized expression level of this gene relative to the no ES control normalized expression levels. All other groups fall within the mean and standard deviation of the control groups.

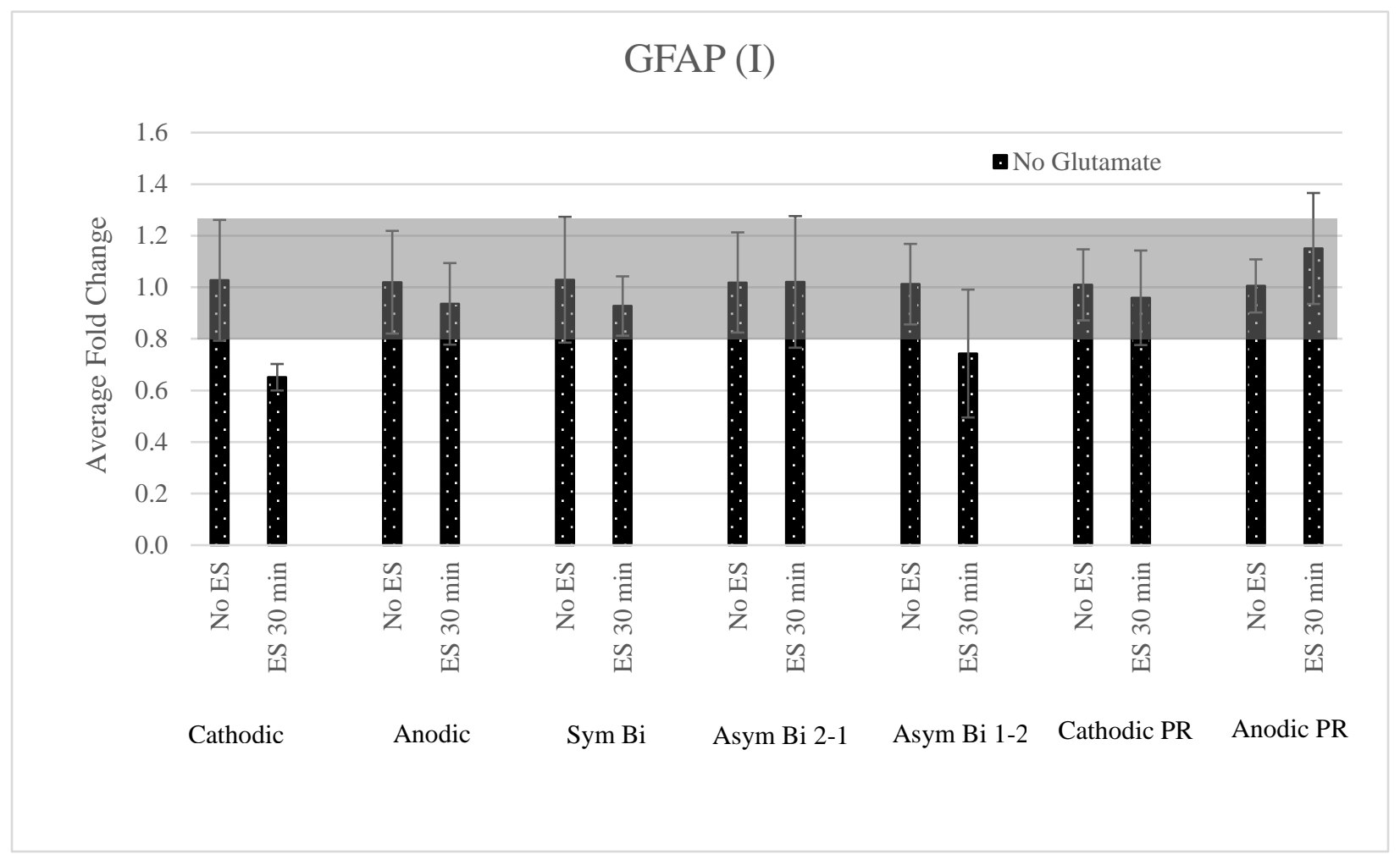

Figure 11: Comparison of GFAP normalized gene expression with the 7 ES waveforms to the GFAP normalized gene expression without ES. Values are mean \pm SD for $n=3$ independent replicates. 
GFAP Results (II) - The normalized GFAP expression in the presence of added glutamate is shown in Figure 12. When added glutamate is present, the asymmetric biphasic 2-1 and cathodic PR waveforms result in increases by approximately $110 \%$ and 60\%, respectively, in the normalized expression level of this gene relative to the normalized expression level of the no ES control. All other groups fall within the mean and standard deviation of the control groups.

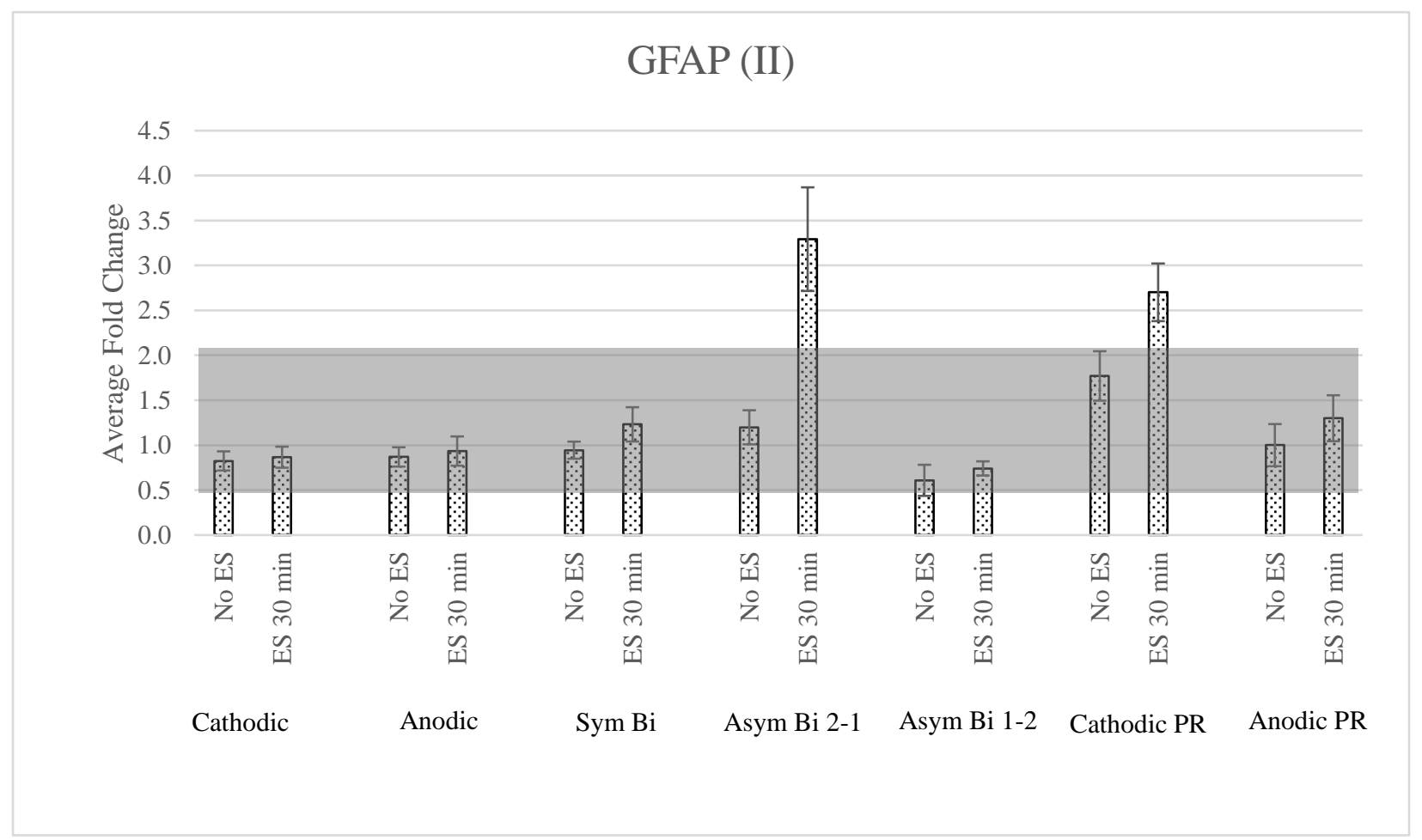

Figure 12: Comparison of GFAP normalized gene expression with the 7 ES waveforms and glutamate to the GFAP normalized gene expression with only glutamate. Values are mean \pm $\mathrm{SD}$ for $\mathrm{n}=3$ independent replicates. 
GFAP Results (III) - The normalized GFAP expression with and without added glutamate in the presence of the 7 waveforms of ES is shown in Figure 13. The asymmetric biphasic 2-1 and cathodic PR waveforms, in the presence of added glutamate, result in increases by approximately $180 \%$ and $130 \%$ respectively in the normalized expression level of this gene relative to the no ES control groups' normalized expression levels. This indicates that ES did not return the levels of expression, increased by glutamate, for this gene to control levels. It suggests that the ES enhanced the increase in GFAP gene expression due to glutamate. All other groups fall within the mean and standard deviation of the control groups.

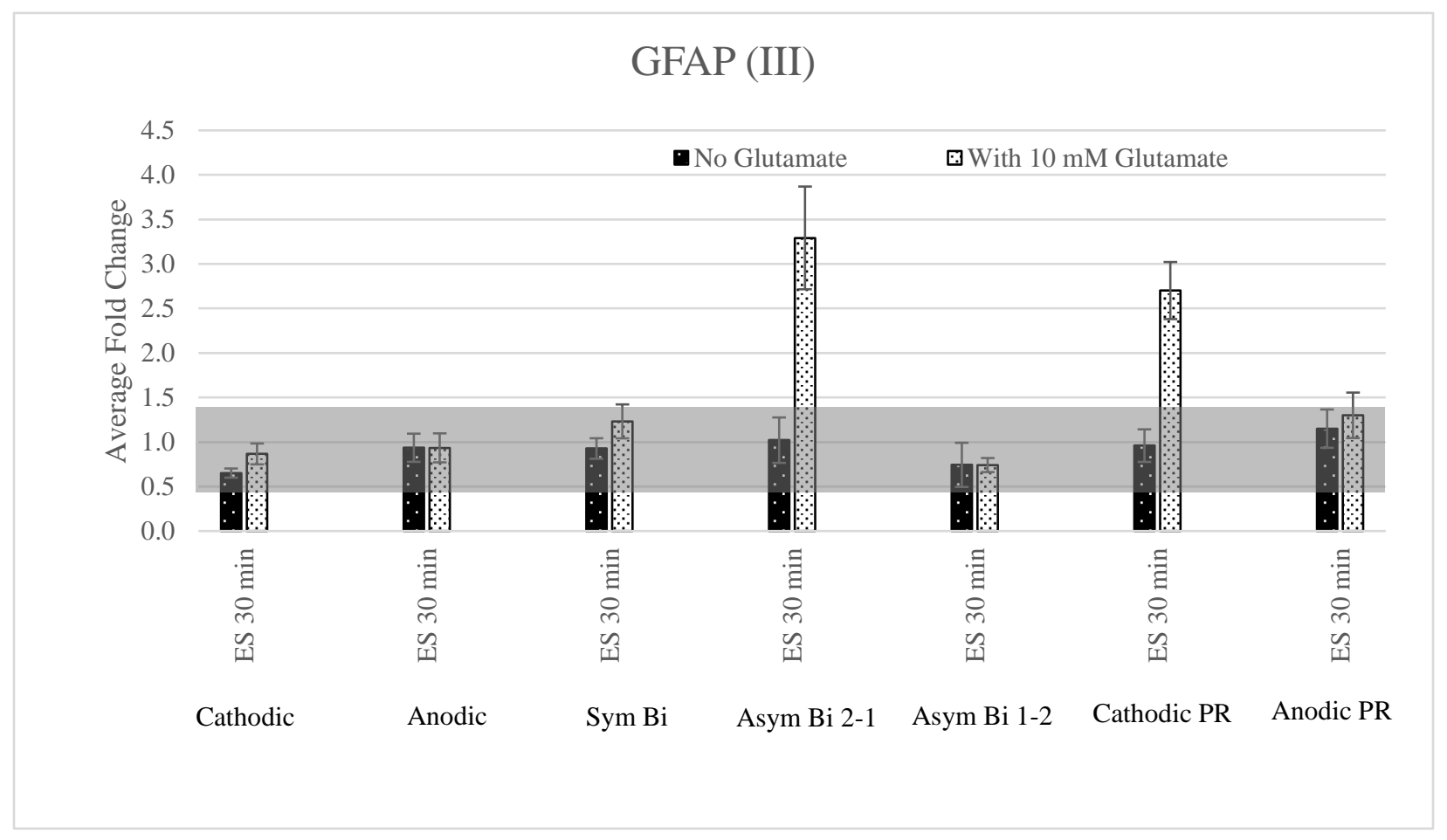

Figure 13: Comparison of GFAP normalized gene expression with the 7 ES waveforms and the 7 ES waveforms with glutamate to the GFAP normalized gene expression control groups without ES. Values are mean \pm SD for $n=3$ independent replicates. 
GS Results (I) - With no glutamate added the GAPDH normalized GS expression with and without the 7 waveforms of ES are shown in Figure 14. The anodic PR waveform results in an increase by approximately $15 \%$ in the normalized expression level of this gene relative to the no ES control normalized expression levels. The cathodic monophasic waveform results in a decrease by approximately $20 \%$ in the normalized expression level of this gene relative to the no ES control normalized expression levels. All other groups fall within the mean and standard deviation of the control groups.

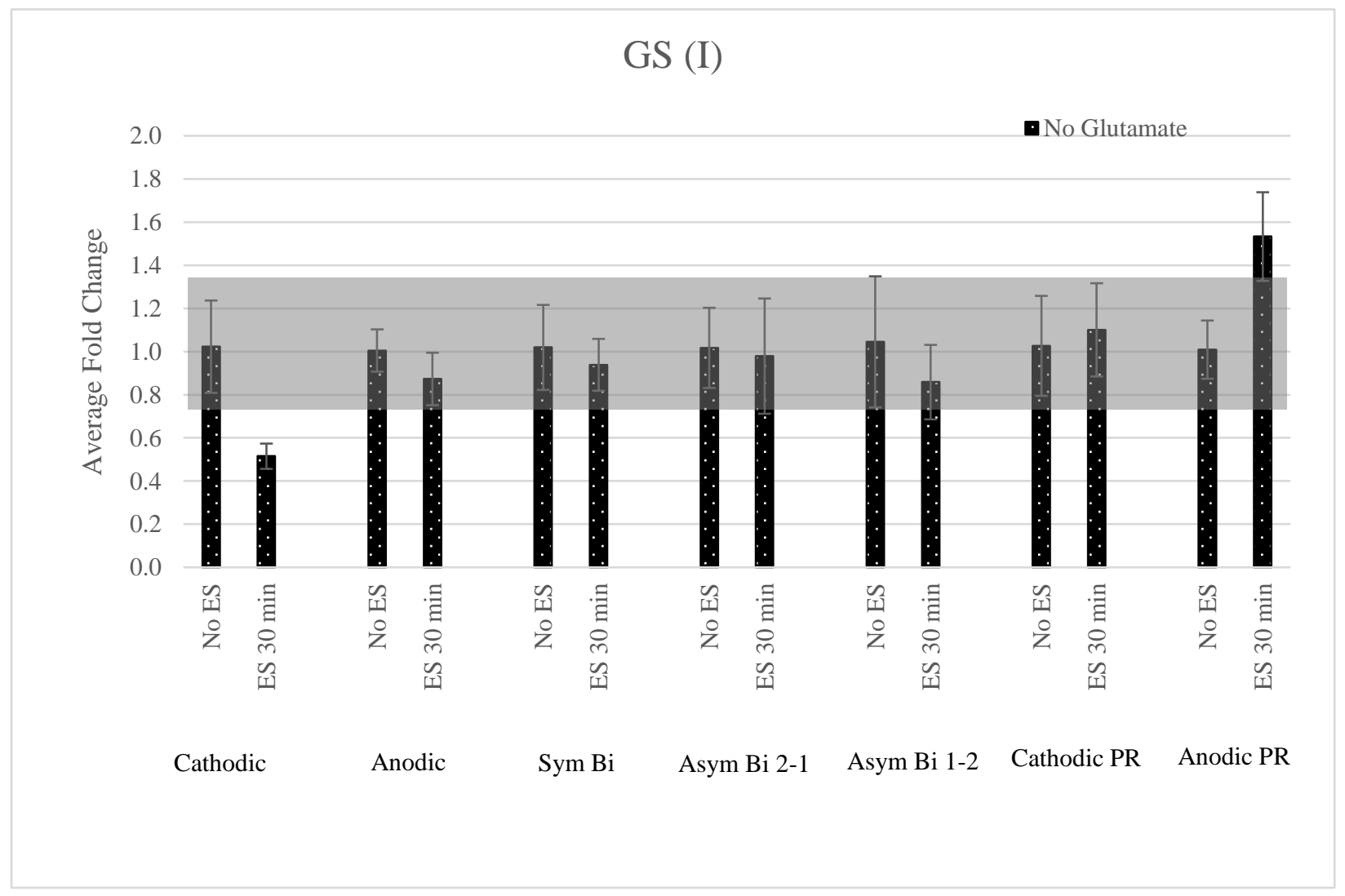

Figure 14: Comparison of GS normalized gene expression with the 7 ES waveforms to the GS normalized gene expression without ES. Values are mean \pm SD for $\mathrm{n}=3$ independent replicates. 
GS Results (II) - The normalized GS expression in the presence of added glutamate is shown in Figure 15. When added glutamate is present, the anodic PR waveform results in an increase by approximately $100 \%$ in the normalized expression level of this gene relative to the normalized expression level of the no ES control. Normalized expression levels for anodic monophasic and cathodic PR waveforms are very near the cut-off, however, the standard deviations fall within the control region. All other groups fall within the mean and standard deviation of the control groups.

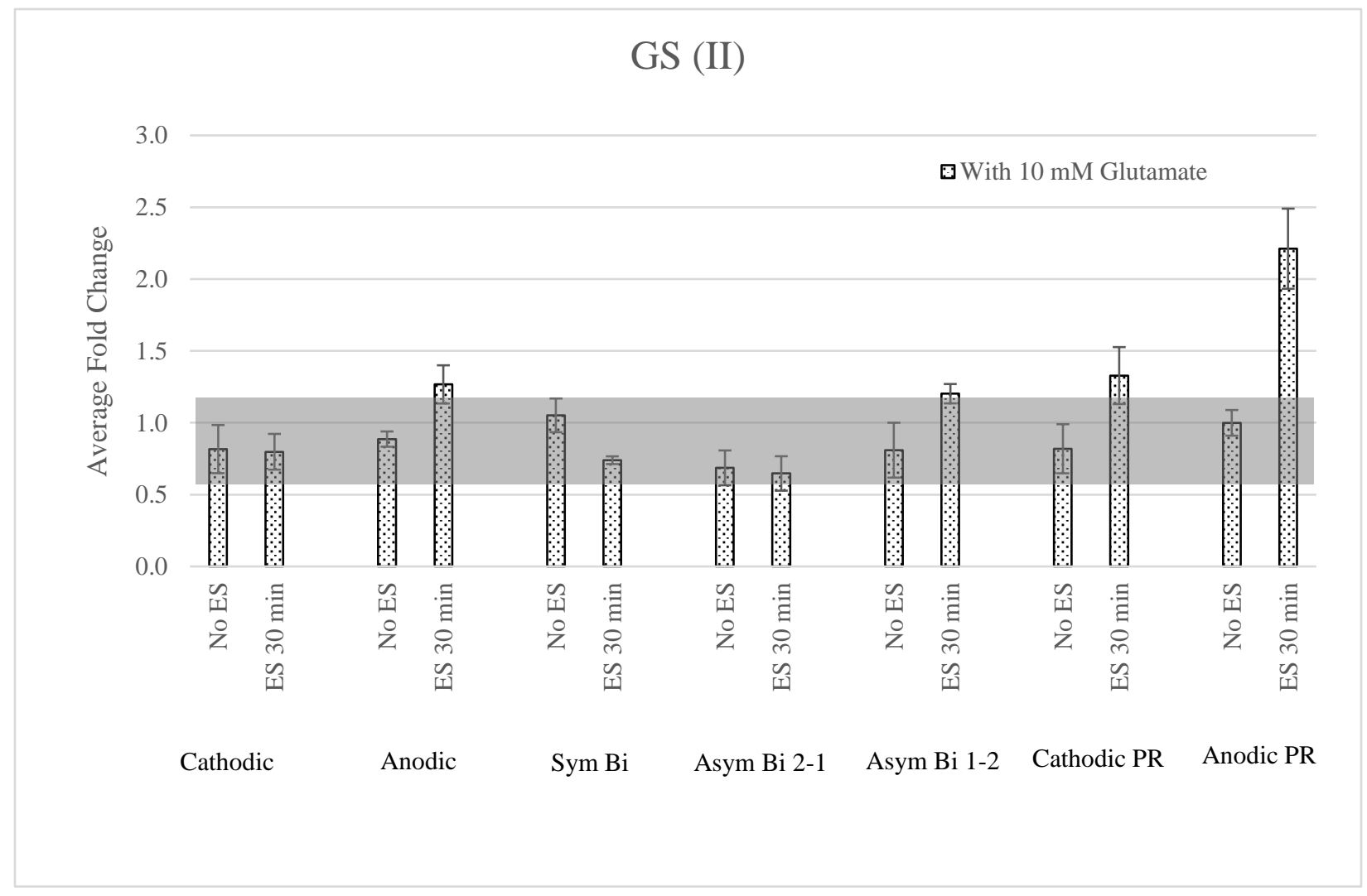

Figure 15: Comparison of GS normalized gene expression with the 7 ES waveforms and glutamate to the GS normalized gene expression with only glutamate. Values are mean \pm SD for $\mathrm{n}=3$ independent replicates. 
GS Results (III) - The normalized GS expression with and without added glutamate in the presence of the 7 waveforms of ES is shown in Figure 16. The anodic PR waveform, in the absence or presence of added glutamate, result in increases by approximately $20 \%$ and $90 \%$, respectively, in the normalized expression level of this gene relative to the no ES control groups' normalized expression levels. The cathodic monophasic waveform, in the absence of added glutamate, results in a decrease by approximately $5 \%$ in the normalized expression level of this gene relative to the no ES control groups' normalized expression levels. All other groups fall within the mean and standard deviation of the control groups.

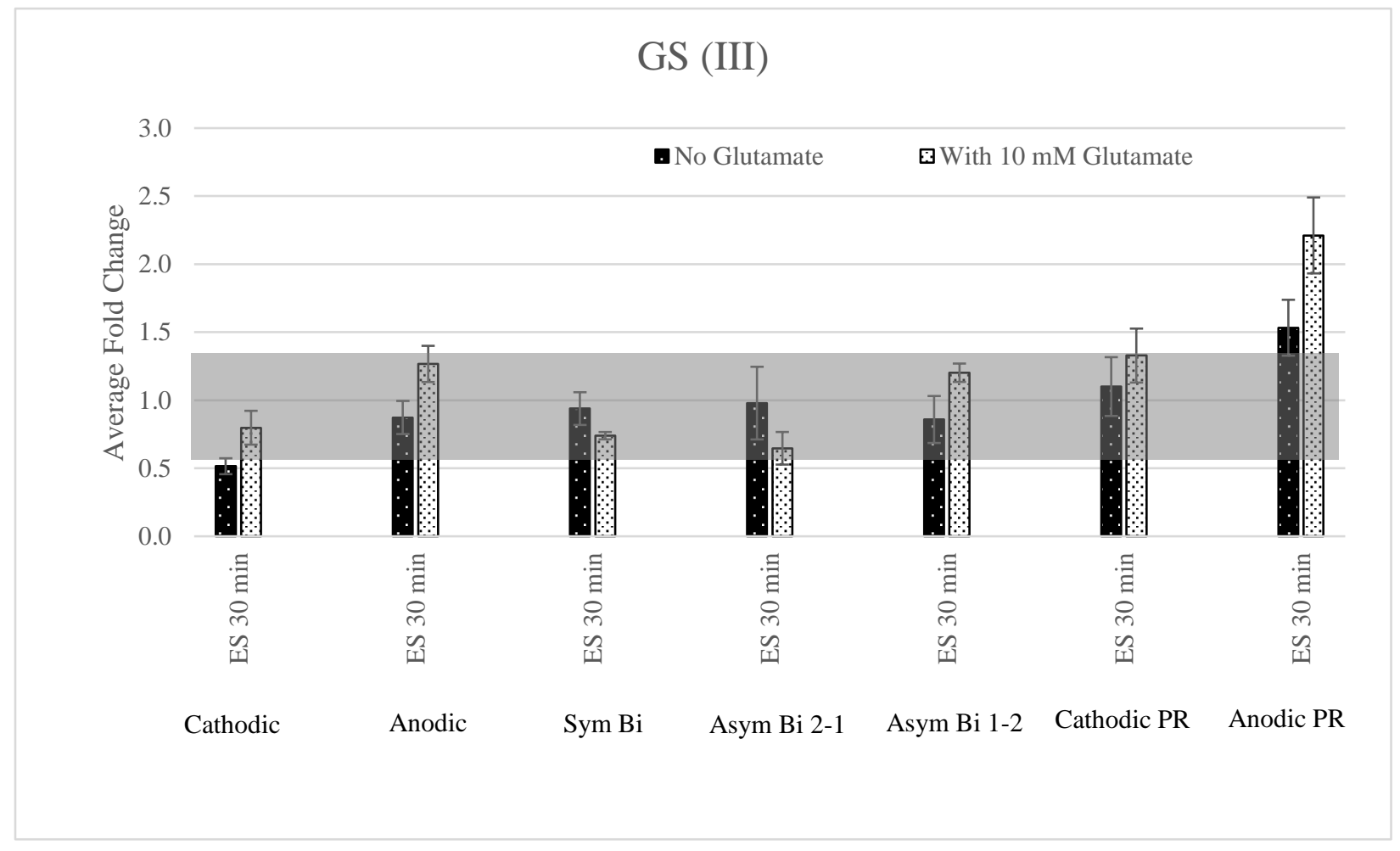

Figure 16: Comparison of GS normalized gene expression with the 7 ES waveforms and the 7 ES waveforms with glutamate to the GS normalized gene expression control groups without ES. Values are mean $\pm \mathrm{SD}$ for $\mathrm{n}=3$ independent replicates. 
GSR Results (I) -With no glutamate added the GAPDH normalized GSR expression with and without the 7 waveforms of ES are shown in Figure 17. The cathodic monophasic waveform resulted in a decrease of approximately $15 \%$ in the normalized expression level of this gene relative to the no ES control normalized expression levels. All other groups fall within the mean and standard deviation of the control groups.

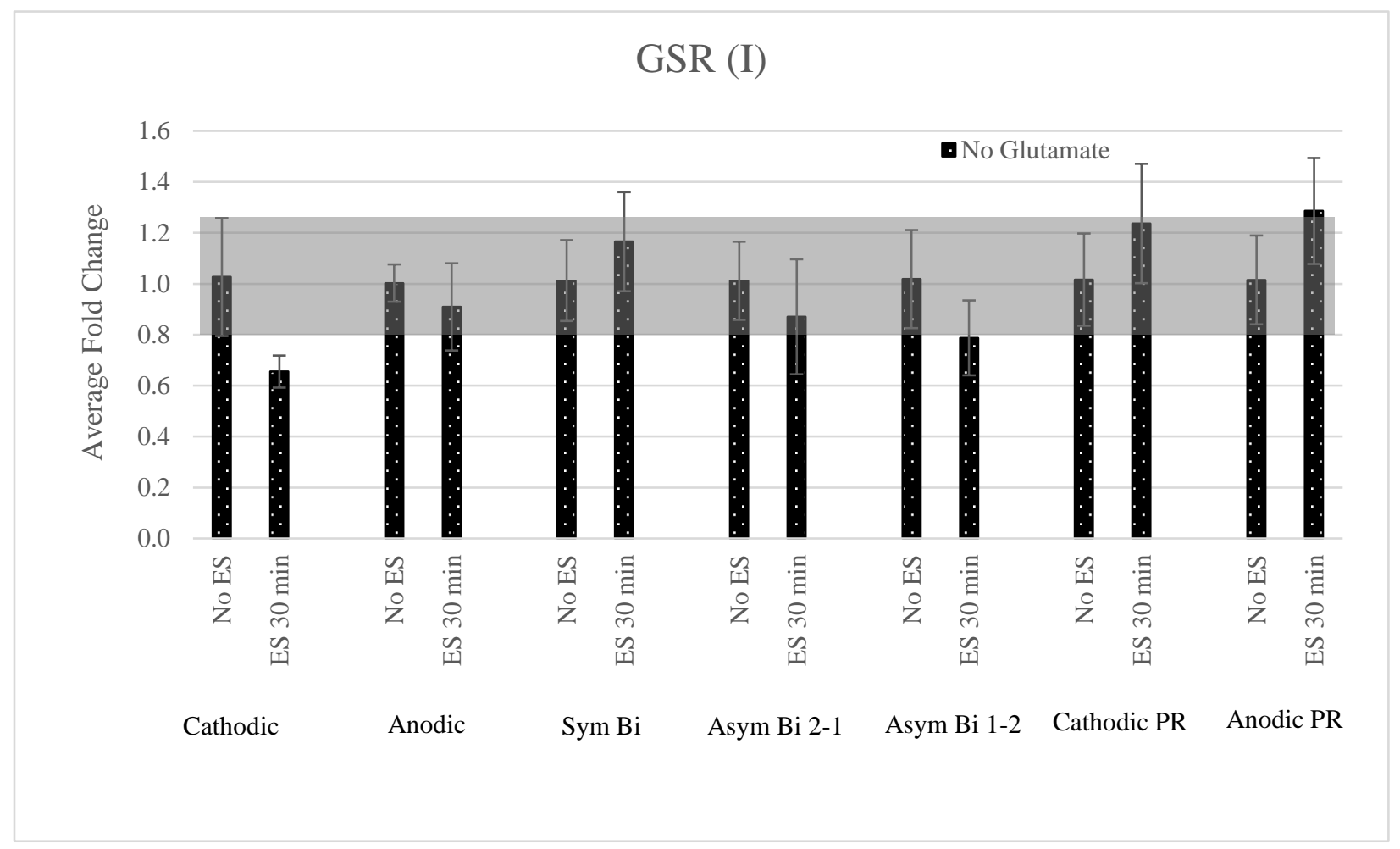

Figure 17: Comparison of GSR normalized gene expression with the 7 ES waveforms to the GSR normalized gene expression without ES. Values are mean \pm SD for $n=3$ independent replicates. 
GSR Results (II) - The normalized GSR expression in the presence of added glutamate is shown in Figure 18. When added glutamate is present, the anodic PR and asymmetric biphasic 2-1 waveforms result in increases by approximately $60 \%$ and $30 \%$, respectively, in the normalized expression level of this gene relative to the normalized expression level of the no ES control. All other groups fall within the mean and standard deviation of the control groups.

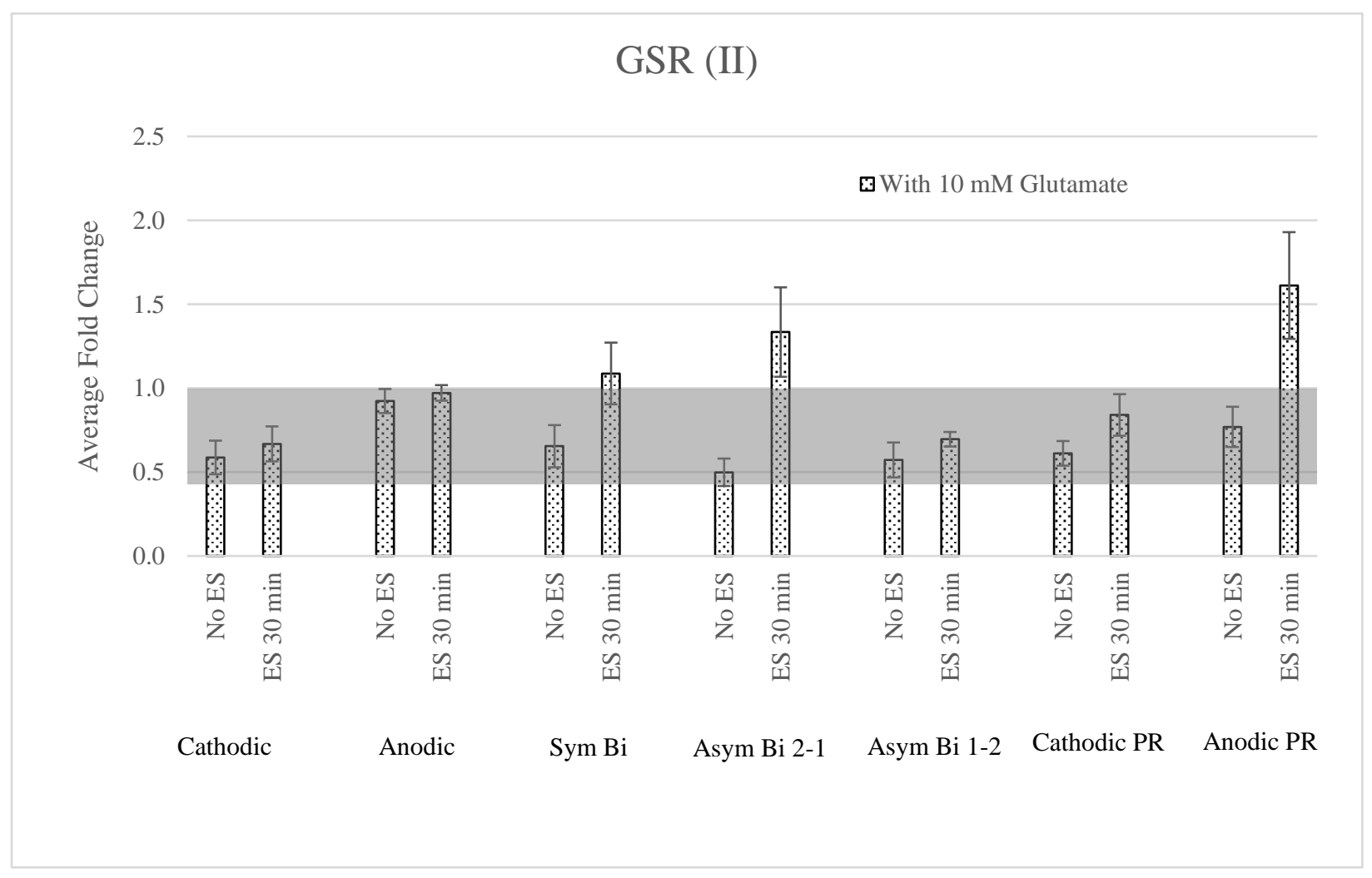

Figure 18: Comparison of GSR normalized gene expression with the 7 ES waveforms and glutamate to the GSR normalized gene expression with only glutamate. Values are mean \pm $\mathrm{SD}$ for $\mathrm{n}=3$ independent replicates. 
GSR Results (III) - The normalized GSR expression with and without added glutamate in the presence of the 7 waveforms of ES is shown in Figure 19. The anodic PR waveform, in the presence of added glutamate, results in an increase by approximately $30 \%$ in the normalized expression level of this gene relative to the no ES control groups' normalized expression levels. This implies that ES helps cells respond to glutamate stress by increasing expression of this gene. All other groups fall within the mean and standard deviation of the control groups.

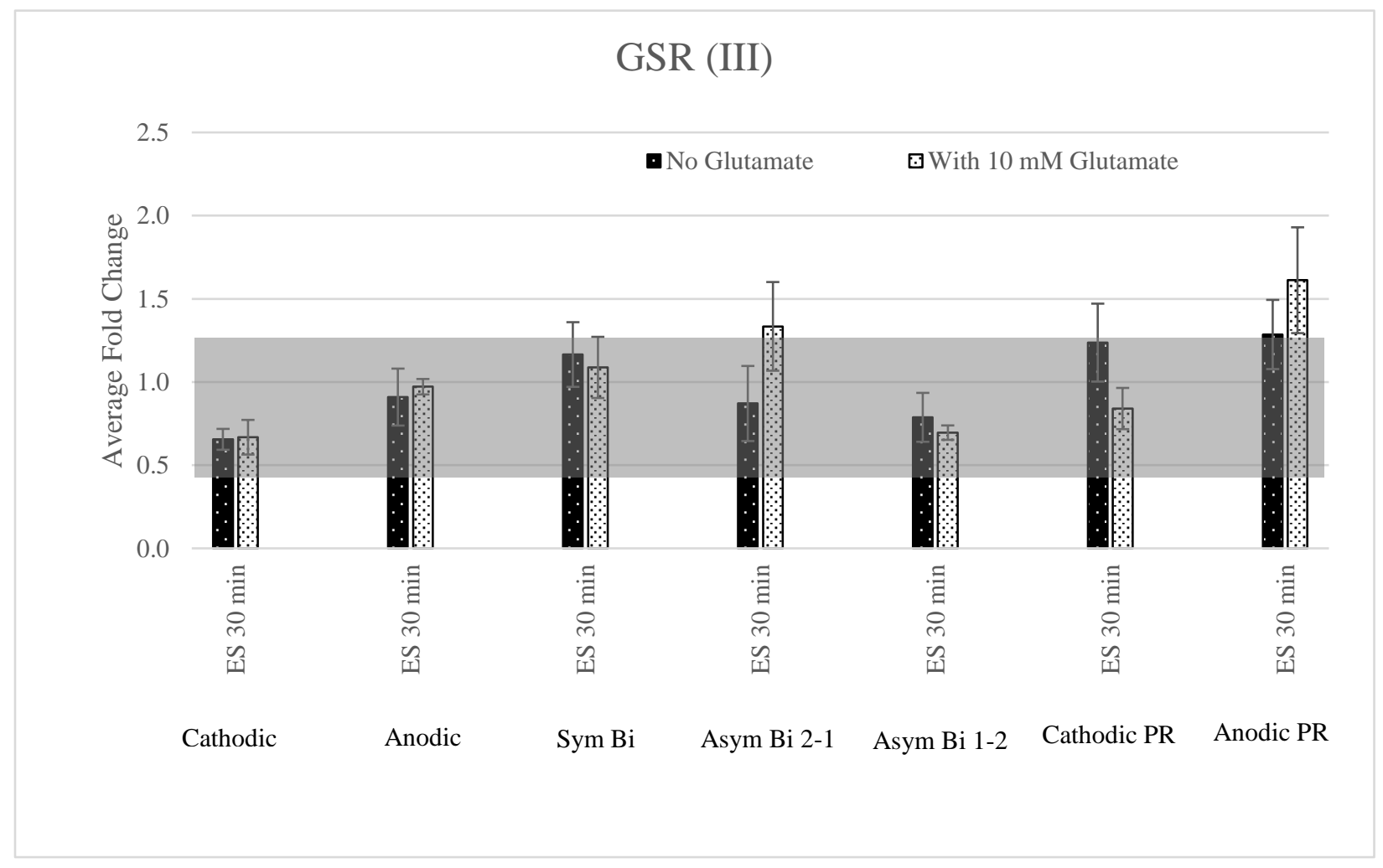

Figure 19: Comparison of GSR normalized gene expression with the 7 ES waveforms and the 7 ES waveforms with glutamate to the GSR normalized gene expression control groups without ES. Values are mean $\pm \mathrm{SD}$ for $\mathrm{n}=3$ independent replicates. 
HMOXI Results (I) - With no glutamate added the GAPDH normalized HMOX1 expression with and without the 7 waveforms of ES are shown in Figure 20. The anodic PR waveform results in an increase of approximately $30 \%$ in the normalized expression level of this gene relative to the no ES control normalized expression levels. The symmetric biphasic waveform results in a decrease of approximately $10 \%$ in the normalized expression level of this gene relative to the no ES control normalized expression levels. Normalized expression levels for cathodic monophasic and asymmetric biphasic 2-1 waveforms are very near the cut-off, however, the standard deviations fall within the control region. All other groups fall within the mean and standard deviation of the control groups.

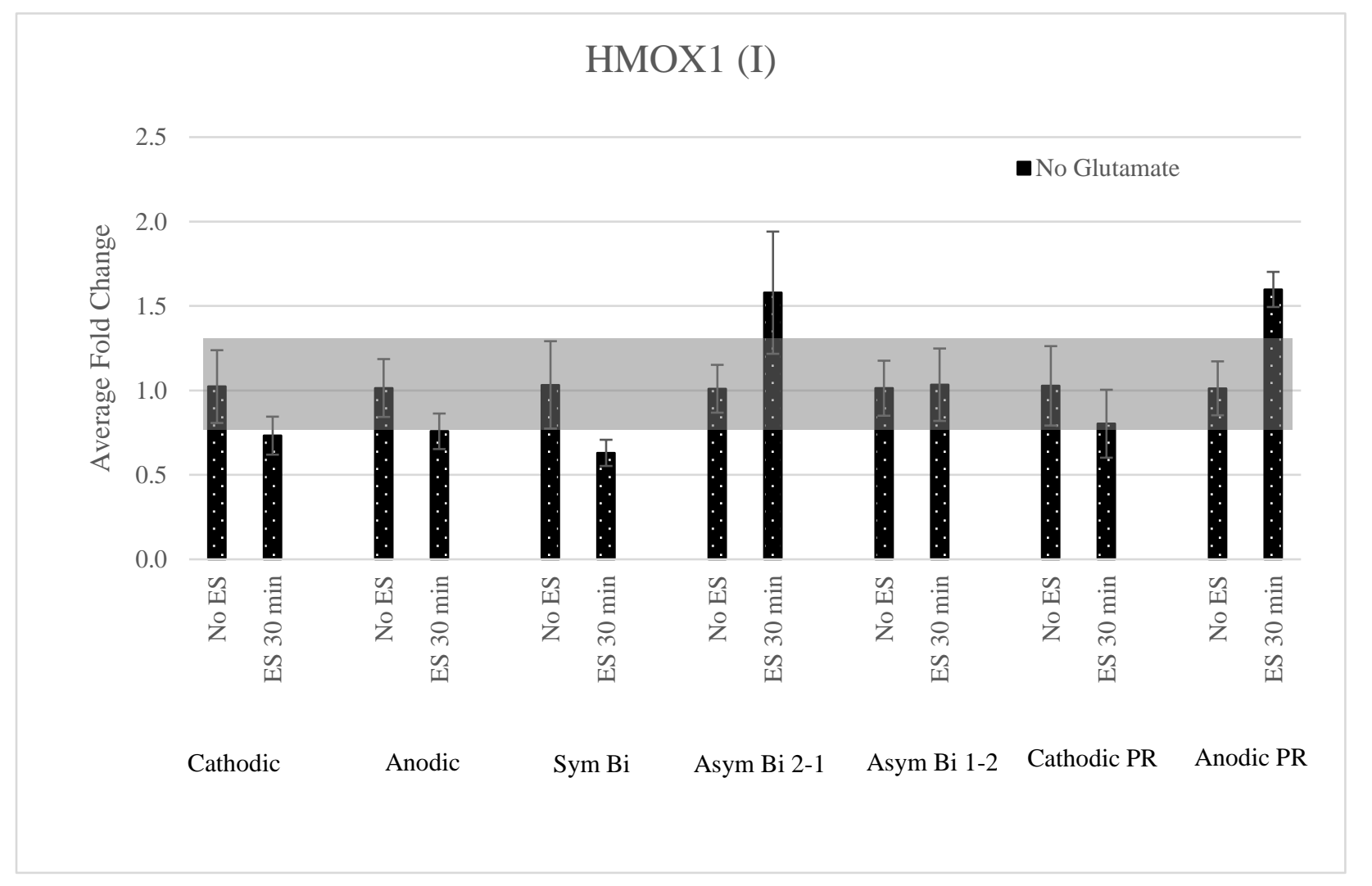

Figure 20: Comparison of HMOX1 normalized gene expression with the 7 ES waveforms to the HMOX1 normalized gene expression without ES. Values are mean $\pm \mathrm{SD}$ for $\mathrm{n}=3$ independent replicates. 
HMOX1 Results (II) - The normalized HMOX1 expression in the presence of added glutamate is shown in Figure 21. When added glutamate is present, the anodic PR waveform results in an increase by approximately $170 \%$ in the normalized expression level of this gene relative to the normalized expression level of the no ES control. All other groups fall within the mean and standard deviation of the control groups.

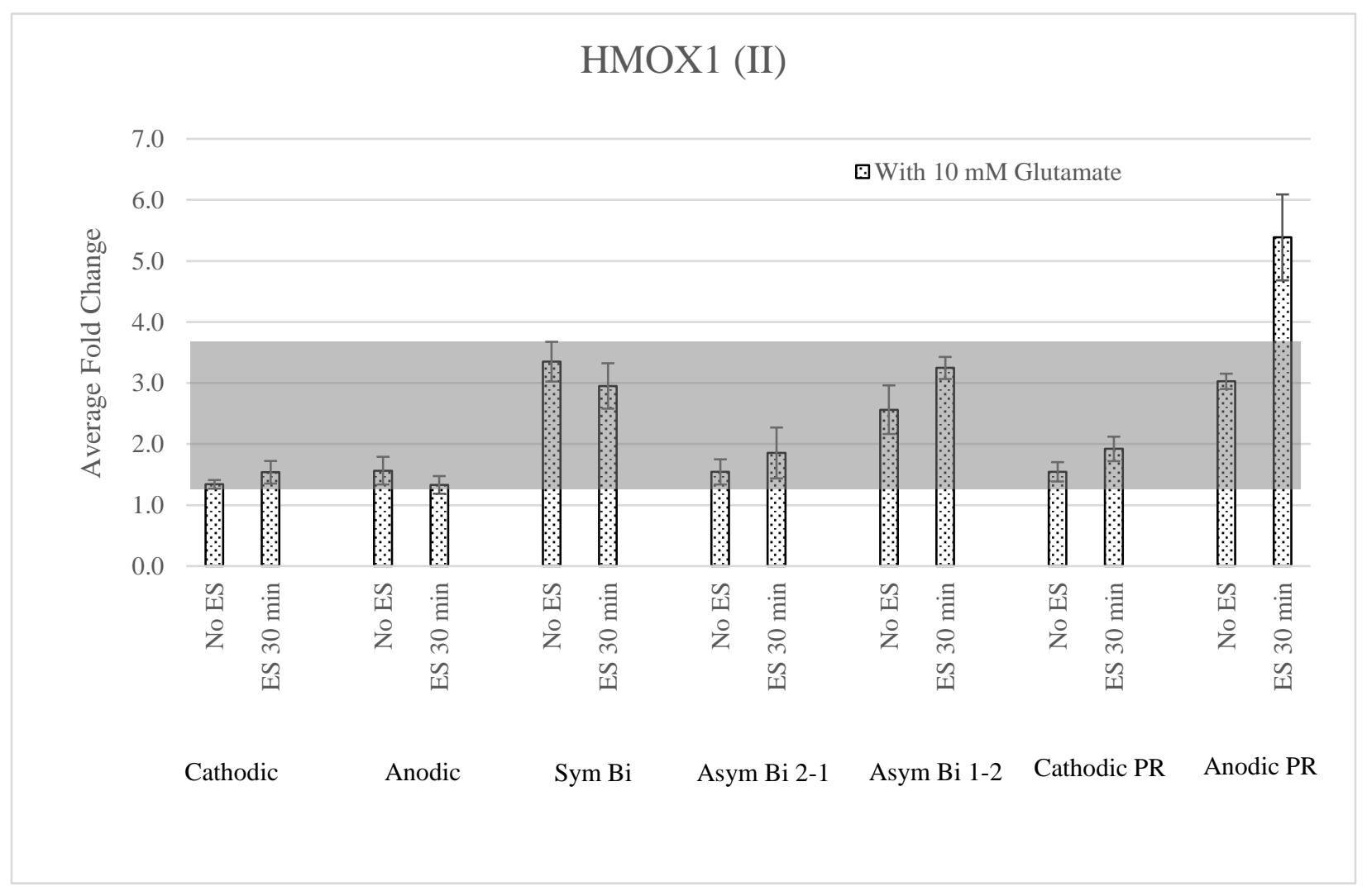

Figure 21: Comparison of HMOX1 normalized gene expression with the 7 ES waveforms and glutamate to the HMOX1 normalized gene expression with only glutamate. Values are mean $\pm \mathrm{SD}$ for $\mathrm{n}=3$ independent replicates. 
HMOX1 Results (III) - The normalized HMOX1 expression with and without added glutamate in the presence of the 7 waveforms of ES is shown in Figure 22. The anodic PR waveform, in the presence of added glutamate, results in an increase by approximately $170 \%$ in the normalized expression level of this gene relative to the no ES control groups' normalized expression levels. The symmetric biphasic waveform, in the absence of added glutamate, results in a decrease by approximately $5 \%$ in the normalized expression level of this gene relative to the no ES control groups' normalized expression levels. All other groups fall within the mean and standard deviation of the control groups.

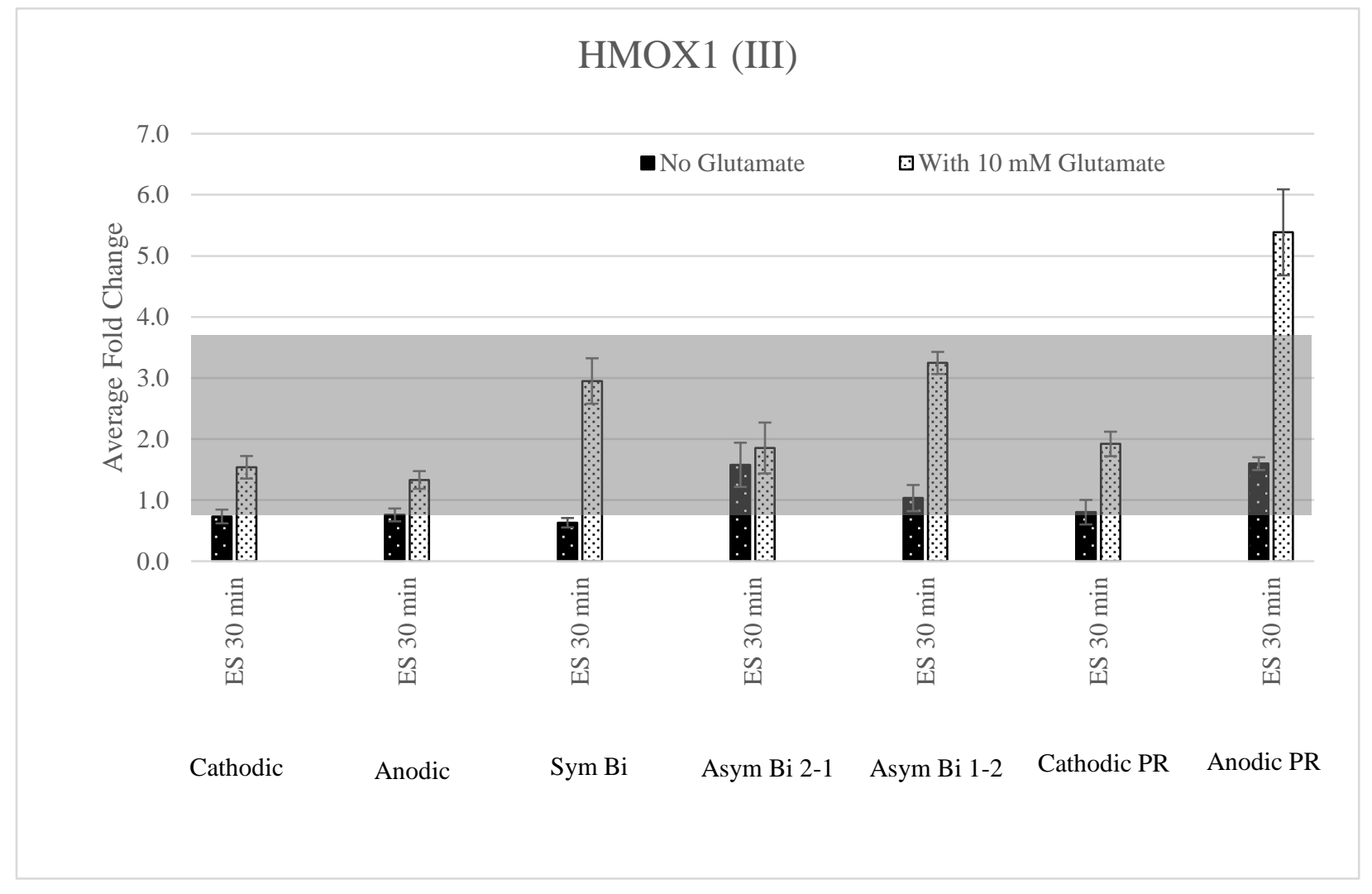

Figure 22: Comparison of HMOX1 normalized gene expression with the 7 ES waveforms and the $7 \mathrm{ES}$ waveforms with glutamate to the HMOX1 normalized gene expression control groups without ES. Values are mean $\pm \mathrm{SD}$ for $\mathrm{n}=3$ independent replicates. 
MT2A Results (I) - With no glutamate added the GAPDH normalized MT2A expression with and without the 7 waveforms of ES are shown in Figure 23. Normalized expression levels for symmetric biphasic waveform is very near the cut-off, however, the standard deviation falls within the control region. All other groups fall within the mean and standard deviation of the control groups.

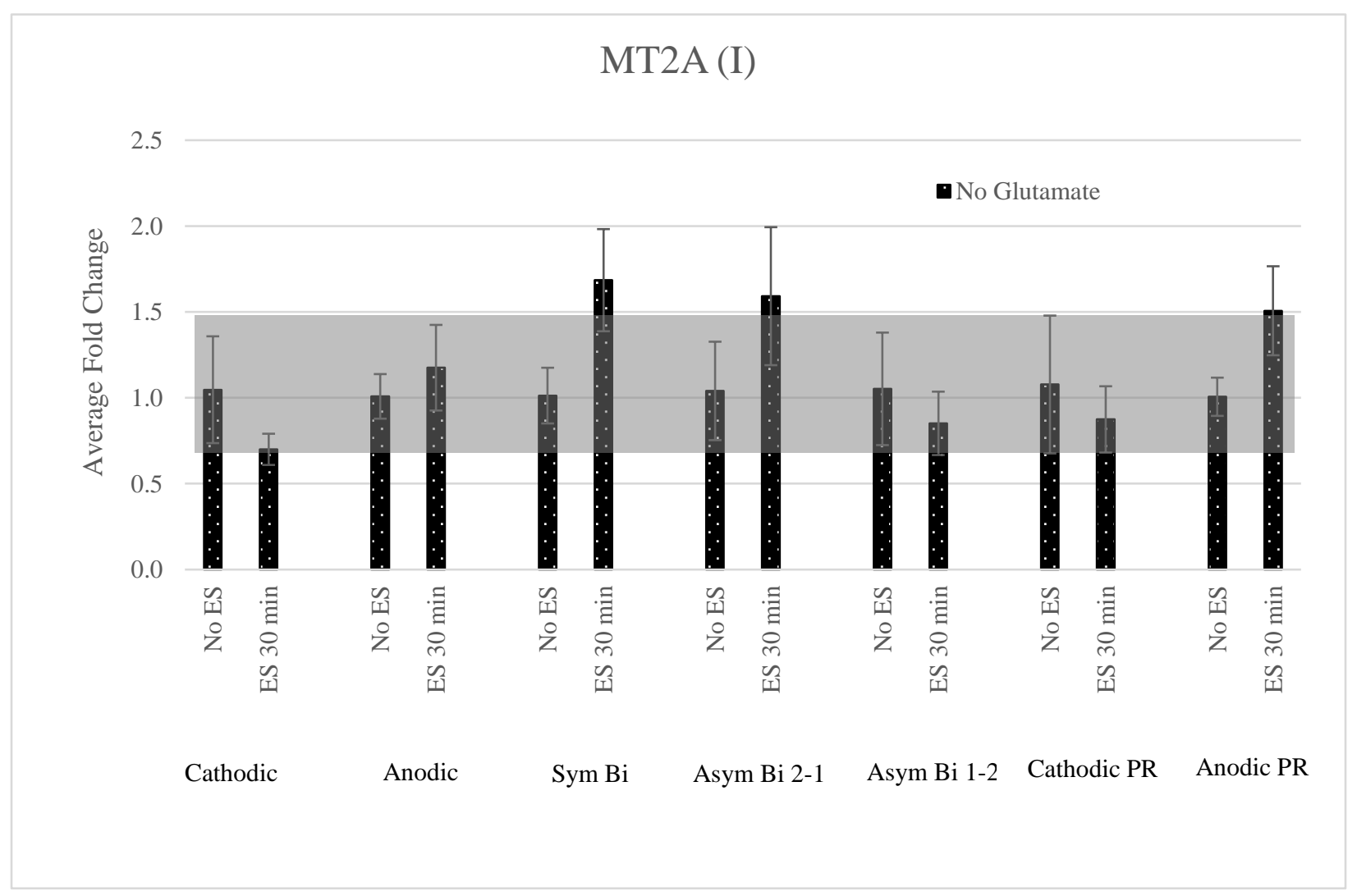

Figure 23: Comparison of MT2A normalized gene expression with the 7 ES waveforms to the MT2A normalized gene expression without ES. Values are mean \pm SD for $n=3$ independent replicates. 
MT2A Results (II) - The normalized MT2A expression in the presence of added glutamate is shown in Figure 24. All groups fall within the mean and standard deviation of the control groups.

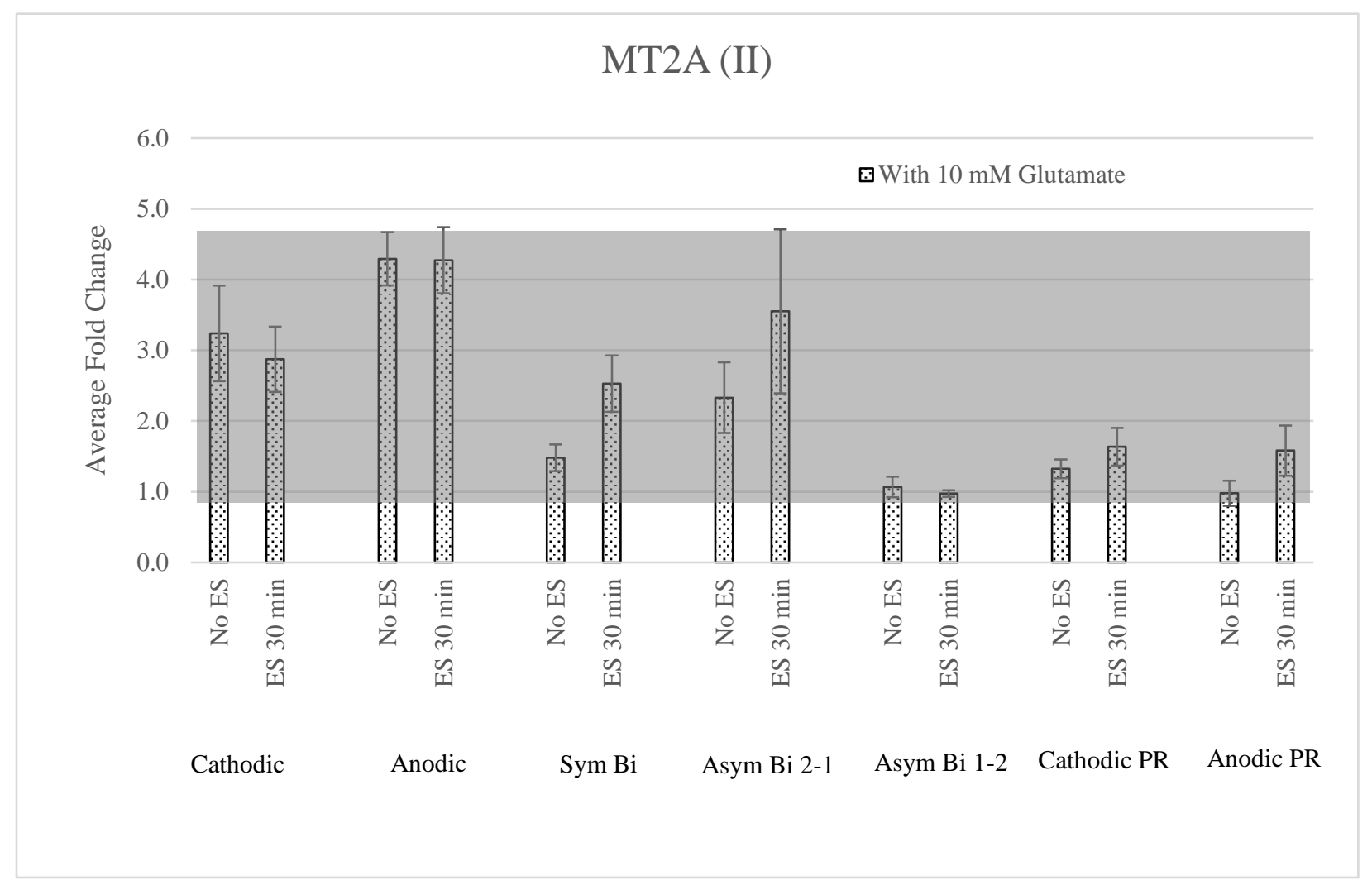

Figure 24: Comparison of MT2A normalized gene expression with the 7 ES waveforms and glutamate to the MT2A normalized gene expression with only glutamate. Values are mean \pm $\mathrm{SD}$ for $\mathrm{n}=3$ independent replicates. 
MT2A Results (III) - The normalized MT2A expression with and without added glutamate in the presence of the 7 waveforms of ES is shown in Figure 25. All groups fall within the mean and standard deviation of the control groups.

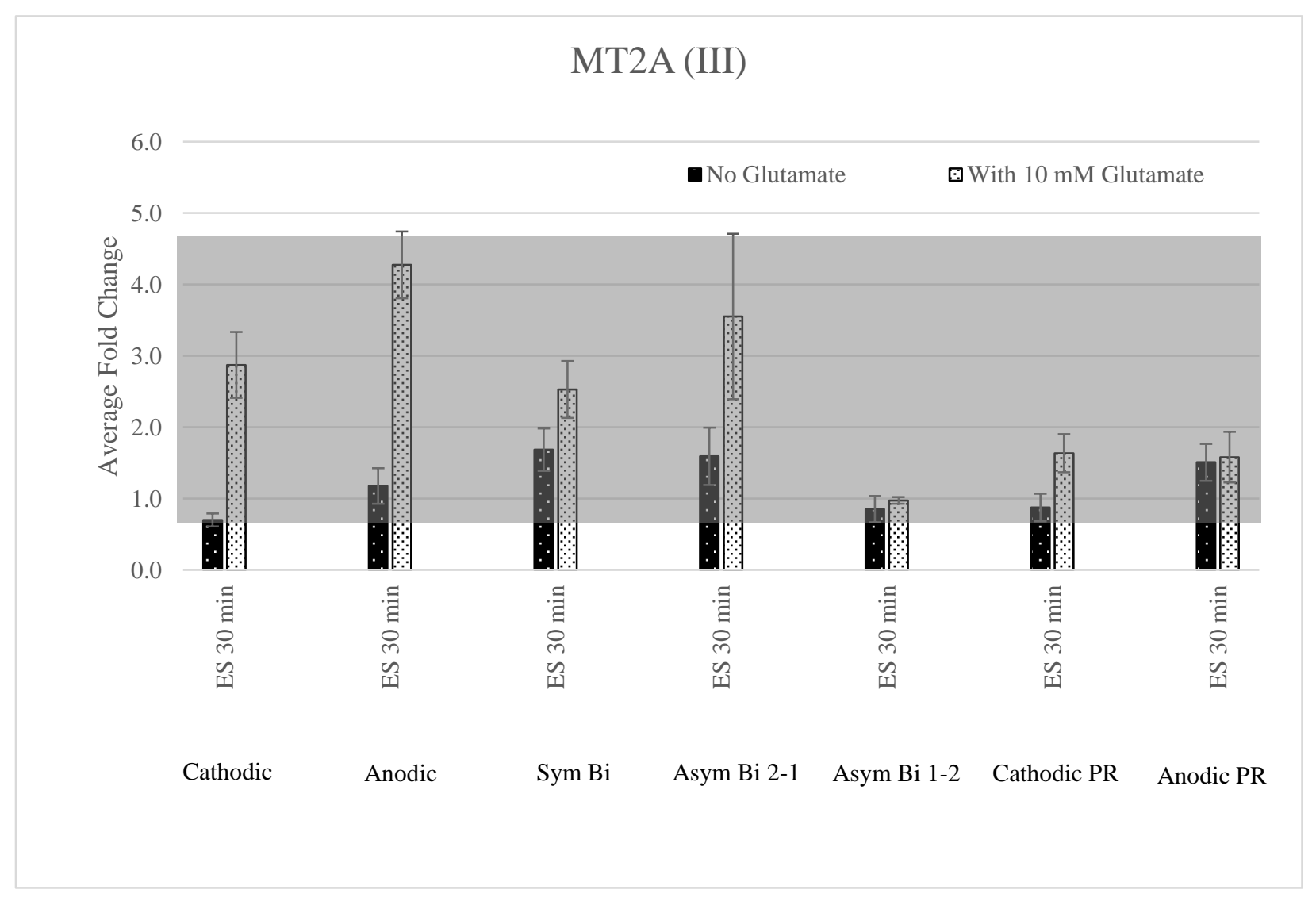

Figure 25: Comparison of MT2A normalized gene expression with the 7 ES waveforms and the 7 ES waveforms with glutamate to the MT2A normalized gene expression control groups without ES. Values are mean \pm SD for $n=3$ independent replicates. 
S100A4 Results (I) - With no glutamate added the GAPDH normalized S100A4 expression with and without the 7 waveforms of ES are shown in Figure 26. The anodic PR waveform results in an increase by approximately $40 \%$ in the normalized expression level of this gene relative to the no ES control normalized expression levels. The cathodic monophasic and anodic monophasic waveforms result in decreases of $20 \%$ and $10 \%$, respectively, in the normalized expression level of this gene relative to the no ES control normalized expression levels. Normalized expression levels for the asymmetric biphasic 1-2 waveform is very near the cut-off, however, the standard deviations fall within the control region. All other groups fall within the mean and standard deviation of the control groups.

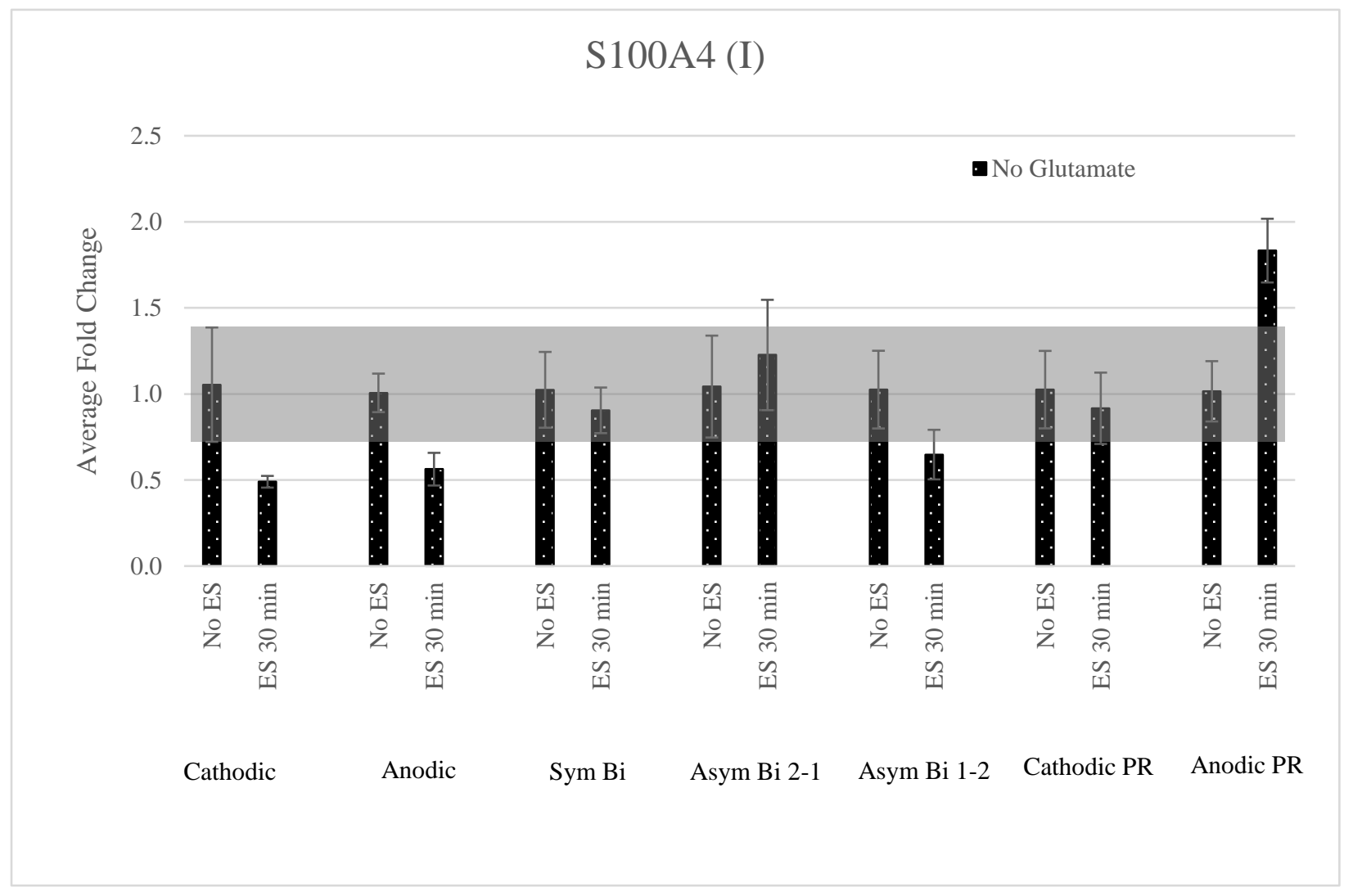

Figure 26: Comparison of S100A4 normalized gene expression with the 7 ES waveforms to the S100A4 normalized gene expression without ES. Values are mean \pm SD for $\mathrm{n}=3$ independent replicates. 
S100A4 Results (II) - The normalized S100A4 expression in the presence of added glutamate is shown in Figure 27. When added glutamate is present, the anodic PR waveform results in an increase by approximately $40 \%$ in the normalized expression level of this gene relative to the normalized expression level of the no ES control. All other groups fall within the mean and standard deviation of the control groups.

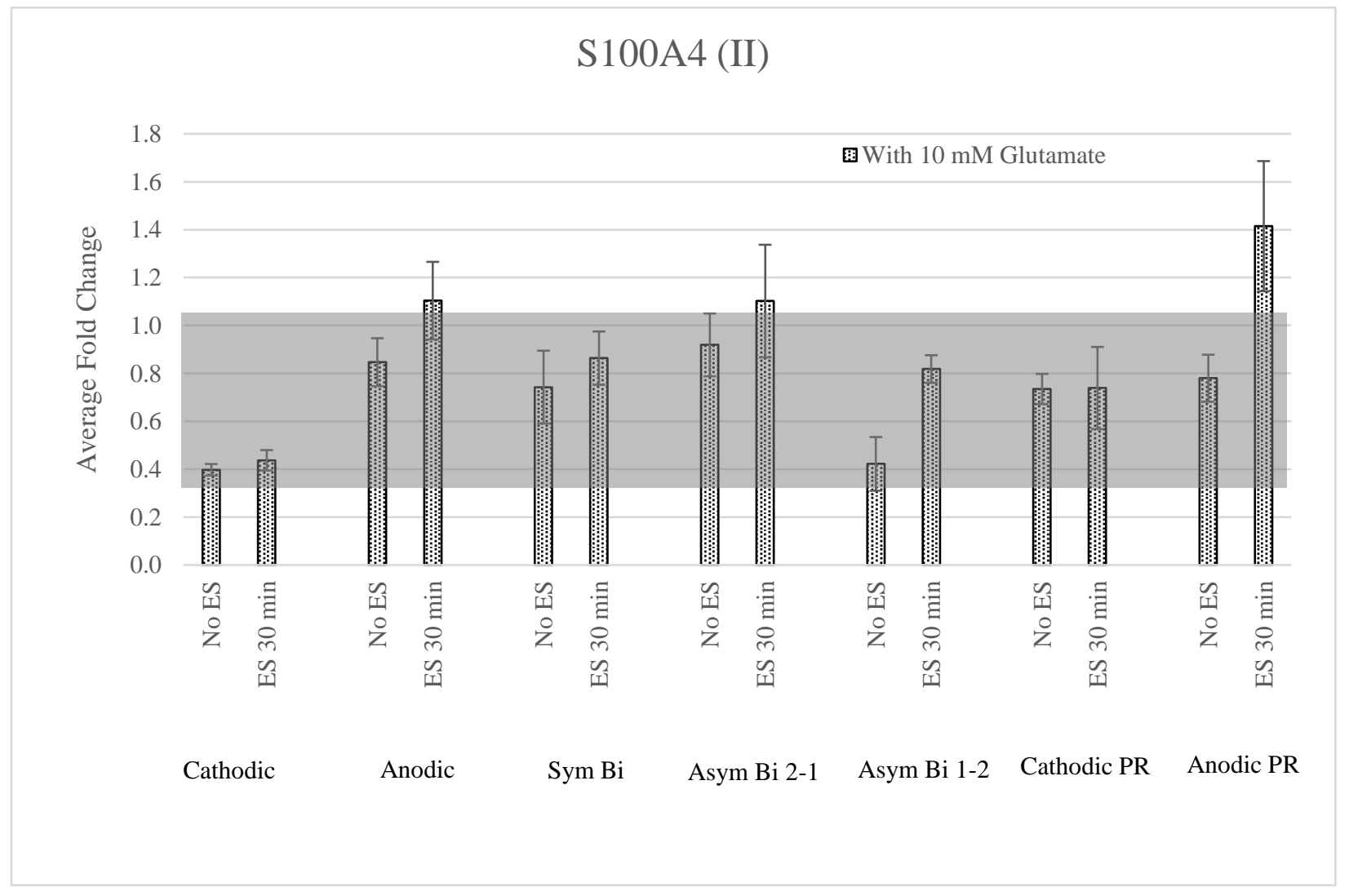

Figure 27: Comparison of S100A4 normalized gene expression with the 7 ES waveforms and glutamate to the S100A4 normalized gene expression with only glutamate. Values are mean $\pm \mathrm{SD}$ for $\mathrm{n}=3$ independent replicates. 
S100A4 Results (III) - The normalized S100A4 expression with and without added glutamate in the presence of the 7 waveforms of ES is shown in Figure 28. The anodic PR waveform, in the absence of added glutamate, results in an increase by approximately $40 \%$ in the normalized expression level of this gene relative to the no ES control groups' normalized expression levels. All other groups fall within the mean and standard deviation of the control groups.

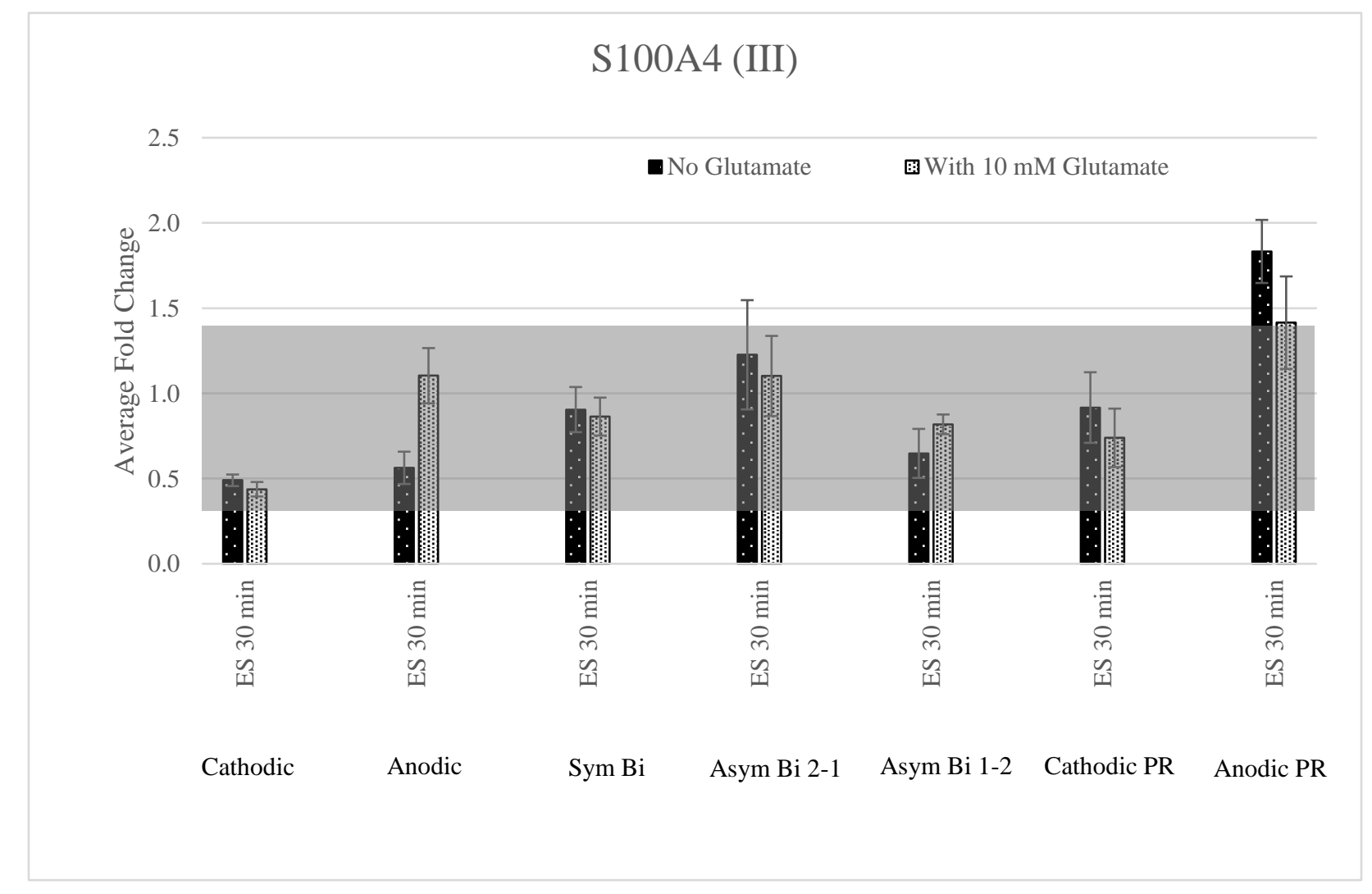

Figure 28: Comparison of S100A4 normalized gene expression with the 7 ES waveforms and the 7 ES waveforms with glutamate to the S100A4 normalized gene expression control groups without ES. Values are mean $\pm \mathrm{SD}$ for $\mathrm{n}=3$ independent replicates. 
SLC7A11 Results (I) - With no glutamate added the GAPDH normalized SLC7A11 expression with and without the 7 waveforms of ES are shown in Figure 29. The anodic PR waveform resulted in an increase by approximately $40 \%$ in the normalized expression level of this gene relative to the no ES control normalized expression levels. The cathodic monophasic waveform results in a decrease by approximately $30 \%$ in the normalized expression level of this gene relative to the no ES control normalized expression levels. All other groups fall within the mean and standard deviation of the control groups.

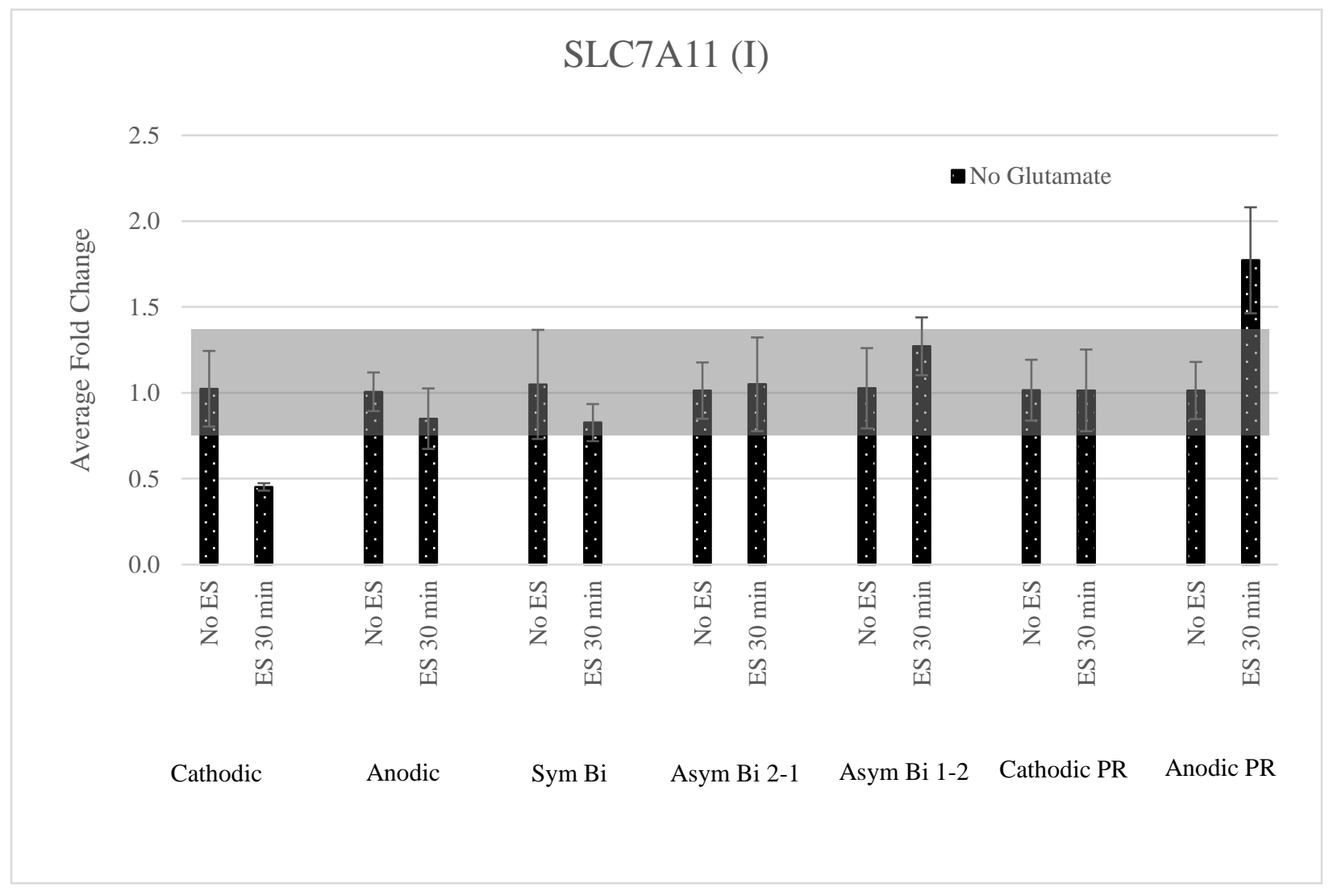

Figure 29: Comparison of SLC7A11 normalized gene expression with the 7 ES waveforms to the SLC7A11 normalized gene expression without ES. Values are mean \pm SD for $\mathrm{n}=3$ independent replicates. 
SLC7A11 Results (II) - The normalized SLC7A11 expression in the presence of added glutamate is shown in Figure 30. All groups fall within the mean and standard deviation of the control groups.

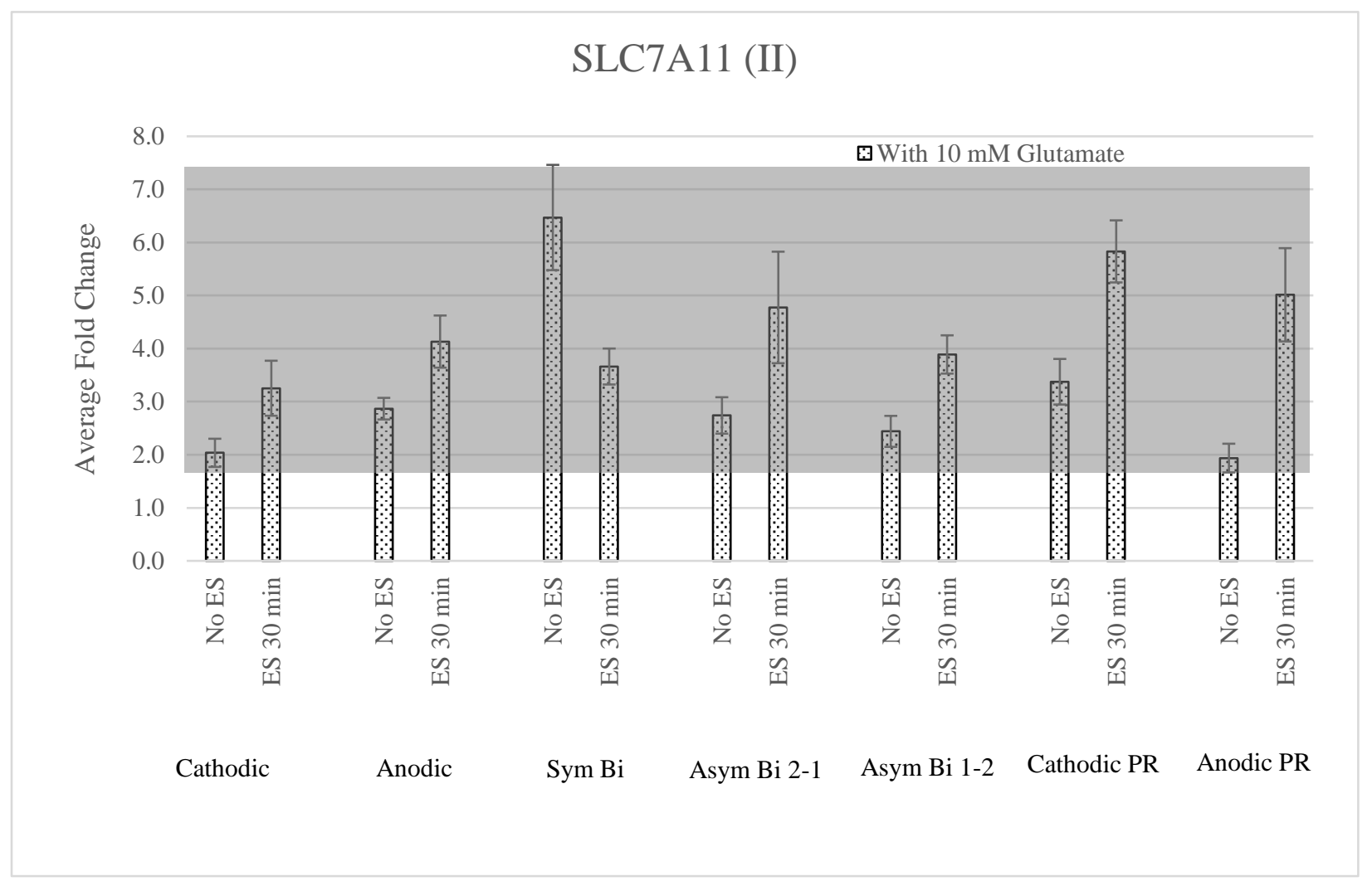

Figure 30: Comparison of SLC7A11 normalized gene expression with the 7 ES waveforms and glutamate to the SLC7A11 normalized gene expression with only glutamate. Values are mean $\pm S D$ for $n=3$ independent replicates. 
SLC7A11 Results (III) - The normalized SLC7A11 expression with and without added glutamate in the presence of the 7 waveforms of ES is shown in Figure 31. The cathodic monophasic waveform, in the absence of added glutamate, results in a decrease by approximately $10 \%$ in the normalized expression level of this gene relative to the no ES control groups' normalized expression levels. All other groups fall within the mean and standard deviation of the control groups.

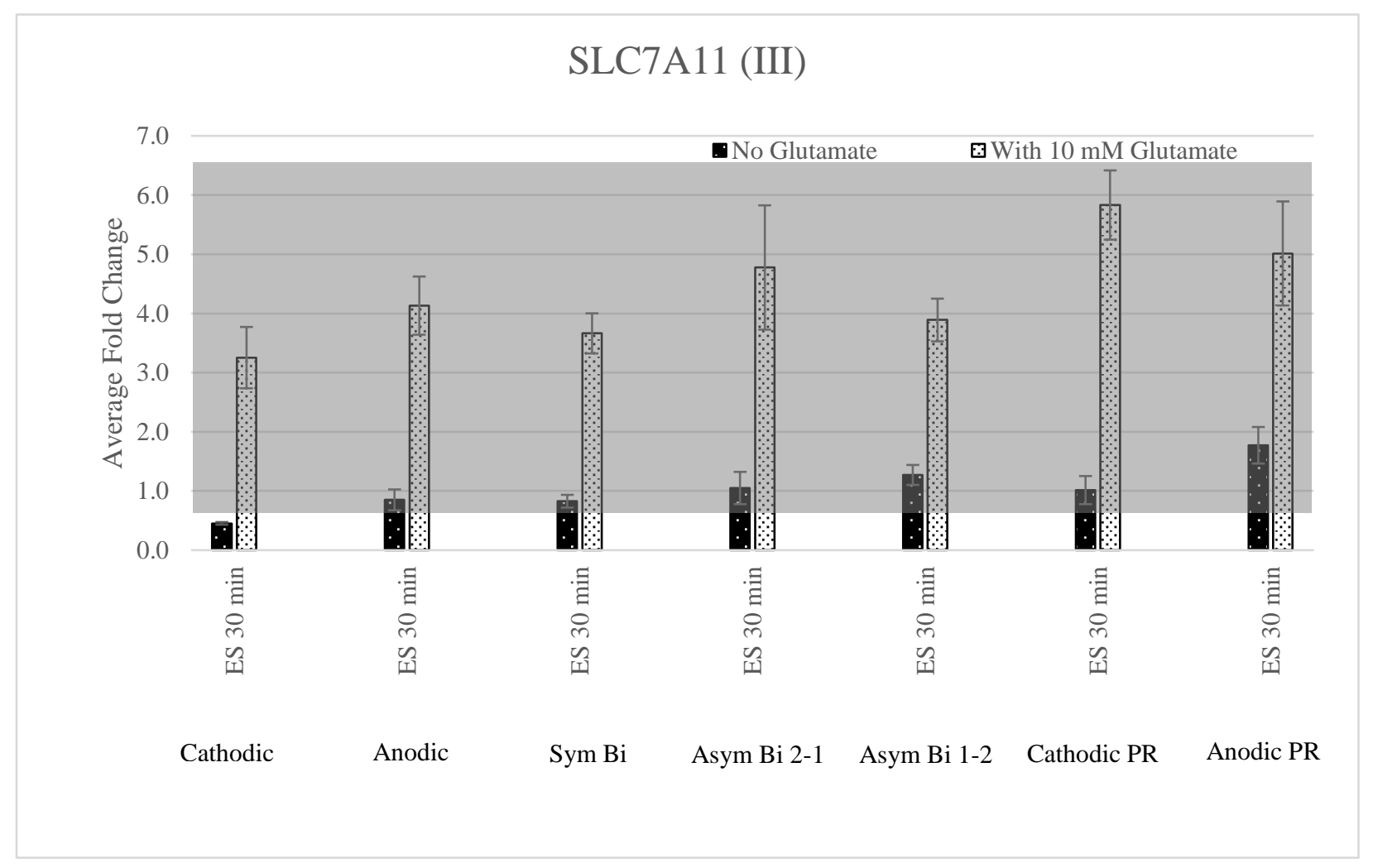

Figure 31: Comparison of SLC7A11 normalized gene expression with the 7 ES waveforms and the 7 ES waveforms with glutamate to the SLC7A11 normalized gene expression control groups without ES. Values are mean \pm SD for $n=3$ independent replicates. 
QPCR Results Summary - The relative changes in gene expression results are summarized in Tables 2 and 3. Using the conservative exclusionary criteria, the anodic PR waveform was found to have the most increases in relative gene expression with 15 . The cathodic monophasic was found to have the most decreases in relative gene expression with 7 . Interestingly, this waveform was only modulating gene expression in the absence of glutamate. Asymmetric Biphasic 1-2 had no changes in relative gene expression lying outside the exclusionary regions. All other ES waveforms were found to have modulated one or more genes sufficiently so as to satisfy the exclusionary criteria. Two of the clinically relevant waveforms, cathodic monophasic and symmetric biphasic are found to only down regulate gene expression and show no changes in the presence of added glutamate. The MT2A and SLC7A11 show the fewest changes in relative gene expression; however, the exclusionary regions on these graphs encompass a very wide range. By eye, there appear to be major changes in relative gene expression that are obscured by the conservative comparisons especially in the presence of glutamate. The most interesting gene in the study was GS because expression of this gene is predicted to be elevated upon addition of glutamate. This was not observed in the presence of ES of various waveforms.

In general, 7 of the 8 genes tested exhibited changes in gene expression related to application of ES with and without $10 \mathrm{mM}$ glutamate added, in this study, relative to control cells. Since these 8 genes were selected due to the potential roles in cell responses to oxidative stress, these results are interesting. 
Table 2: Tabulated summary of the QPCR results. Bolded arrows ( $\uparrow)$ are ES treatment groups. Non-bolded arrows ( $\uparrow)$ are ES and glutamate treatment groups. The direction of the arrow indicates an increase or decrease. Roman numerals indicate graph type the interpretation came from.

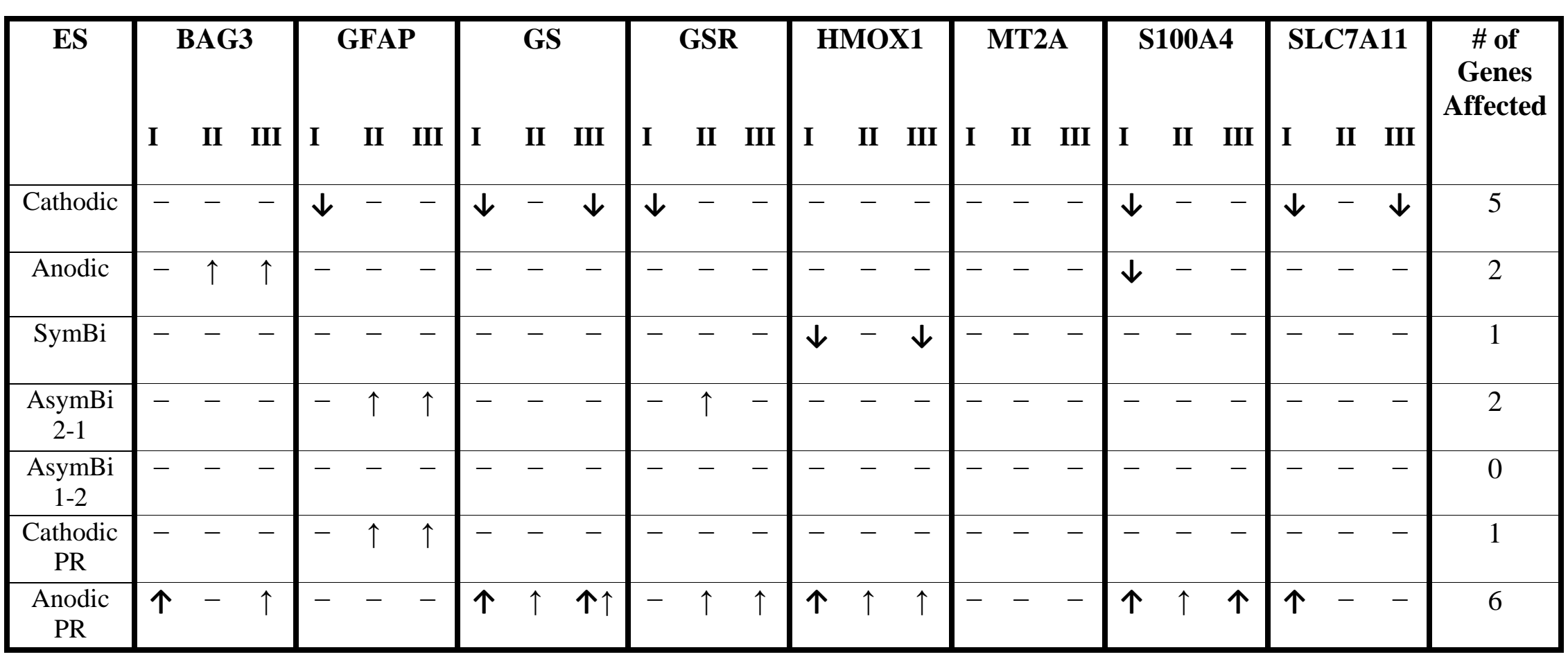


Table 3: A) Tabulated summary of the effect of each waveform on the gene panel as a whole. B) Tabulated summary of the modulation of the gene panel tested.

\begin{tabular}{|c|c|c|c|c|c|c|c|}
\hline A & Cathodic & Anodic & SymBi & AsymBi 2-1 & AsymBi 1-2 & Cathodic PR & Anodic PR \\
\hline Up Regulation & 0 & 3 & 0 & 3 & 0 & 2 & 15 \\
\hline Down Regulation & 7 & 3 & 2 & 0 & 0 & 0 & 0 \\
\hline
\end{tabular}

\begin{tabular}{|c|c|c|c|c|c|c|c|c|}
\hline B & BAG3 & GFAP & GS & GSR & HMOX1 & MT2A & S100A4 & SLC7A11 \\
\hline Up Regulation & 4 & 4 & 4 & 3 & 3 & 0 & 3 & 1 \\
\hline Down Regulation & 0 & 1 & 2 & 1 & 2 & 0 & 2 & 2 \\
\hline
\end{tabular}


Fluorescent Probe Assay Results - The results from the QPCR suggest that there is a perturbation of the transcribed RNA levels of some genes involved with intracellular processes involved with oxidative stress upon application of electrical stimulation. There are also reports in the literature (Salvemini et al., 2011) suggesting an important connection between ROS and RNS and chronic pain. To establish whether or not electrical stimulation can effect ROS and RNS levels in the glioma cells, experiments to monitor the fluorescence signals of two molecular probes, sensitive to either superoxide radicals or nitric oxide radicals, were designed. By introducing the same experimental conditions as the QPCR, effects on ROS and RNS probe signals in response to glutamate addition and/or electrical stimulation application were anticipated. The probe signals were measured at various times typically over the course of 2 hours or more following ES and/or glutamate addition. Data are normalized relative to no treatment (control) cells which are set at 1.0 on the y-axis. Polynomial trend lines of best fit were generated in Microsoft Excel to describe the trends in the signals. Also shown are the comparisons of the first time measurement as a function of \pm glutamate \pm ES relative to control cells. 
Cathodic Passive Recharge - The DAF-FM signal following the cathodic PR waveform treatment is depicted in Figure 32(A,B). Initially the NO· probe signal for all the experimental groups is lower than the control cells without ES or glutamate (Figure 32A). After 2 hours of incubation this changes and the experimental groups' probe signals all exceed the signal of the control cells (Figure 32B). After 4 hours of incubation the combination of glutamate and ES show a 5\% greater signal, but not significantly so, than either treatment alone. These results suggest that the NO- levels of the glioma cells is increased after administration of cathodic PR ES with or without glutamate.

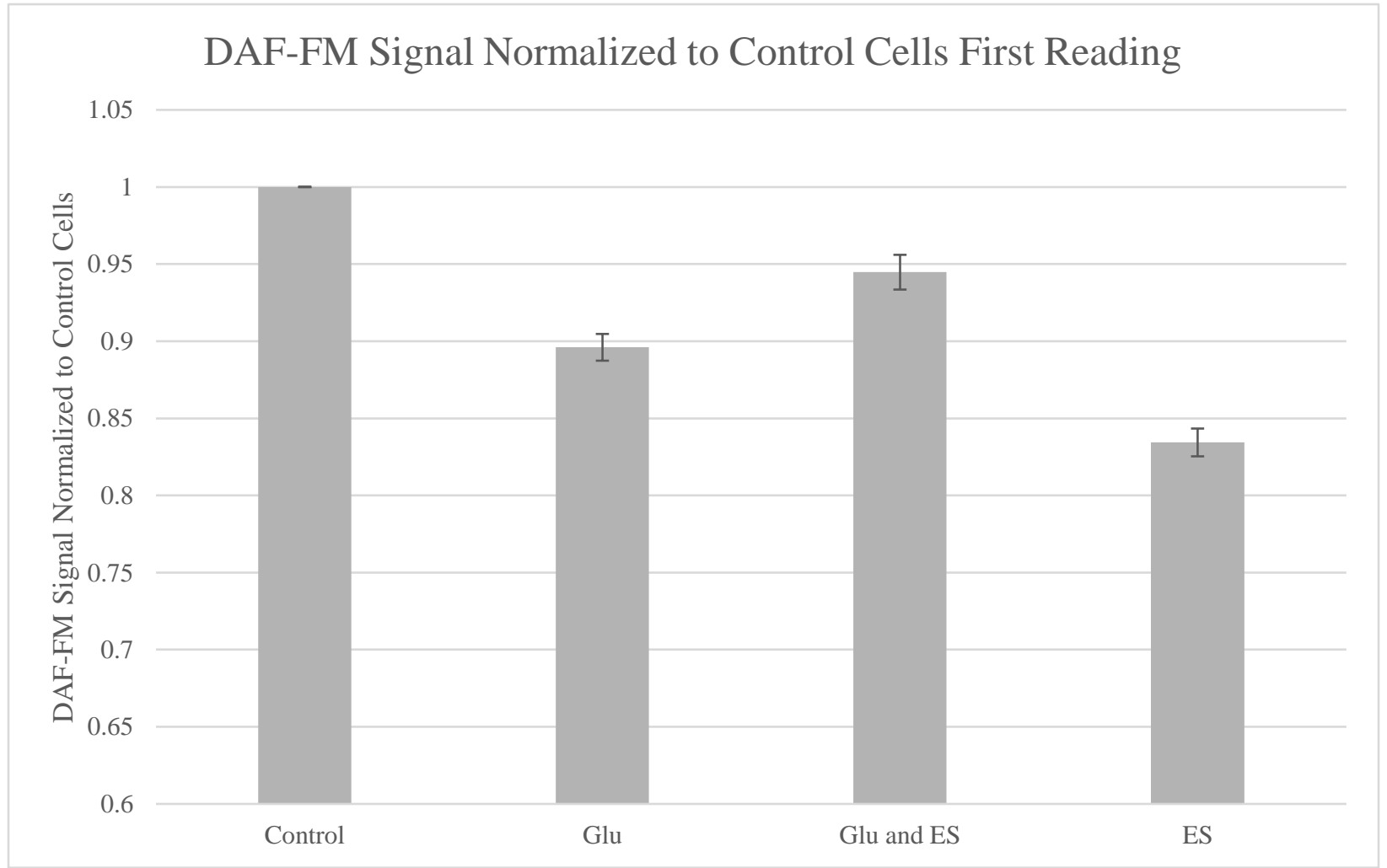

Figure 32 (A): Graphical representation of the normalized DAF-FM signal at the initial reading as a result of cathodic PR ES with or without glutamate treatment. Values are mean \pm SD of five readings for $n=4$ independent replicates. 


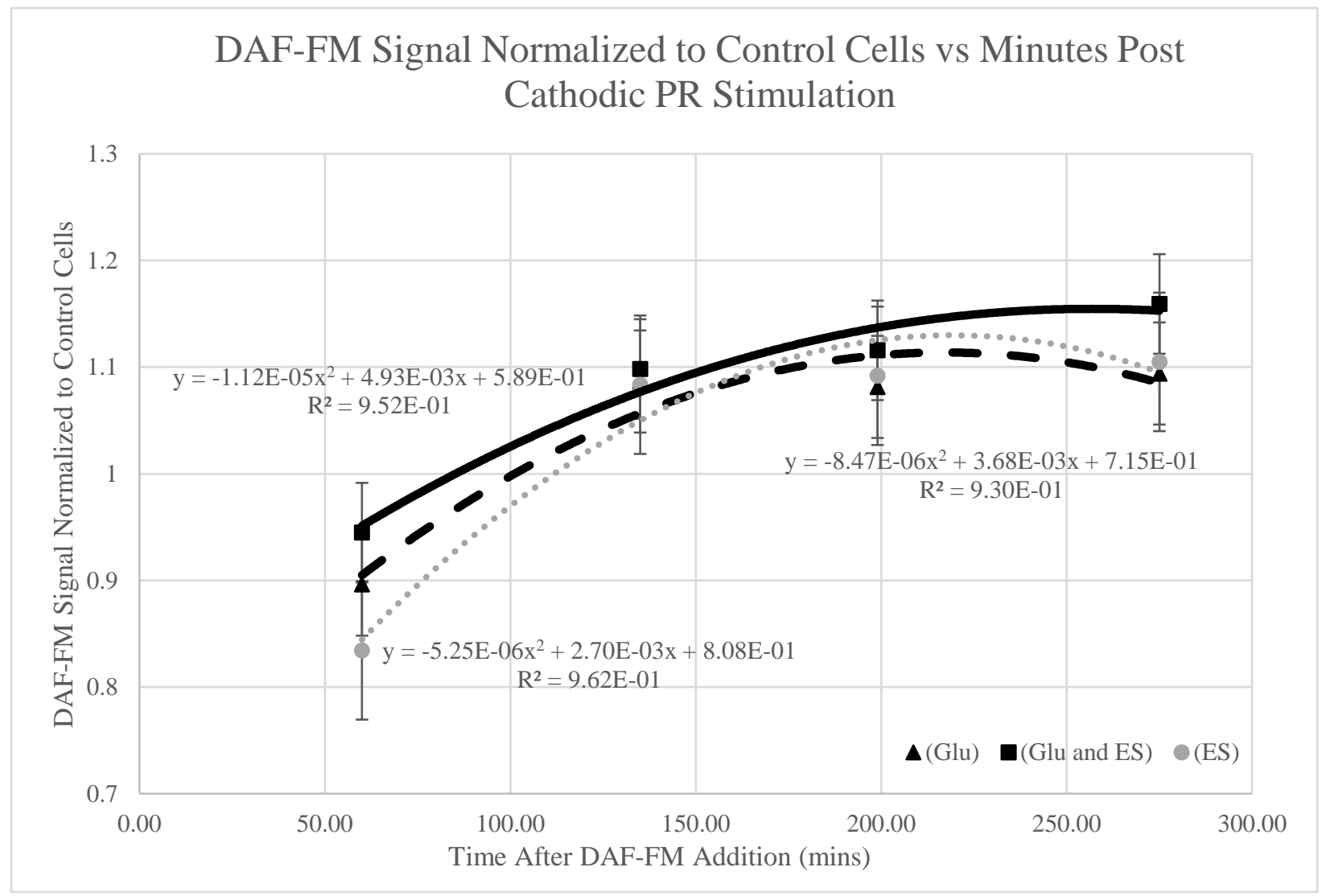

Figure 32 (B): Graphical representation of the normalized DAF-FM signal changing with time as a result of cathodic PR ES with or without glutamate treatment. Values are mean \pm SD of five readings for $n=4$ independent replicates. 
Cathodic Passive Recharge cont. - The Mitosox Red Superoxide probe signal following cathodic PR waveform treatment is depicted in Figure 33(A,B). The cathodic PR stimulation Mitosox probe signal resulted in a decreased signal, of approximately $18 \%$ relative to the control cell signal at the first time point (Figure 33A). Both the added glutamate treatment and ES with added glutamate treatment resulted in higher Mitosox signals than the ES alone, but were still below the signal of the control cells (Figure 34B).

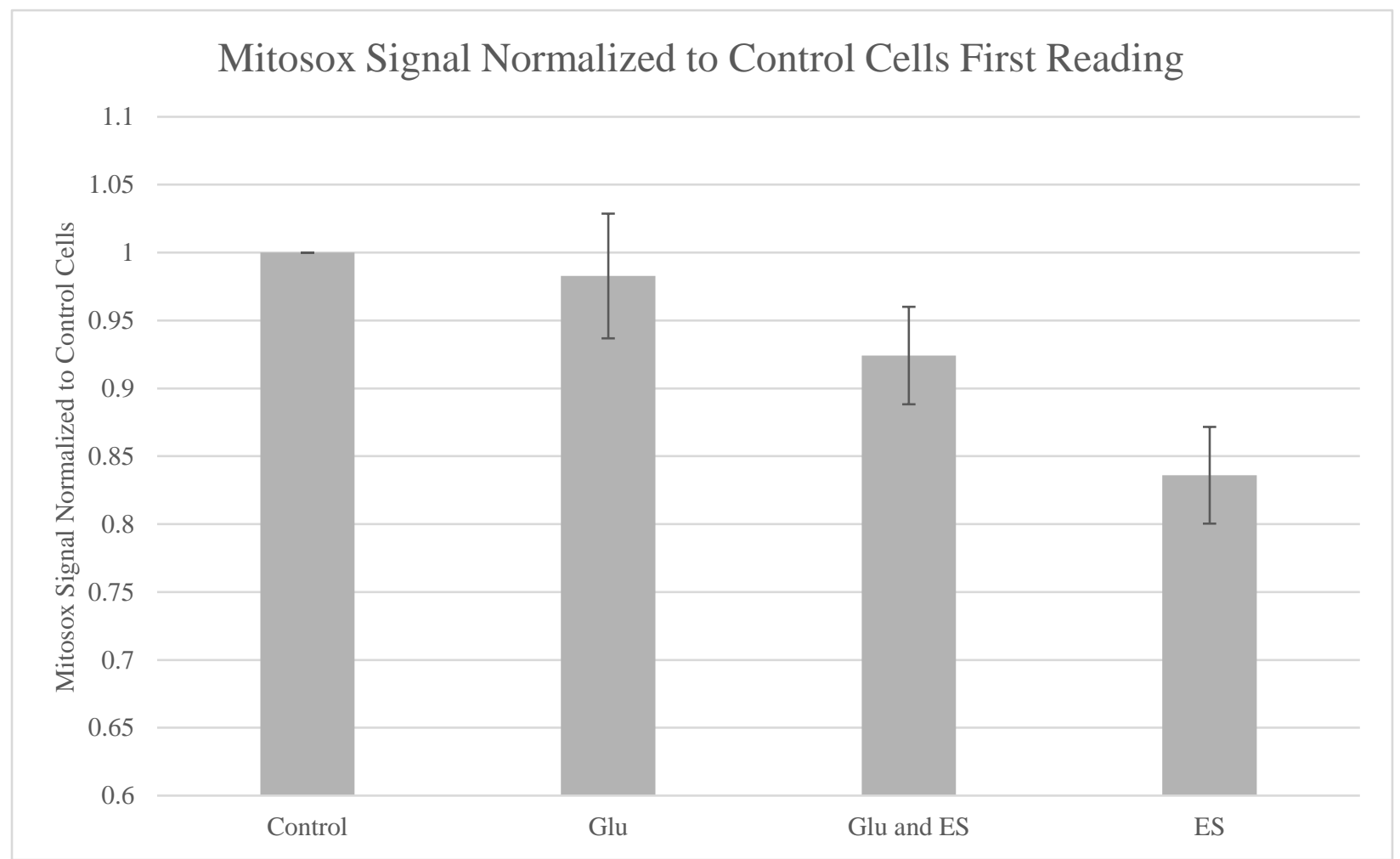

Figure 33 (A): Graphical representation of the normalized Mitosox signal at the initial reading as a result of cathodic PR ES with or without glutamate treatment. Values are mean \pm SD of five readings for $\mathrm{n}=4$ independent replicates. 


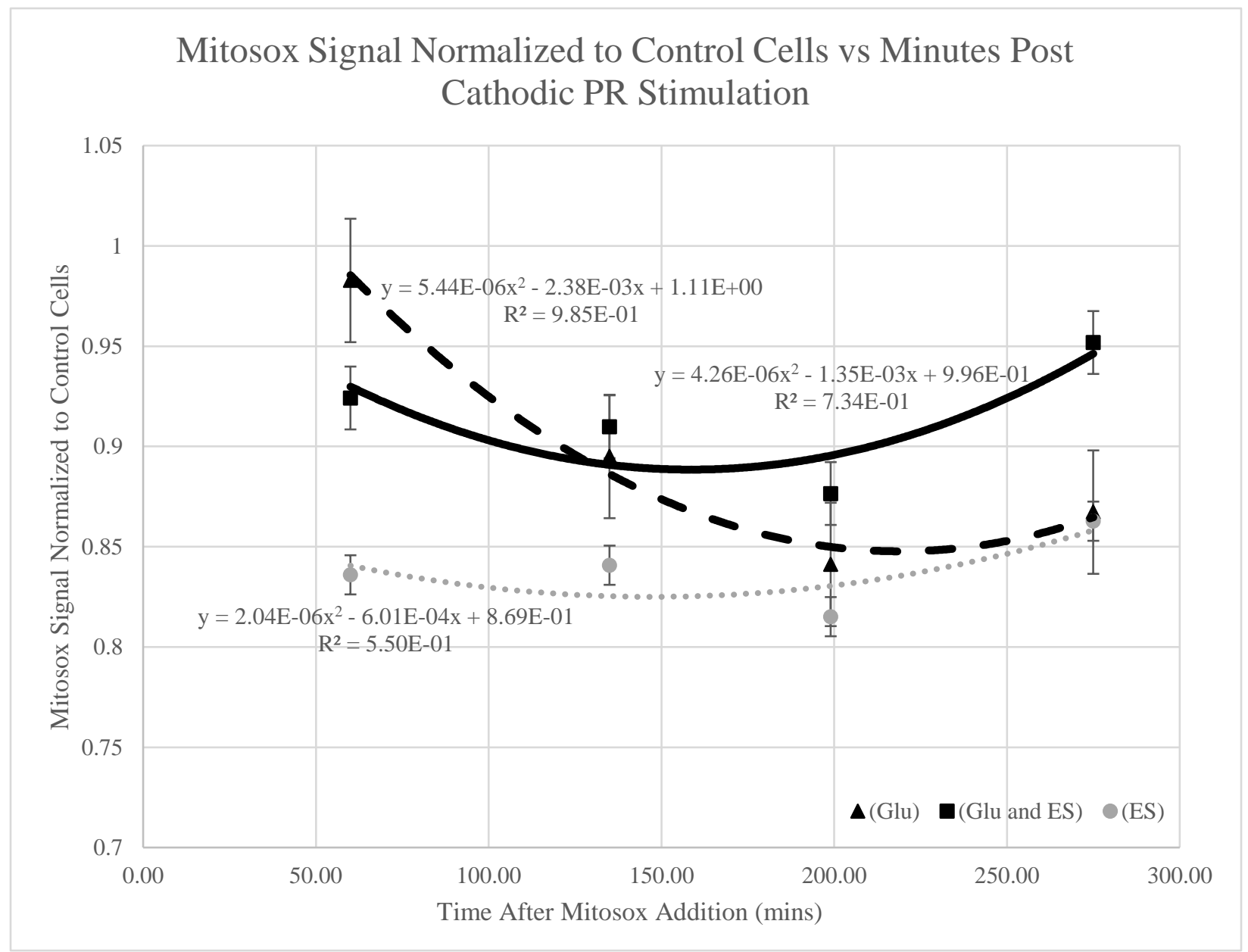

Figure 33 (B): Graphical representation of the normalized Mitosox signal changing with time as a result of cathodic PR ES with or without glutamate treatment. Values are mean \pm SD of five readings for $n=4$ independent replicates. 
Anodic Passive Recharge Results - The DAF-FM signal following anodic PR waveform treatment is depicted in Figure 34(A,B). The effect of anodic PR ES on the DAF-FM signal is negligible relative to the no treatment control cells. Introduction of glutamate causes the signal of DAF-FM to increase by approximately $30 \%$ relative to the no treatment control. When the two treatments are combined glutamate increases the DAF-FM signal initially by about $15 \%$, but, over time, the anodic PR ES lowers the probe signal down to nearly that of the no treatment control cells (Figure 34A,B). This pattern suggests that glutamate increases the production of NO- and anodic PR ES is decreasing this effect of glutamate on the glioma cells. Also the anodic PR ES does not greatly impact NO· levels when glutamate levels are not elevated.

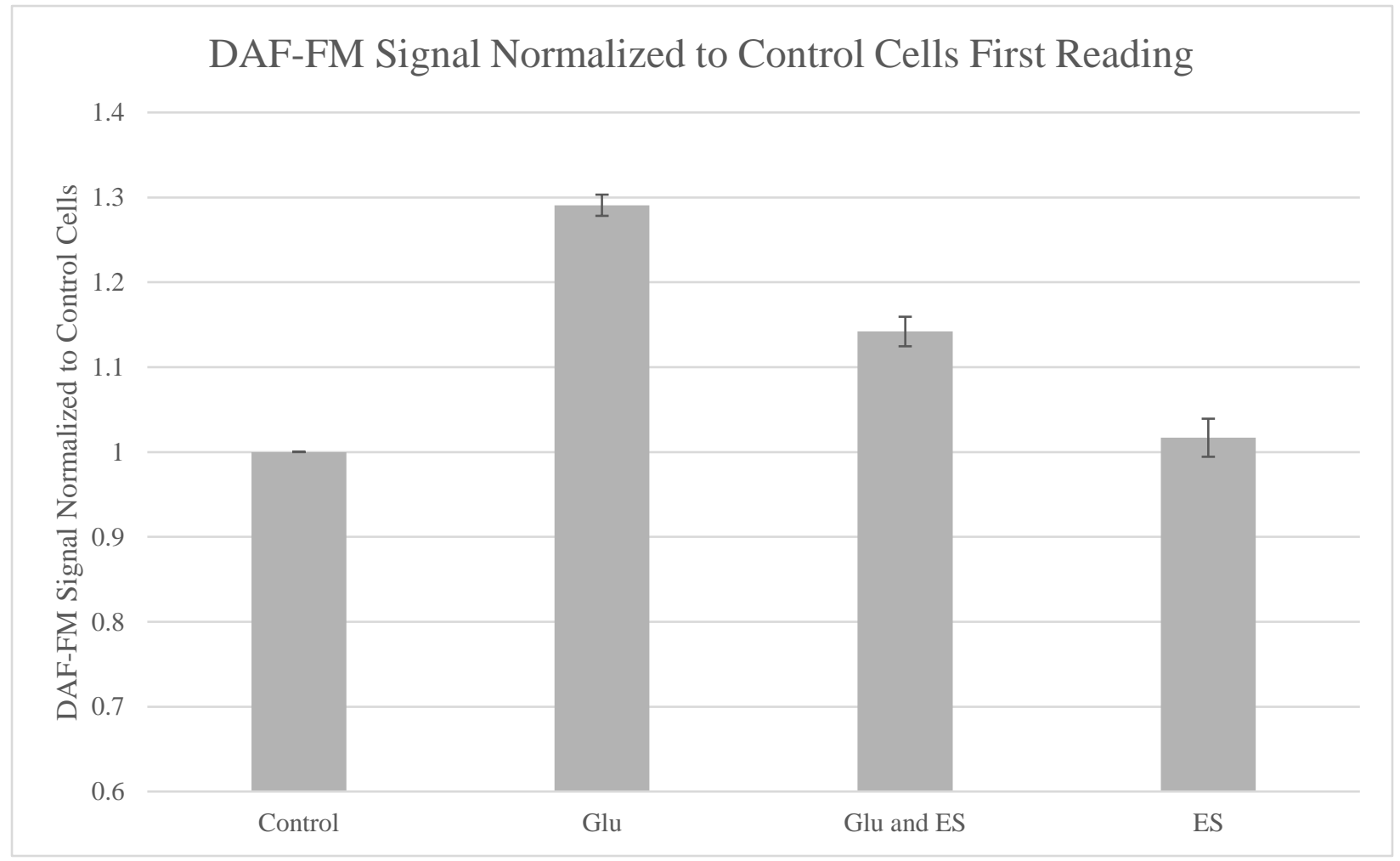

Figure 34 (A): Graphical representation of the normalized DAF-FM signal at the initial reading as a result of anodic PR ES with or without glutamate treatment. Values are mean \pm SD of five readings for $n=4$ independent replicates. 


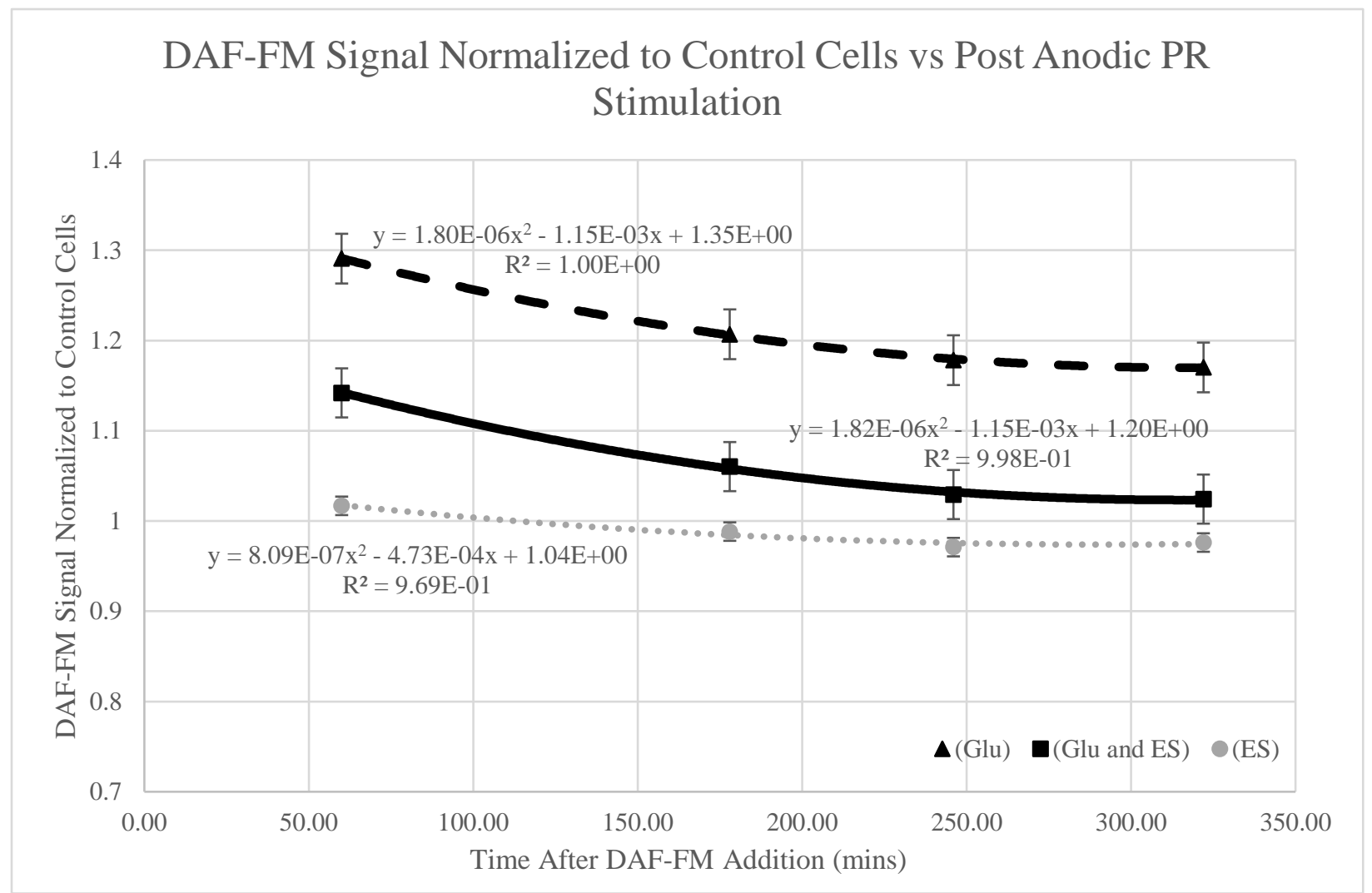

Figure 34 (B): Graphical representation of the normalized DAF-FM signal changing with time as a result of anodic PR ES with or without glutamate treatment. Values are mean \pm SD of five readings for $n=4$ independent replicates. 
Anodic Passive Recharge Results cont. - The Mitosox Red Superoxide probe signal following anodic PR waveform treatment is depicted in Figure 35(A,B). There were no discernable trends in the Mitosox Red signal in response to anodic PR stimulation. Large fluctuations in the Mitosox Red signal, at this time, are likely due to an improper ratio of probe to cell count.

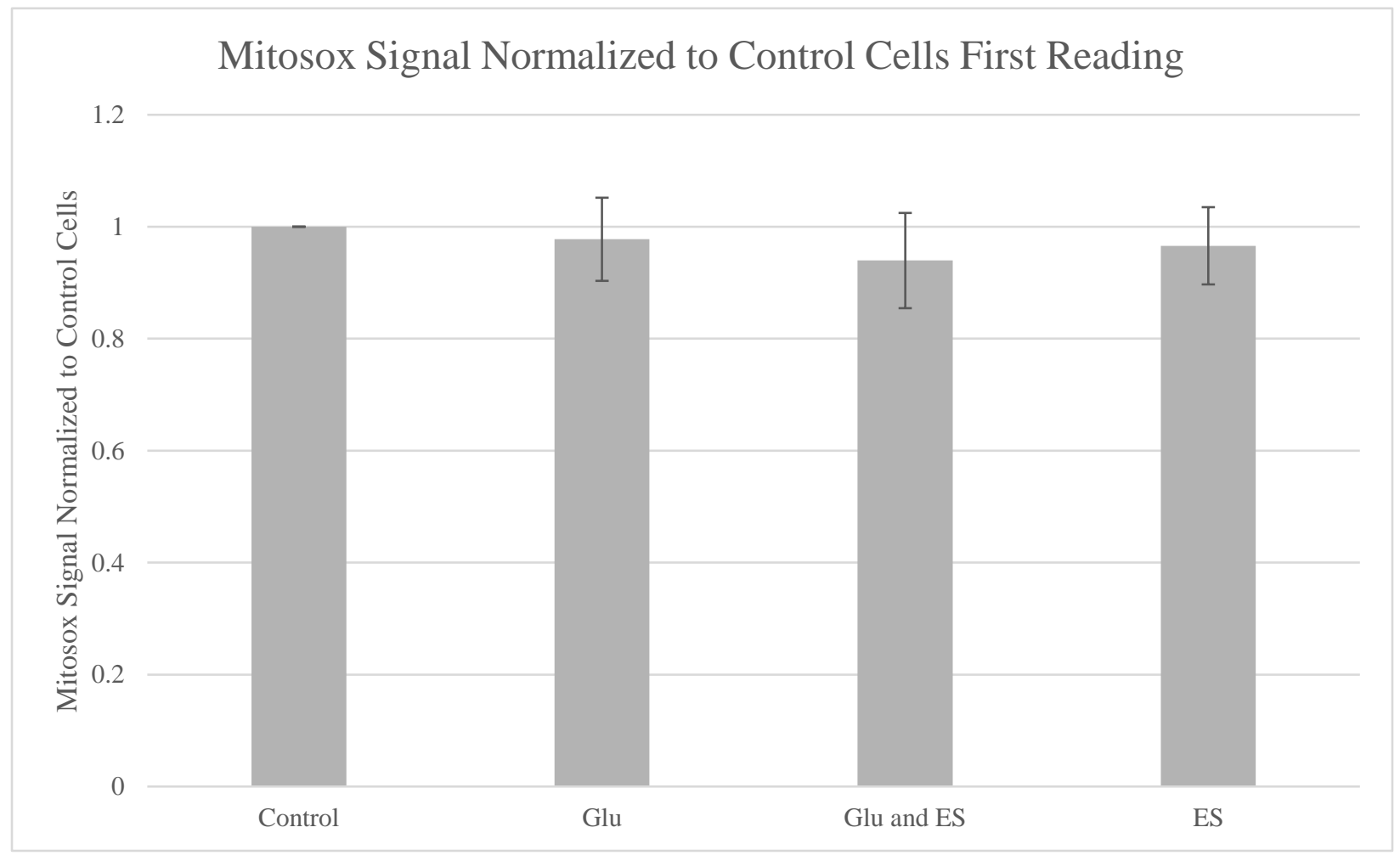

Figure 35 (A): Graphical representation of the normalized Mitosox signal at the initial reading as a result of anodic PR ES with or without glutamate treatment. Values are mean $\pm \mathrm{SD}$ of five readings for $n=4$ independent replicates. 


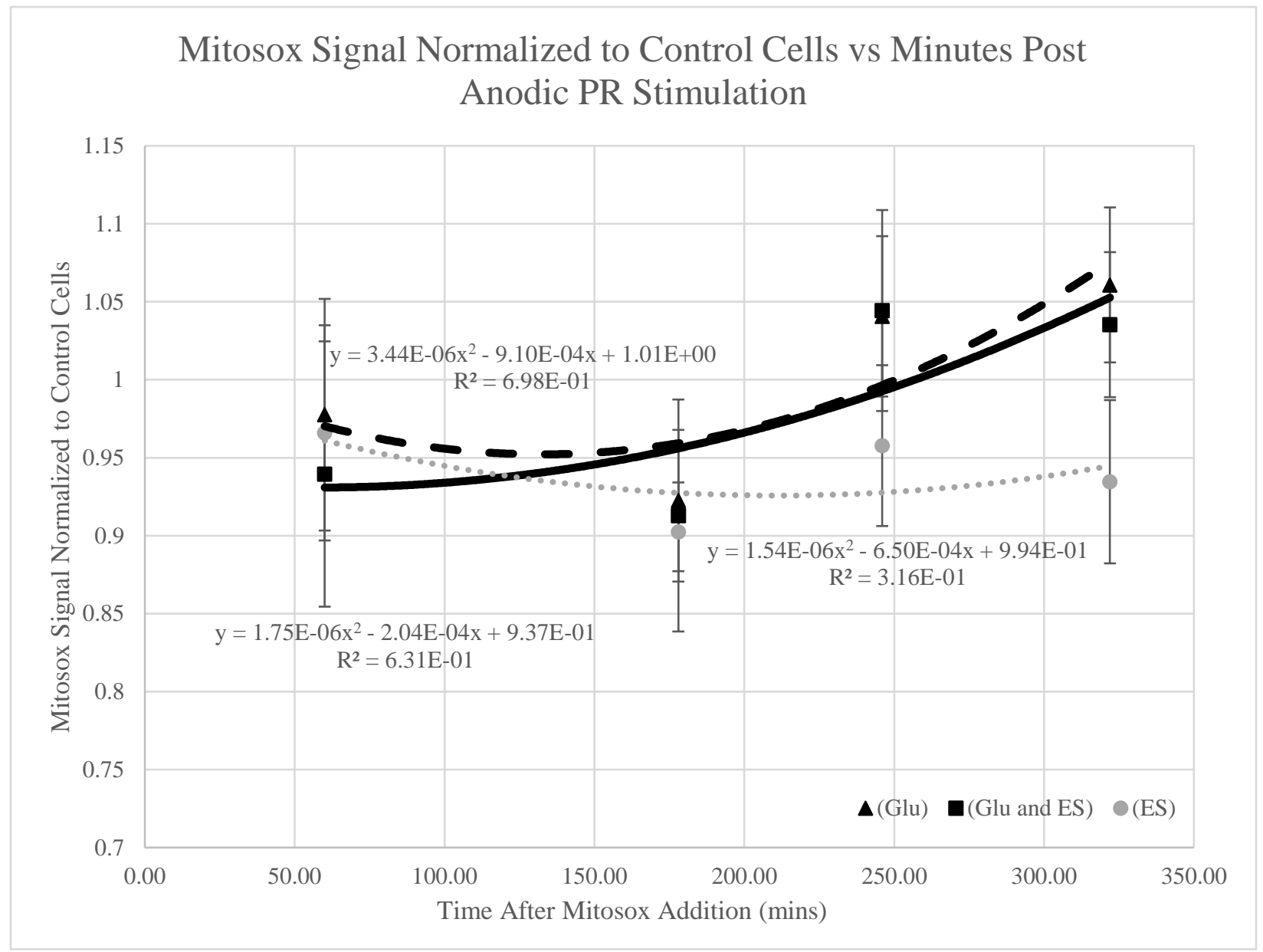

Figure 35 (B): Graphical representation of the normalized Mitosox signal changing with time as a result of anodic PR ES with or without glutamate treatment. Values are mean \pm SD of five readings for $n=4$ independent replicates. 
Cathodic Monophasic Results - The DAF-FM signal following cathodic monophasic waveform treatment is depicted in Figure 36(A,B). Initially all treatment groups showed an increase in the DAF-FM probe signal relative to the no treatment control (Figure 36A). After two hours the signals for the glutamate treatment group and the glutamate and ES treatment group were trending down toward the no treatment control DAF-FM signal. The ES treatment group DAF-FM signal was trending up relative to the no treatment control. Further incubation shows that the cathodic monophasic treatment group DAF-FM signal continues to trend upward. The glutamate treatment group DAF-FM signal continues to trend down. Interestingly, the glutamate and ES treatment group trend inverted and began to trend upward as incubation time increased (Figure 36B). These data suggest cathodic monophasic ES results in increases in the production of NO- in the glioma cells. 


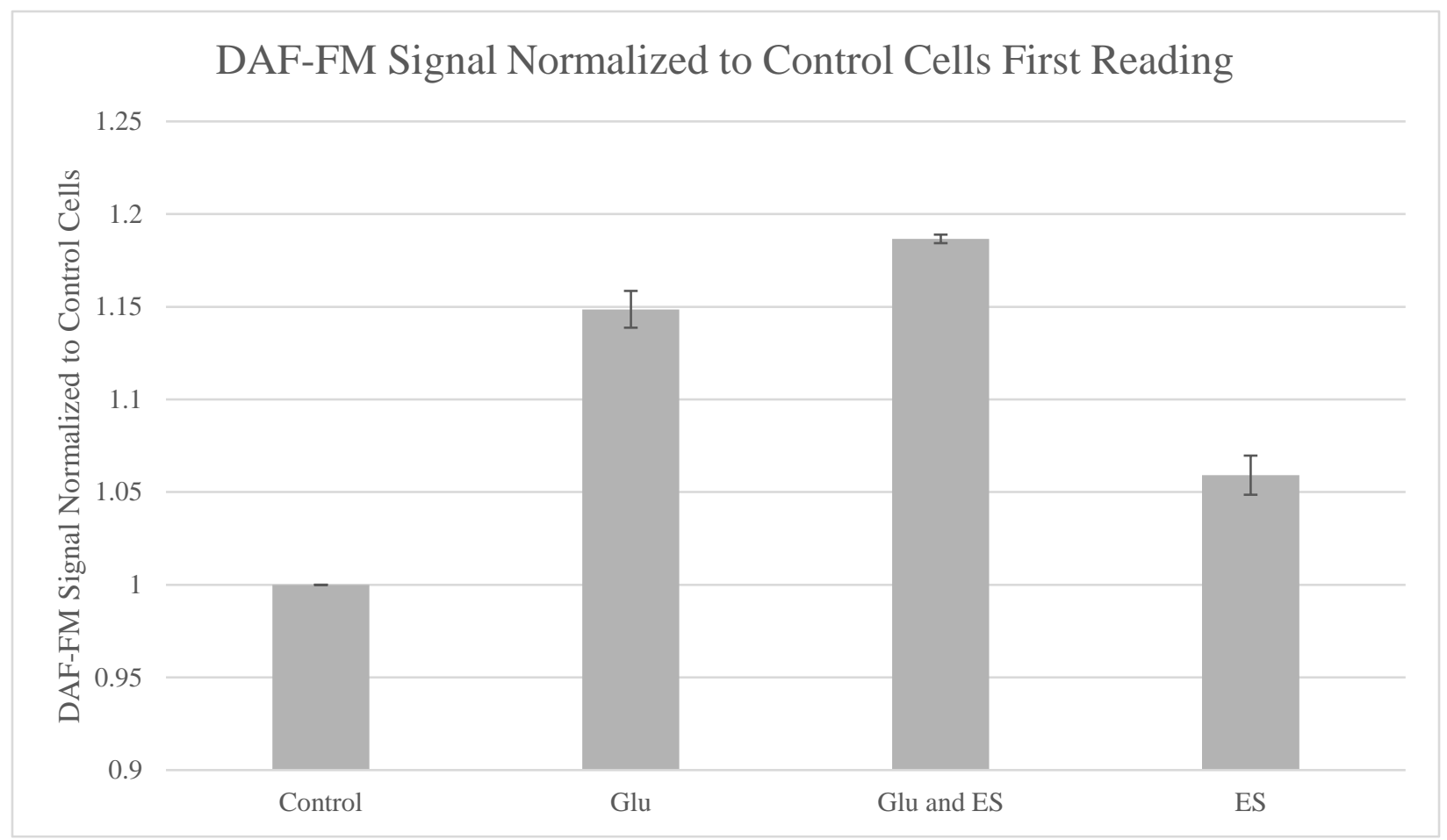

Figure 36 (A): Graphical representation of the normalized DAF-FM signal at the initial reading as a result of cathodic monophasic ES with or without glutamate treatment. Values are mean $\pm \mathrm{SD}$ of five readings for $\mathrm{n}=4$ independent replicates. 


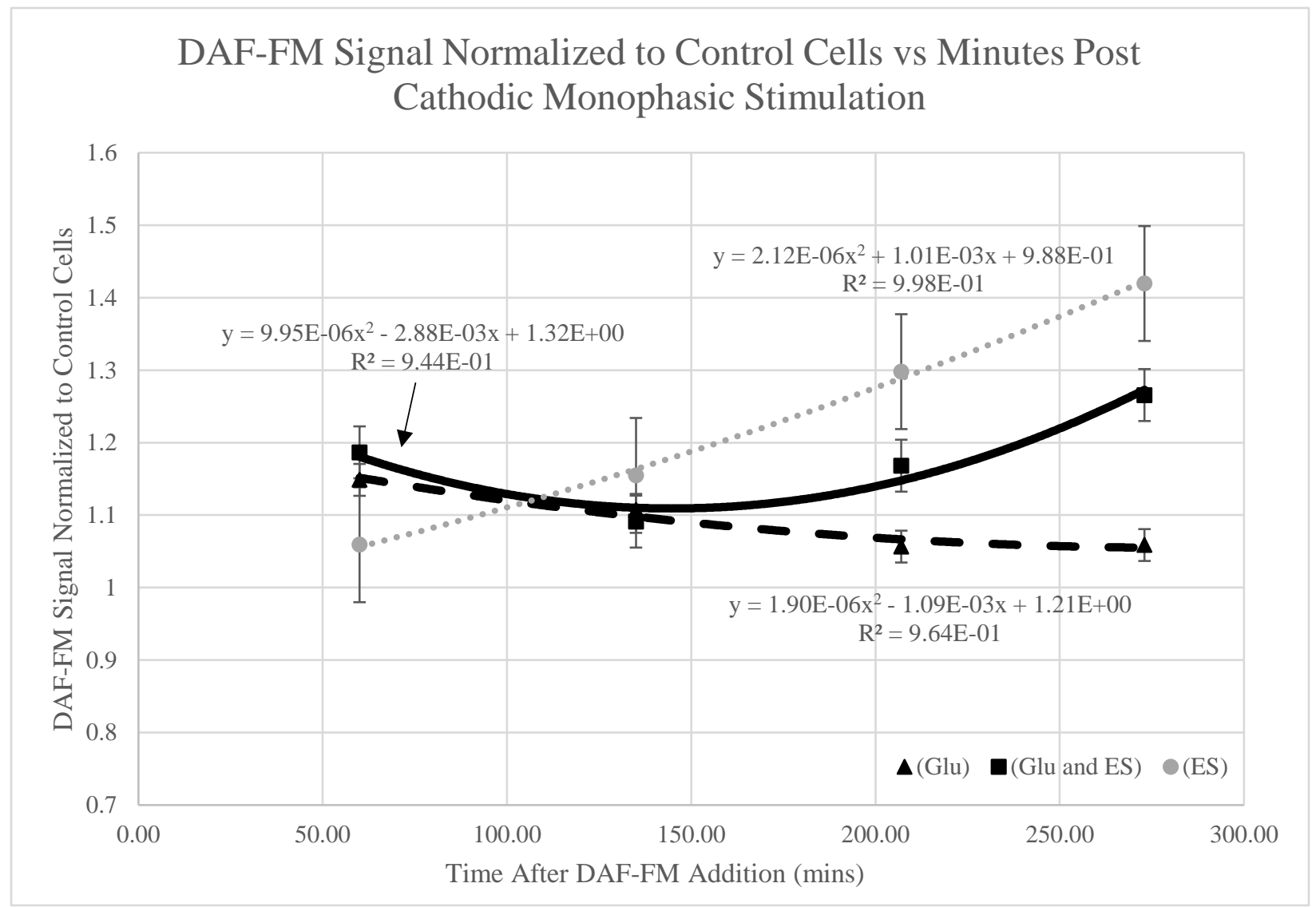

Figure 36 (B): Graphical representation of the normalized DAF-FM signal changing with time as a result of cathodic monophasic ES with or without glutamate treatment. Values are mean \pm SD of five readings for $n=4$ independent replicates. 
Cathodic Monophasic Results cont. - The Mitosox Red Superoxide probe signal following cathodic monophasic waveform treatment is depicted in Figure 37(A,B). Only the ES treatment group signal appears to have increased relative to control cells at the first time point (Figure 37A). The cathodic monophasic electrical stimulation group Mitosox signal is trending down as incubation progresses suggesting the ES treatment utilizing cathodic monophasic stimulation results in decreasing the production of superoxide. The glutamate treatment showed a slight decrease in the Mitosox signal relative to the no treatment control group. This trend in the Mitosox signal is stable over the course of the incubation period. Treatment with both ES and glutamate shows very little deviation from the Mitosox signal of the no treatment control (Figure 37B).

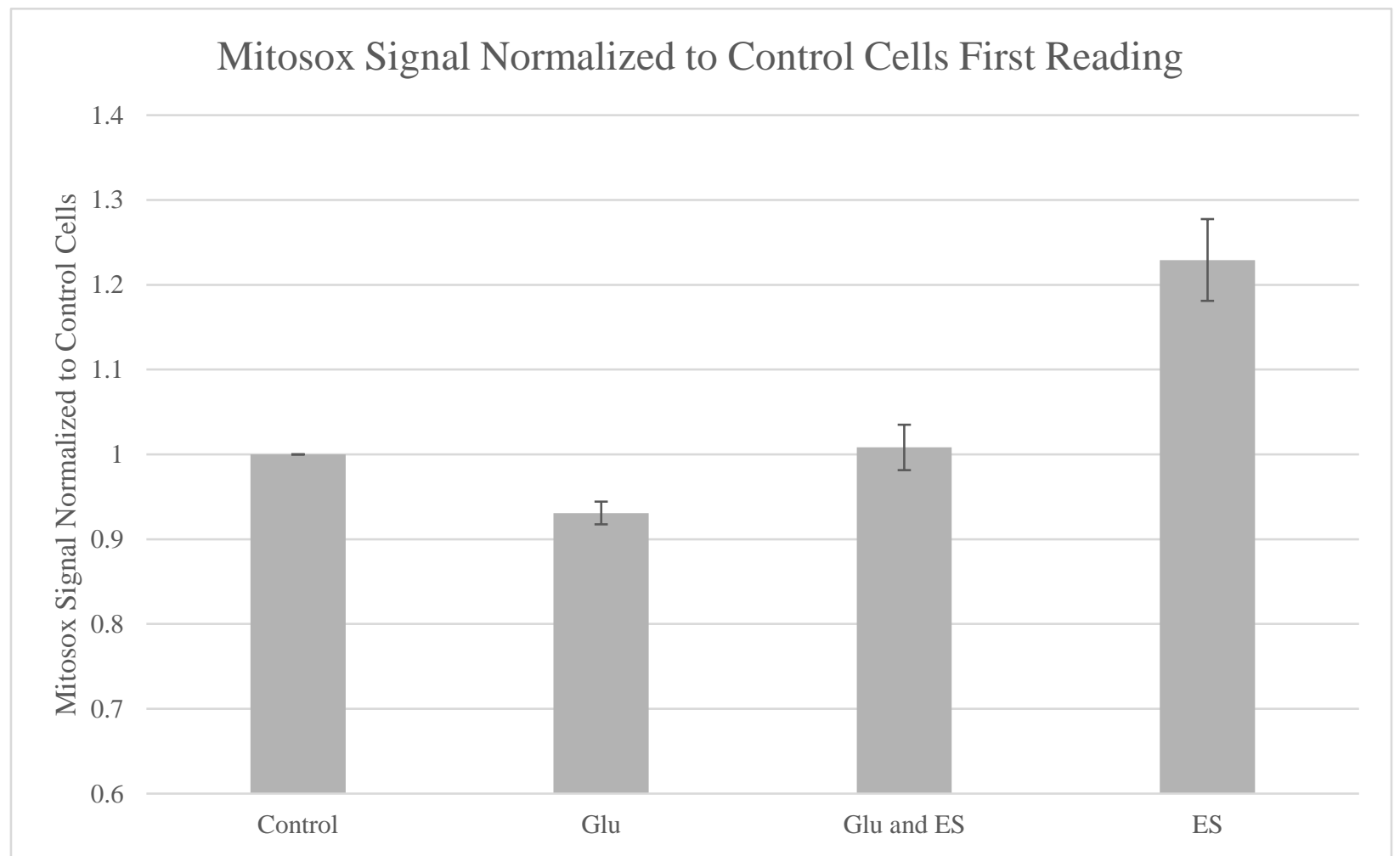

Figure 37 (A): Graphical representation of the normalized Mitosox signal at the initial reading as a result of cathodic monophasic ES with or without glutamate treatment. Values are mean \pm SD of five readings for $\mathrm{n}=4$ independent replicates. 


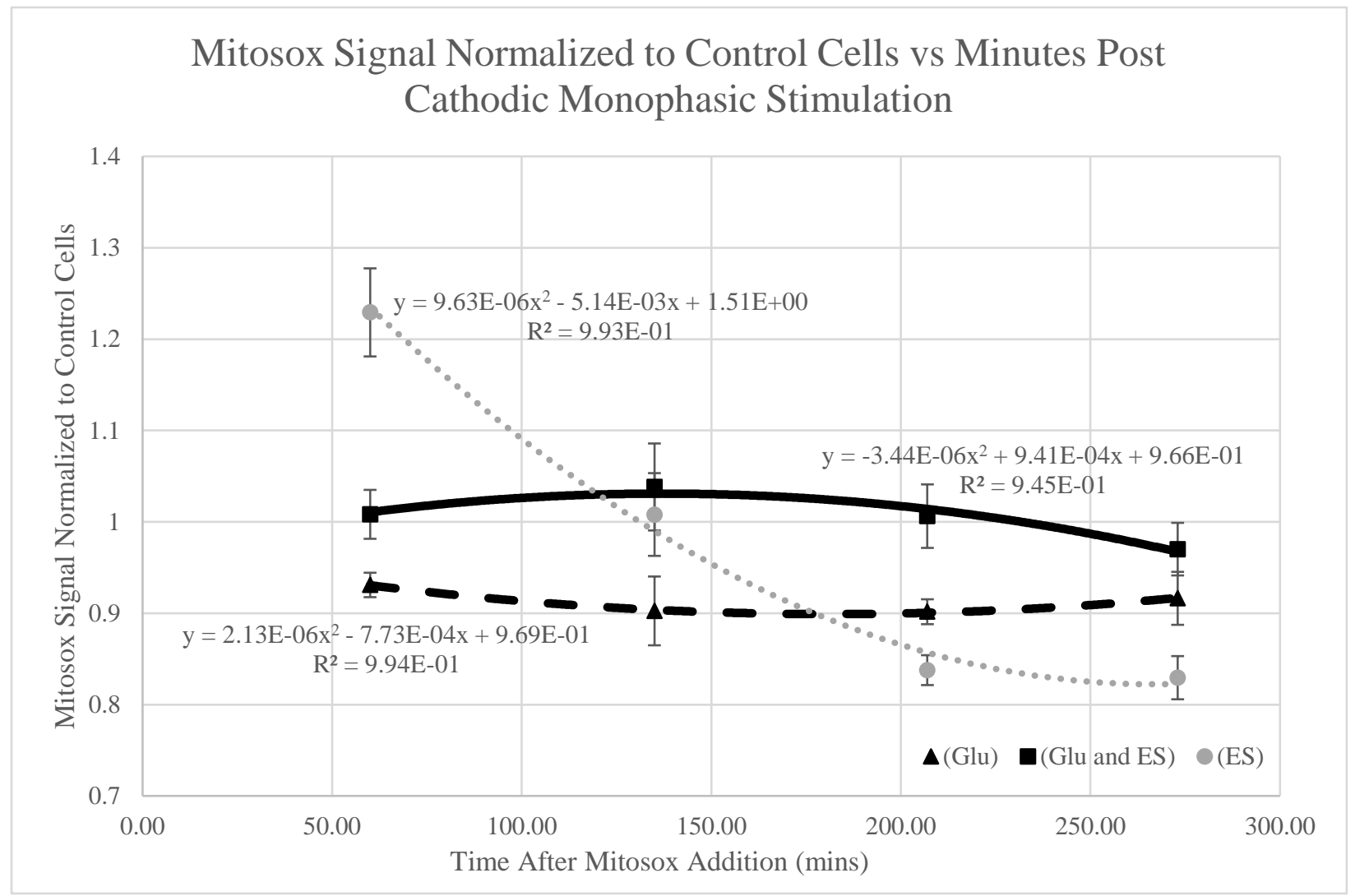

Figure 37 (B): Graphical representation of the normalized Mitosox signal changing with time as a result of cathodic monophasic ES with or without glutamate treatment. Values are mean \pm SD of five readings for $n=4$ independent replicates. 
Anodic Monophasic Results - The DAF-FM signal following anodic monophasic waveform treatment is depicted in Figure 38(A,B). The ES treatment group DAF-FM signal shows very little deviation from the probe signal of the no treatment control. The glutamate treatment group DAF-FM signal was increased relative to the signal of the no treatment control. Treating the glioma cells with both ES and glutamate shows a marked increase in the DAF-FM signal relative to the no treatment control. These results suggest that the anodic monophasic waveform may be inducing the production of NO when the cells are exposed to glutamate.

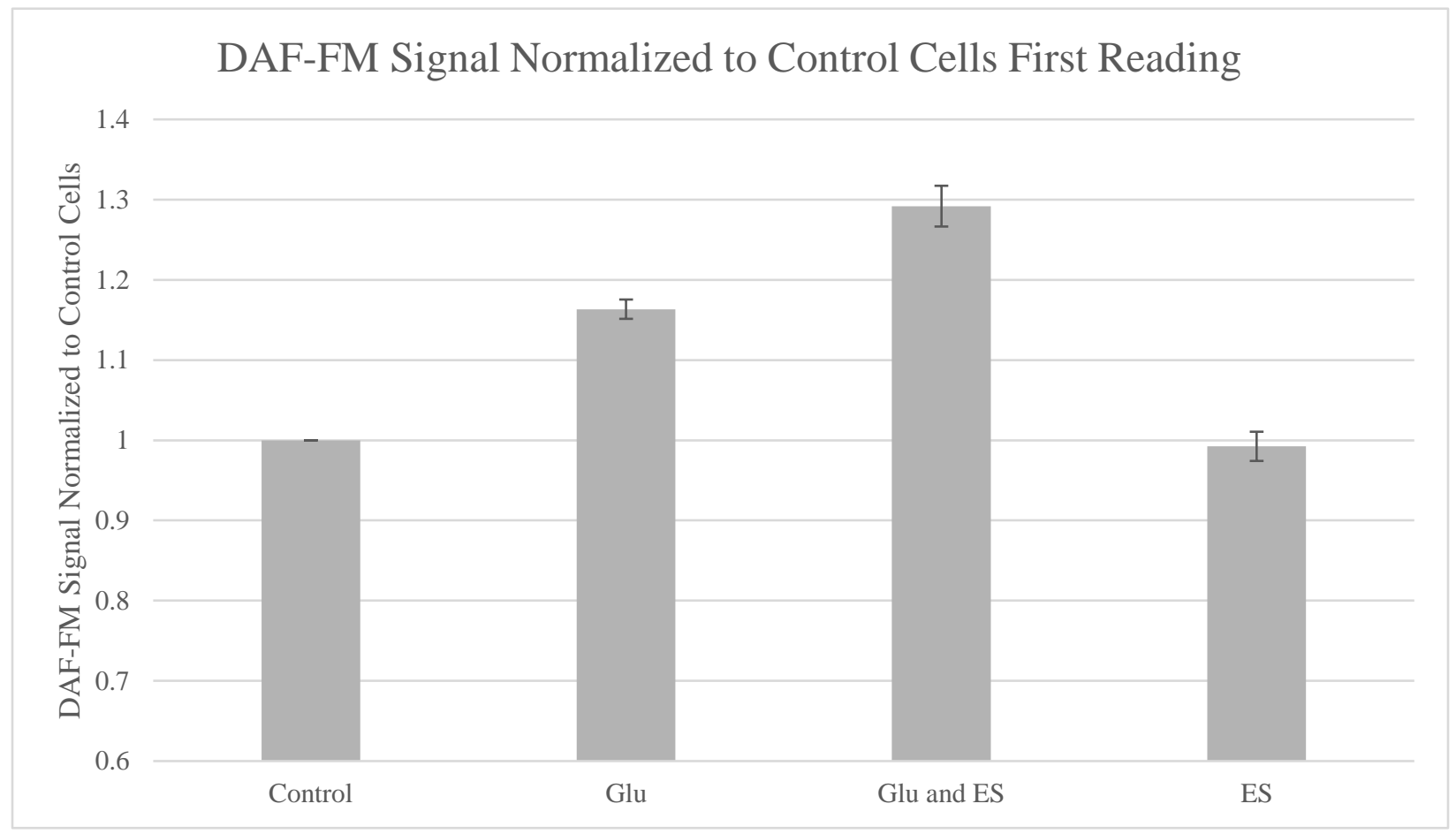

Figure 38 (A): Graphical representation of the normalized DAF-FM signal at the initial reading as a result of anodic monophasic ES with or without glutamate treatment. Values are mean \pm SD of five readings for $n=4$ independent replicates. 


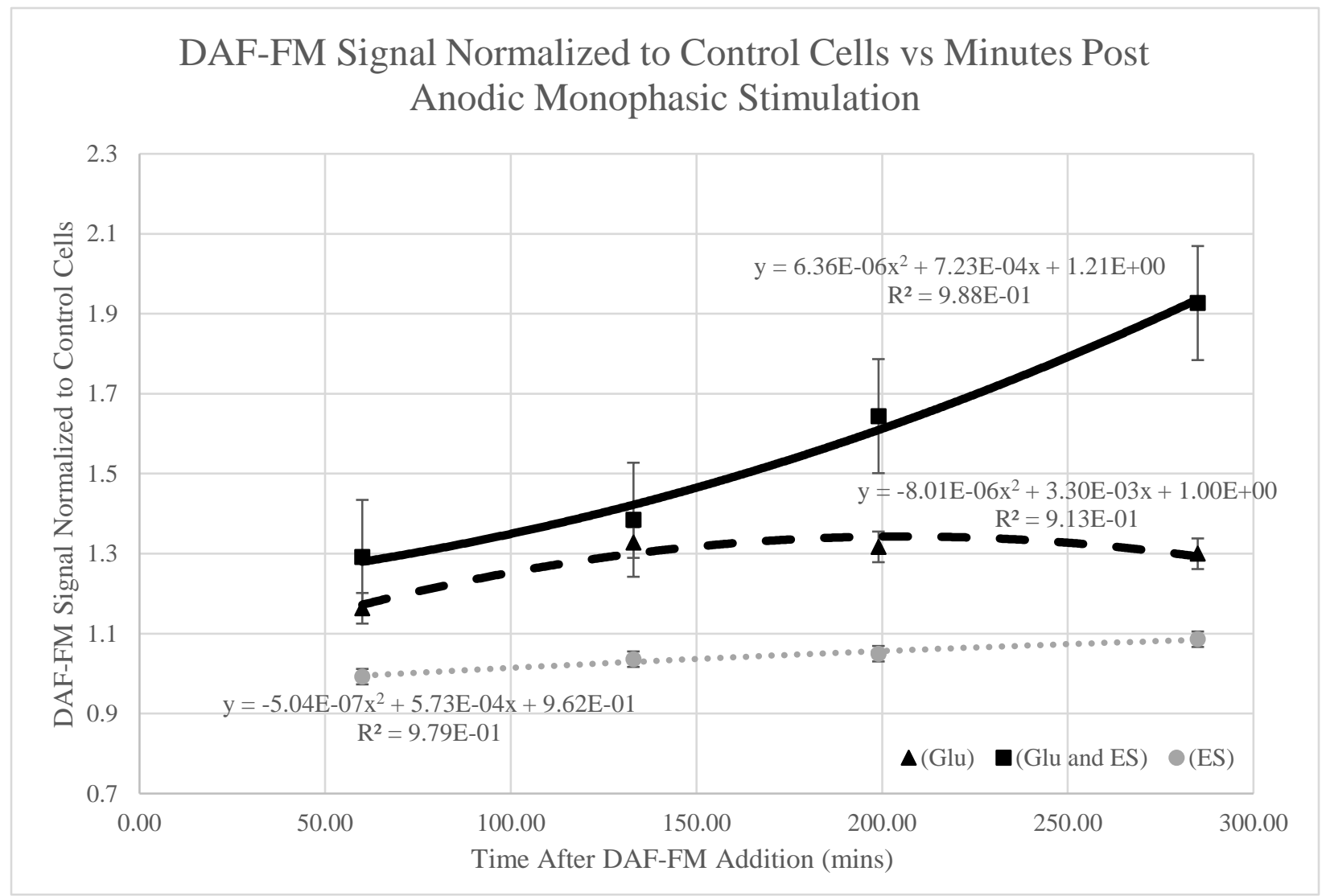

Figure 38 (B): Graphical representation of the normalized DAF-FM signal changing with time as a result of anodic monophasic ES with or without glutamate treatment. Values are mean \pm SD of five readings for $n=4$ independent replicates. 
Anodic Monophasic Results cont. - The Mitosox Red Superoxide probe signal following anodic monophasic waveform treatment is depicted in Figure 39(A,B). All treatment groups resulted in Mitosox signals that are decreased relative to the no treatment control. There were no other discernable trends in the Mitosox Red signal in response to anodic monophasic stimulation. Large fluctuations in the Mitosox Red signal, at this time, are likely due to an improper ratio of probe to cell count.

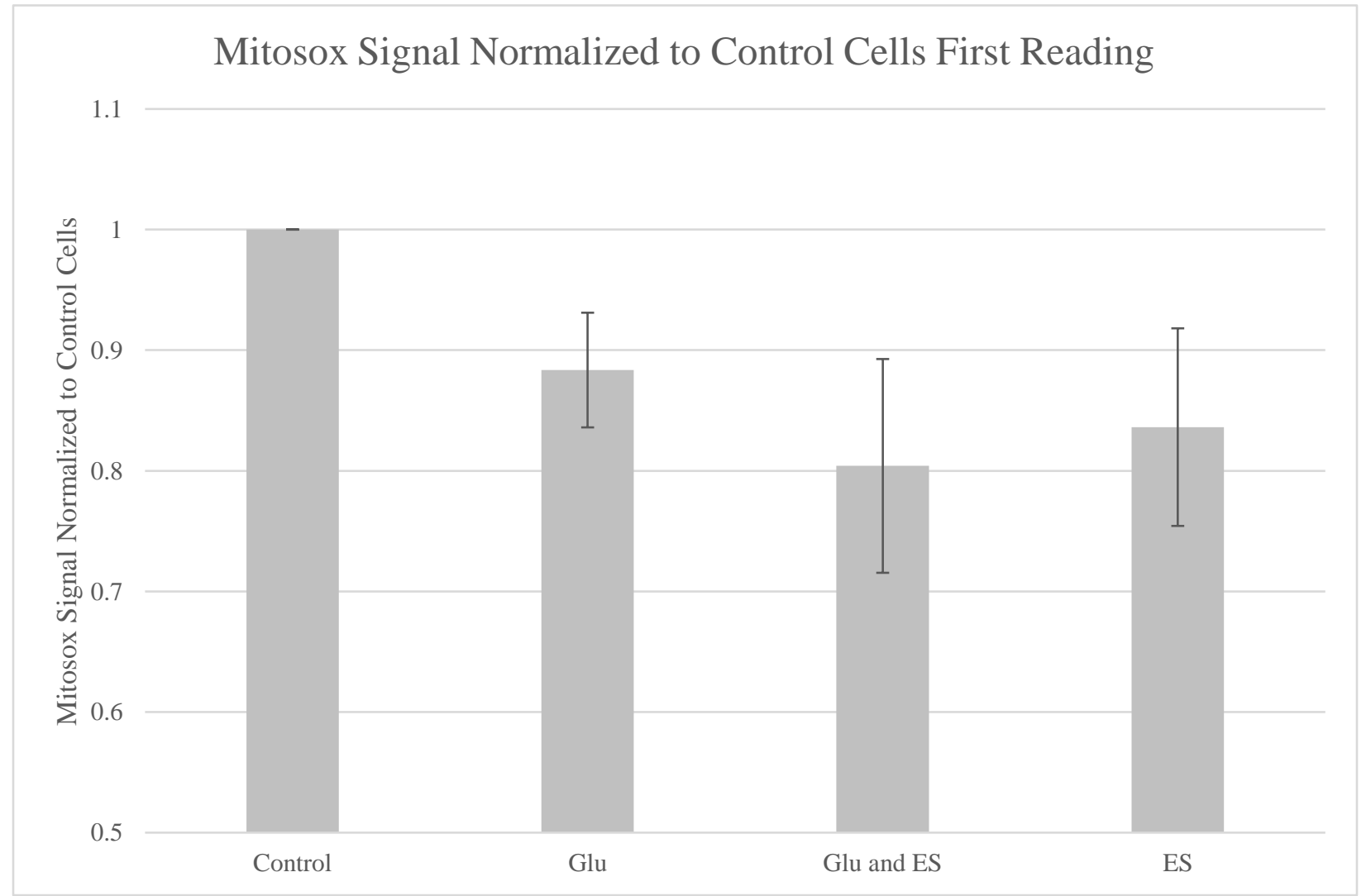

Figure 39 (A): Graphical representation of the normalized Mitosox signal at the initial reading as a result of anodic monophasic ES with or without glutamate treatment. Values are mean \pm SD of five readings for $\mathrm{n}=4$ independent replicates. 


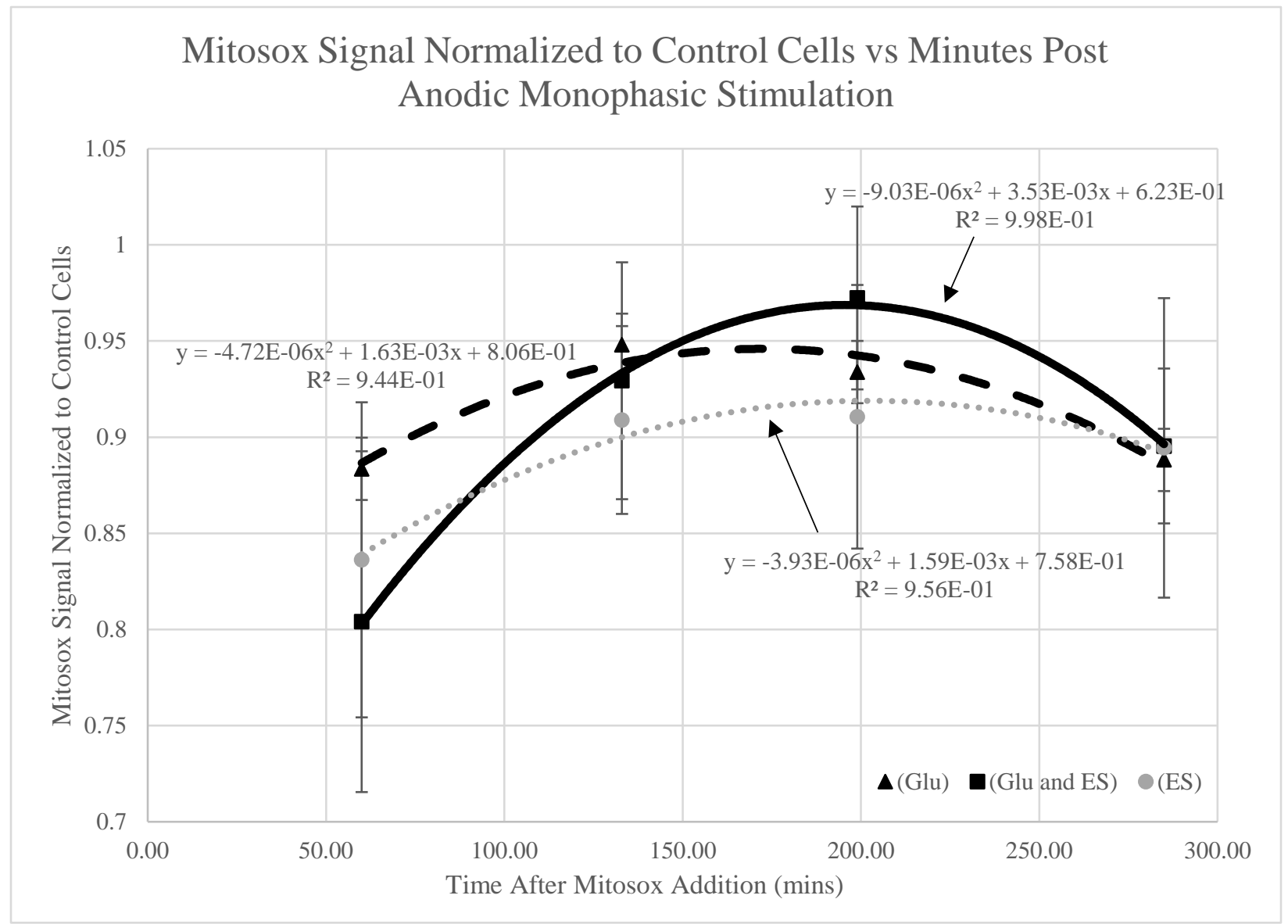

Figure 39 (B): Graphical representation of the normalized Mitosox signal changing with time as a result of anodic monophasic ES with or without glutamate treatment. Values are mean $\pm \mathrm{SD}$ of five readings for $\mathrm{n}=4$ independent replicates. 
Asymmetric Biphasic 1-2 Results - The DAF-FM signal following asymmetric biphasic 1-2 waveform treatment is depicted in Figure 40(A,B). Treatment with glutamate and ES or ES alone resulted in an increase in the DAF-FM signal, relative to the no treatment control, as incubation progressed. The glutamate treatment alone shows a downward trend as incubation progressed (Figure 40B). These results indicate that asymmetric biphasic 1-2 ES can elevate NO· levels independent of added glutamate.

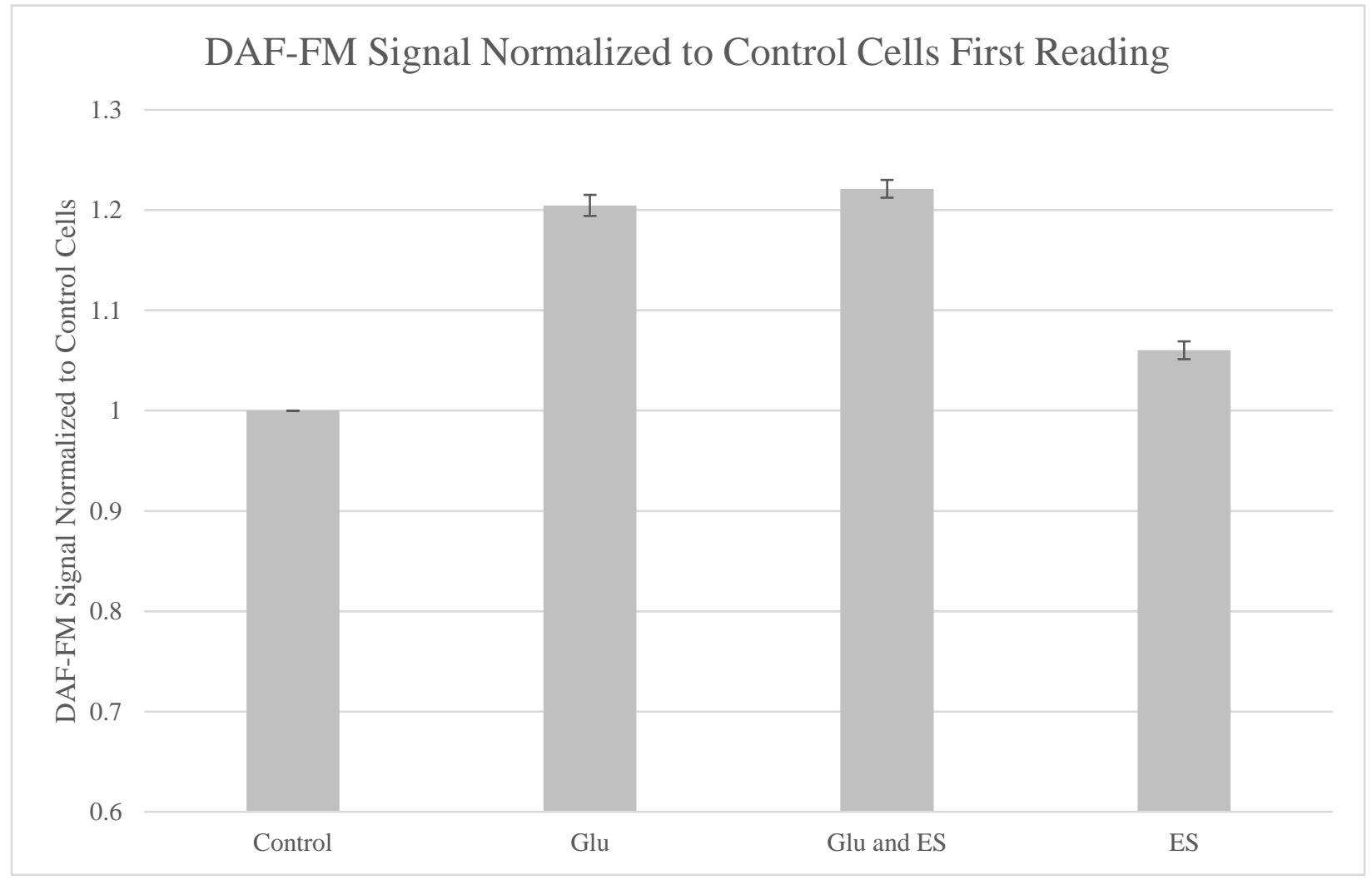

Figure 40 (A): Graphical representation of the normalized DAF-FM signal at the initial reading as a result of asymmetric biphasic 1-2 ES with or without glutamate treatment. Values are mean \pm SD of five readings for $n=4$ independent replicates. 


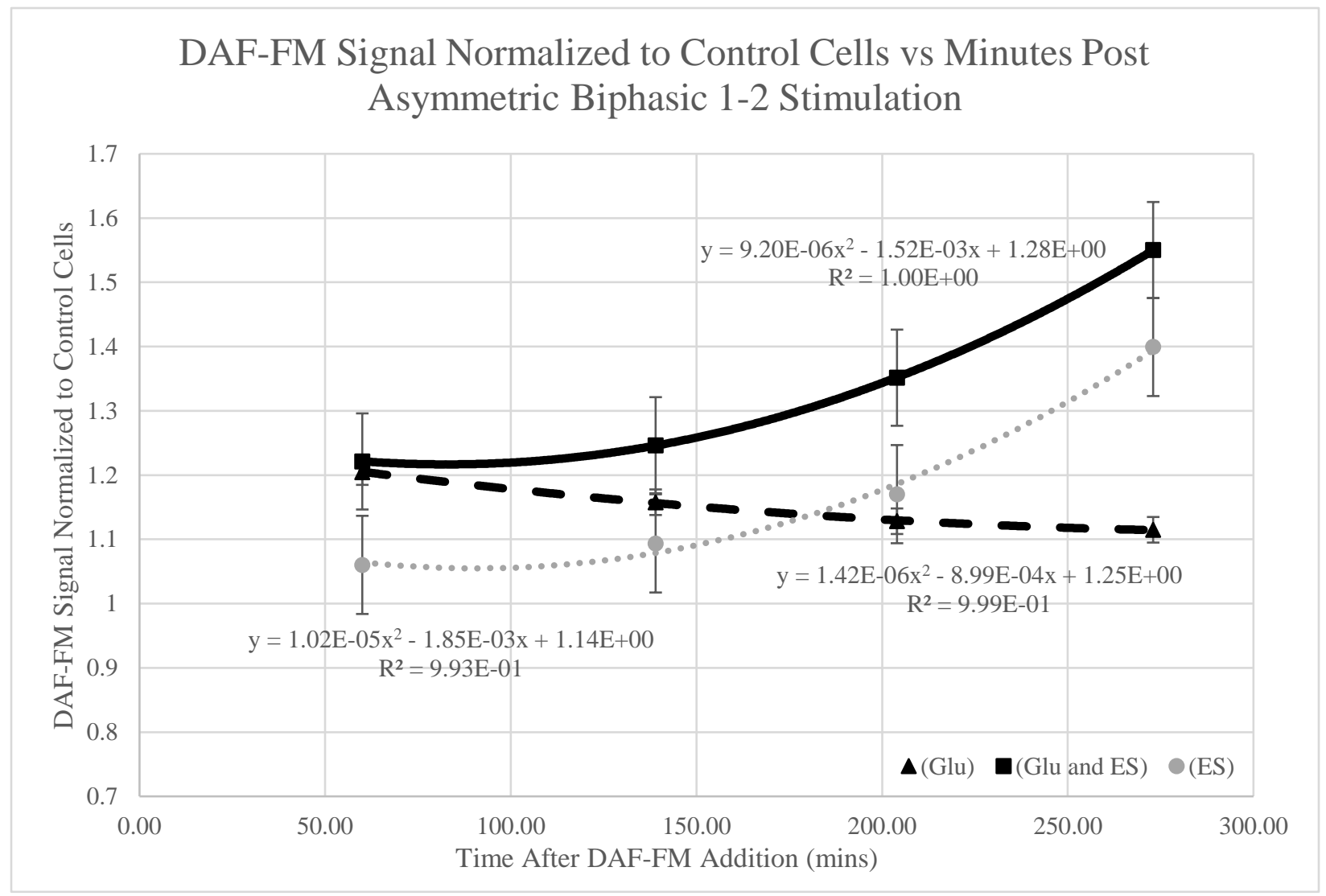

Figure 40 (B): Graphical representation of the normalized DAF-FM signal changing with time as a result of asymmetric biphasic 1-2 ES with or without glutamate treatment. Values are mean \pm SD of five readings for $n=4$ independent replicates. 
Asymmetric Biphasic 1-2 Results cont. - The Mitosox Red Superoxide probe signal following asymmetric biphasic 1-2 waveform treatment is depicted in Figure 41(A,B). There were no discernable trends in the Mitosox Red signal in response to asymmetric biphasic 1-2 stimulation. Large fluctuations in the Mitosox Red signal, at this time, are likely due to an improper ratio of probe to cell count.

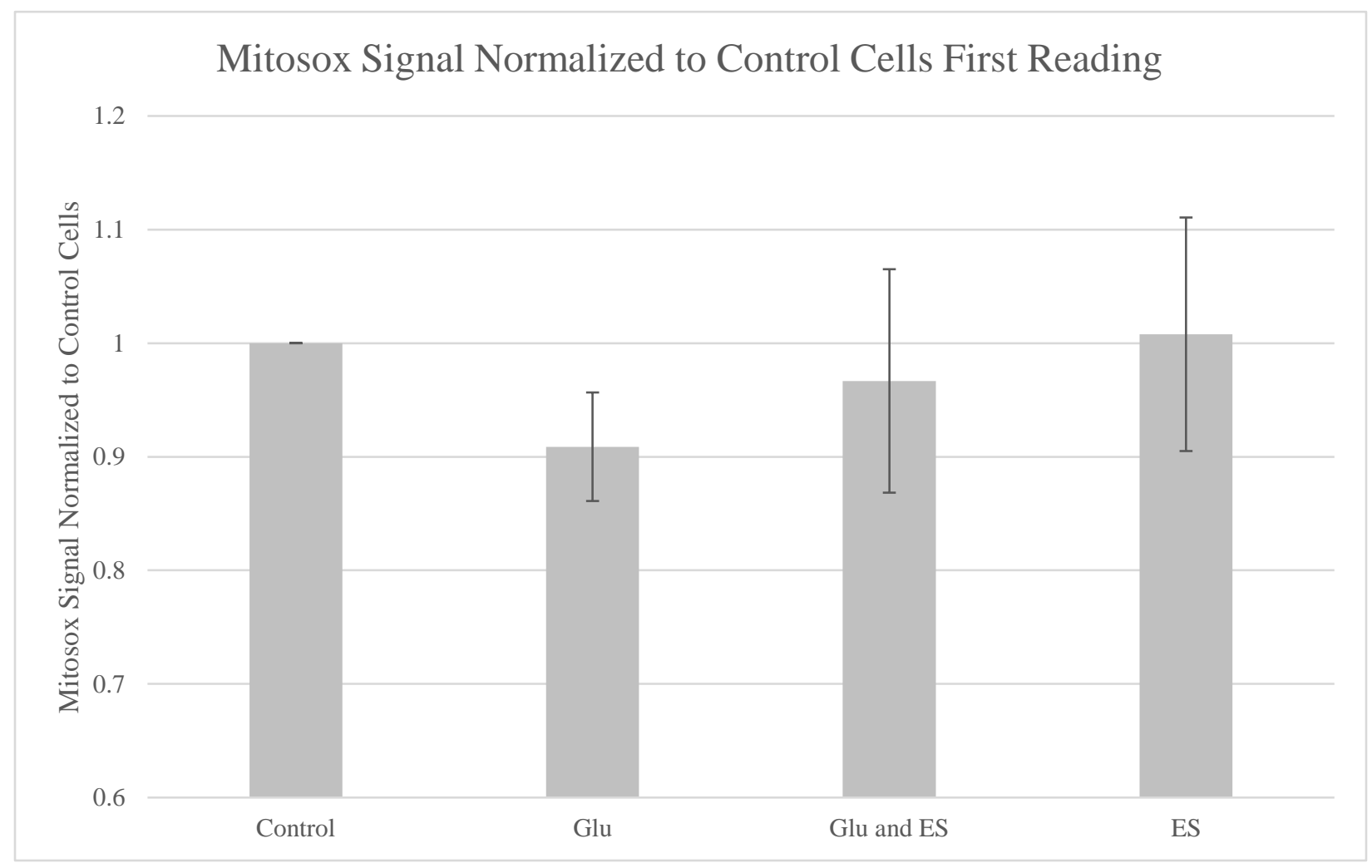

Figure 41 (A): Graphical representation of the normalized Mitosox signal at the initial reading as a result of asymmetric biphasic 1-2 ES with or without glutamate treatment. Values are mean \pm SD of five readings for $n=4$ independent replicates. 


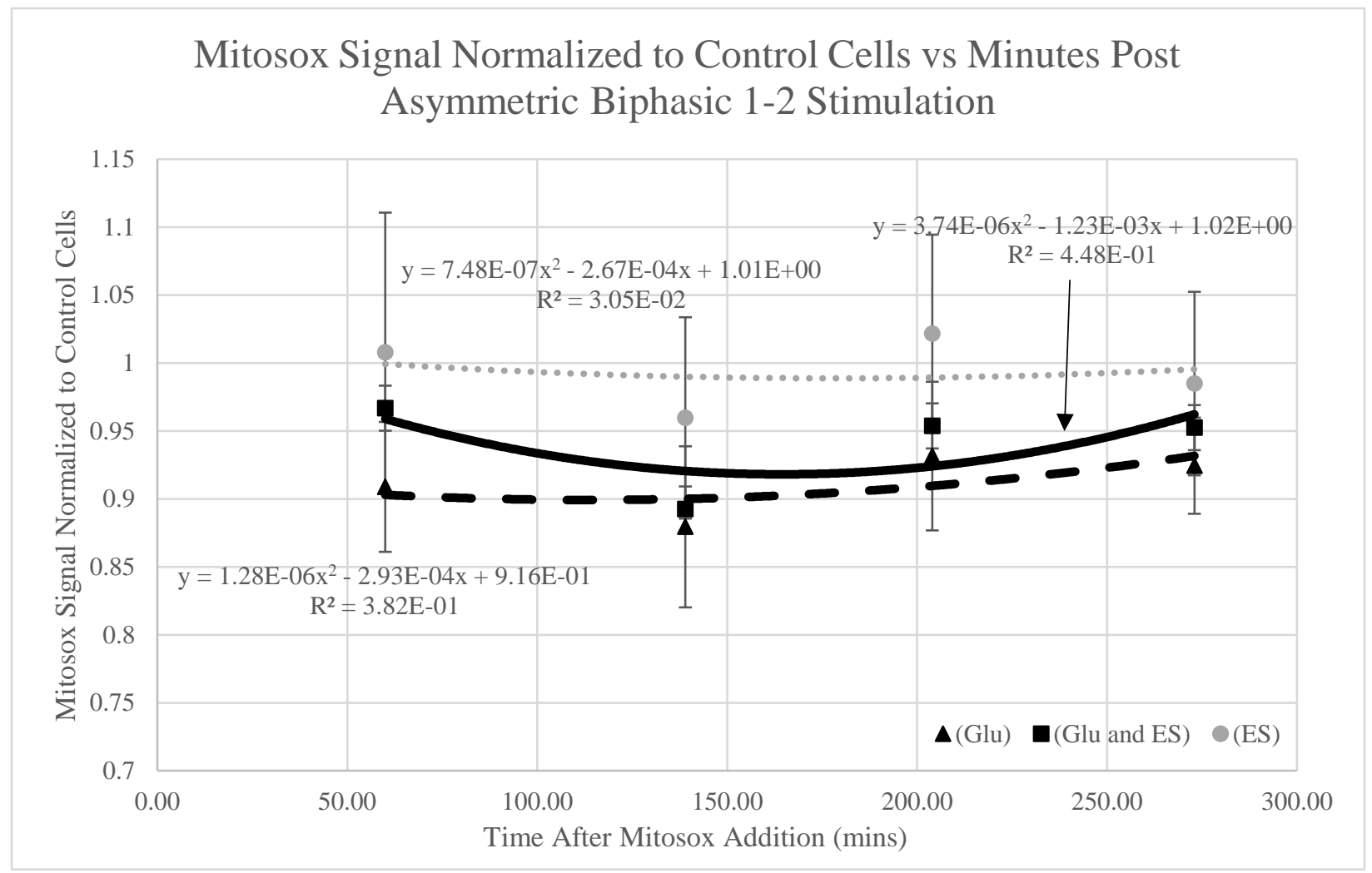

Figure 41 (B): Graphical representation of the normalized Mitosox signal changing with time as a result of asymmetric biphasic 1-2 ES with or without glutamate treatment. Values are mean \pm SD of five readings for $n=4$ independent replicates. 
Asymmetric Biphasic 2-1 Results - The DAF-FM signal following asymmetric biphasic 2-1 waveform treatment is depicted in Figure 42(A,B). The ES treatment group initially shows a DAF-FM signal that is lower than the no treatment control (Figure 42A), and trended downward as the incubation progressed. The glutamate treatment group initially shows a DAF-FM signal that is higher than the no treatment control, but trended downward as the incubation progressed. The treatment group with both ES and glutamate begins moderately higher than the no treatment control, and trended downward as incubation progressed (Figure 42B). These results indicate that NO- levels in the glioma cells are elevated in response to glutamate and reduced in upon application of asymmetric biphasic 2-1 stimulation.

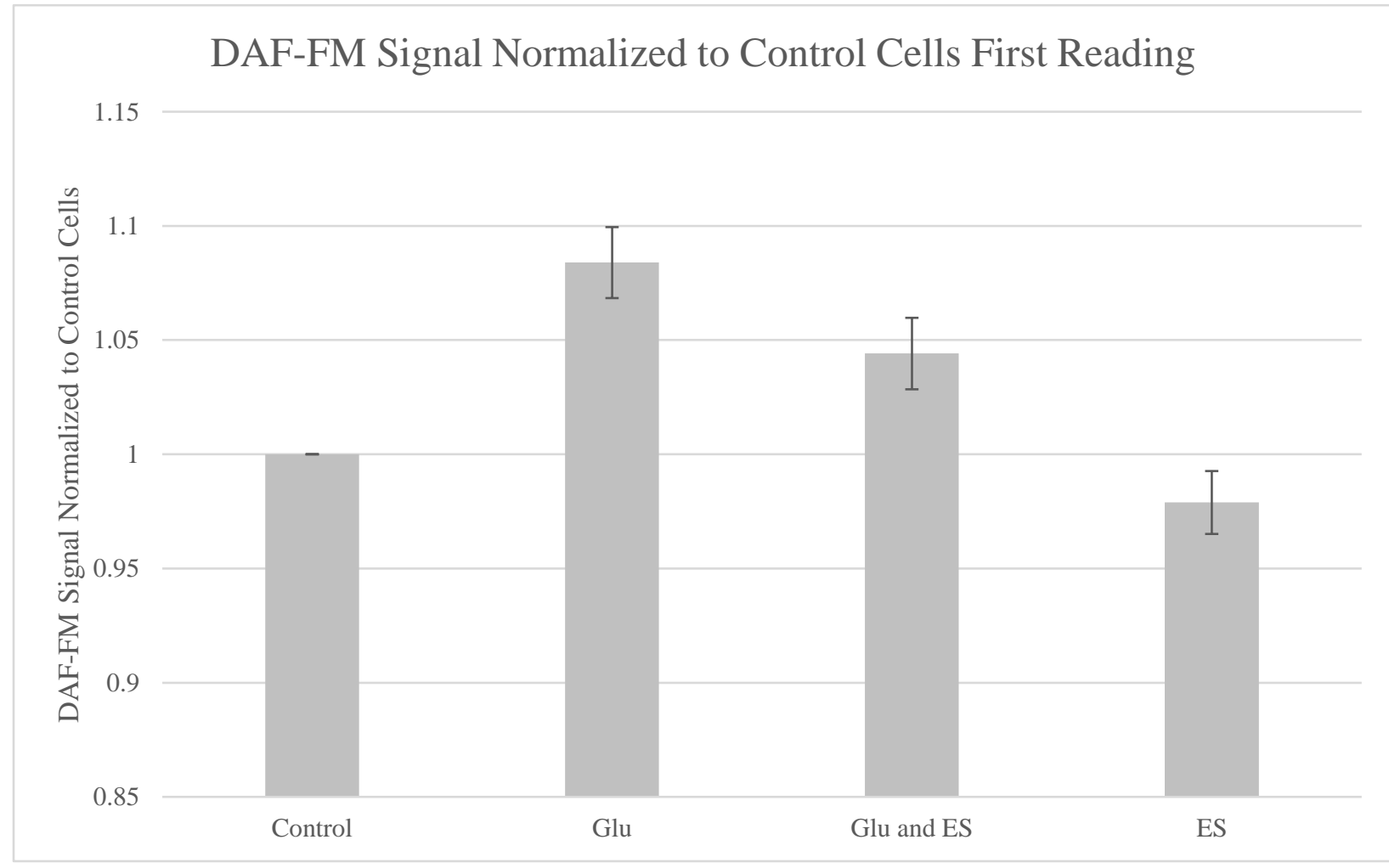

Figure 42 (A): Graphical representation of the normalized DAF-FM signal at the initial reading as a result of asymmetric biphasic 2-1 ES with or without glutamate treatment. Values are mean \pm SD of five readings for $n=4$ independent replicates. 


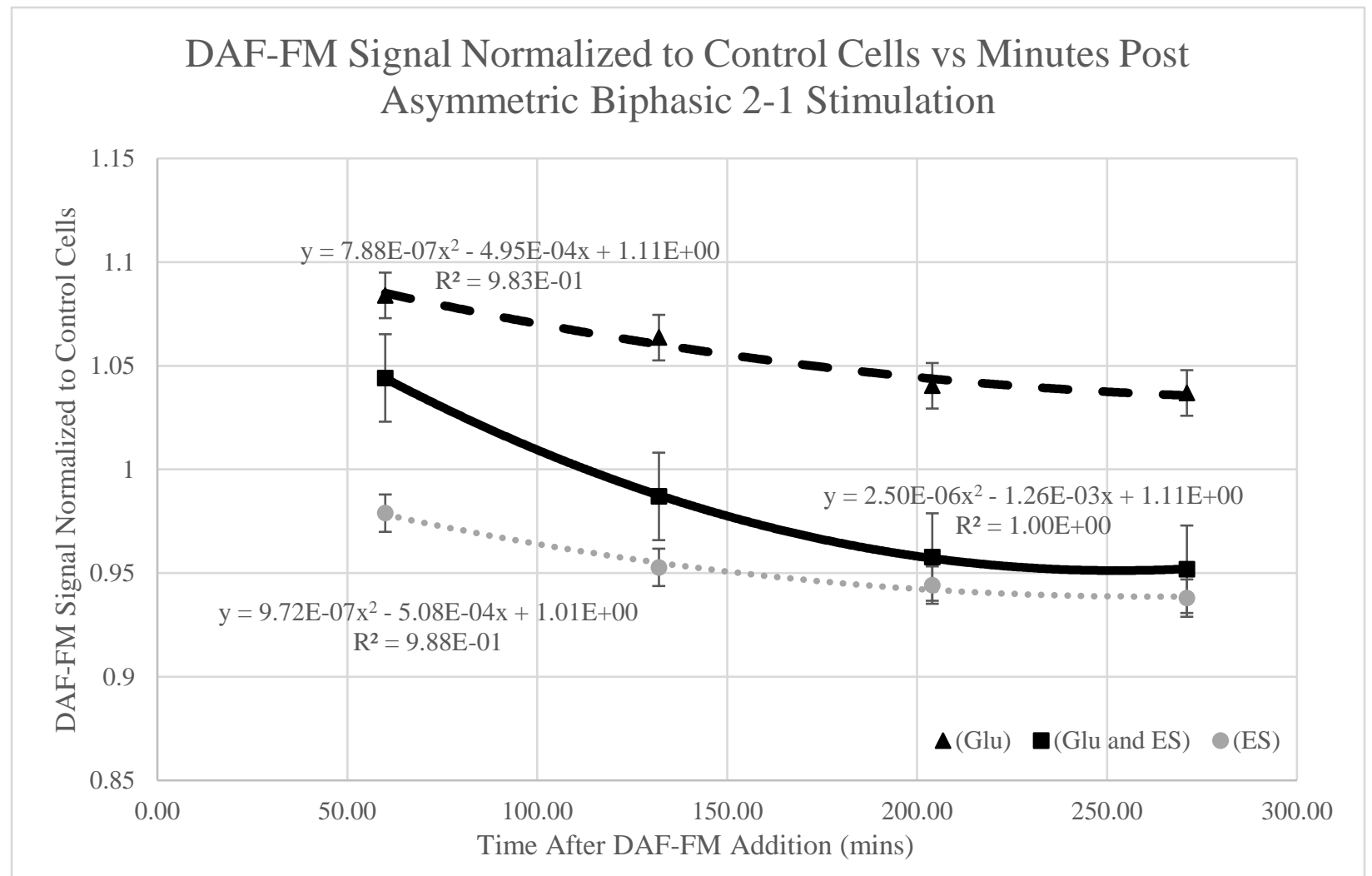

Figure 42 (B): Graphical representation of the normalized DAF-FM signal changing with time as a result of asymmetric biphasic 2-1 ES with or without glutamate treatment. Values are mean \pm SD of five readings for $n=4$ independent replicates. 
Asymmetric Biphasic 2-1 Results cont. - The Mitosox Red Superoxide probe signal following asymmetric biphasic 2-1 waveform treatment is depicted in Figure 43(A,B). There were no discernable trends in the Mitosox Red signal in response to asymmetric biphasic 2-1 stimulation. Large fluctuations in the Mitosox Red signal, at this time, are likely due to an improper ratio of probe to cell count.

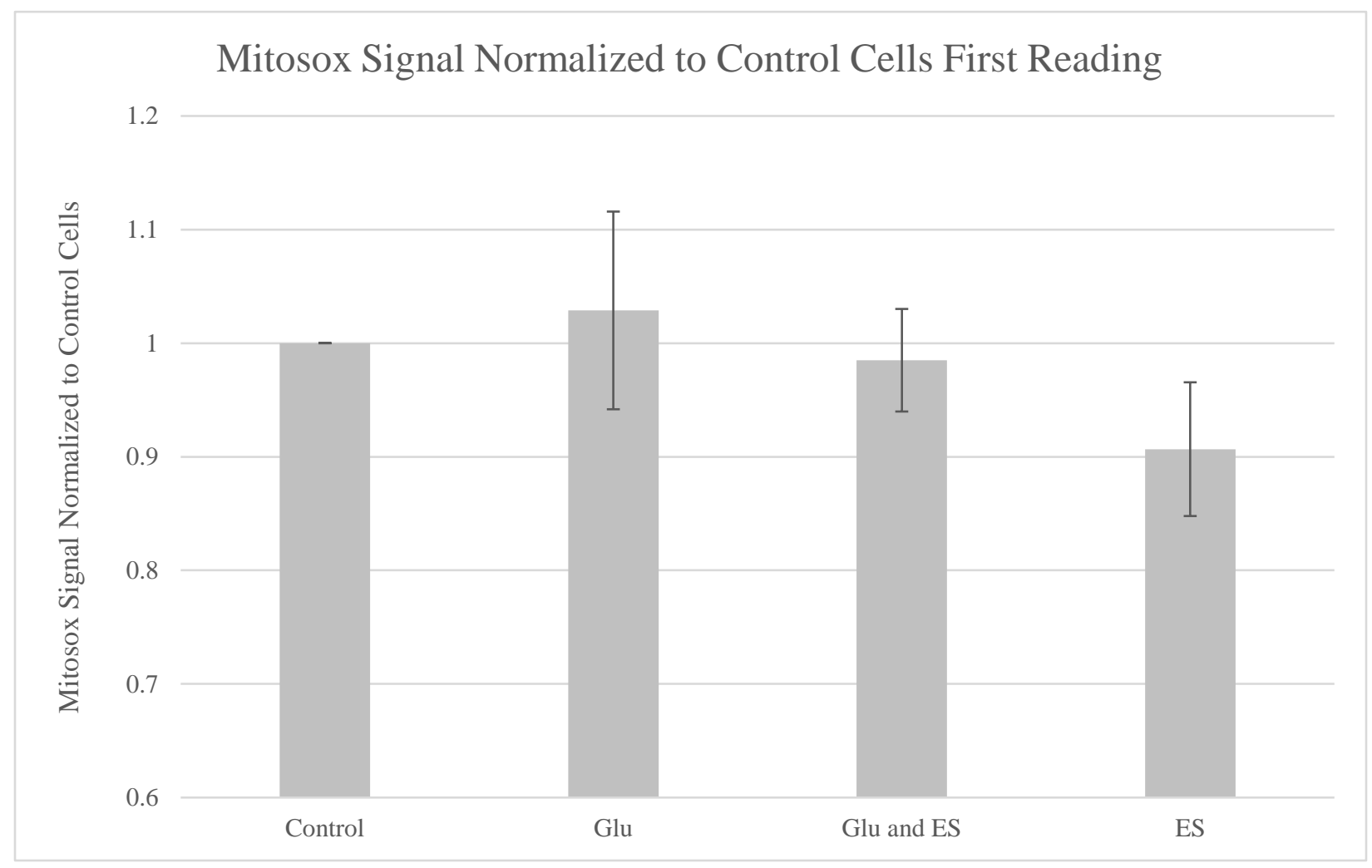

Figure 43 (A): Graphical representation of the normalized Mitosox signal at the initial reading as a result of asymmetric biphasic 2-1 ES with or without glutamate treatment. Values are mean \pm SD of five readings for $n=4$ independent replicates. 


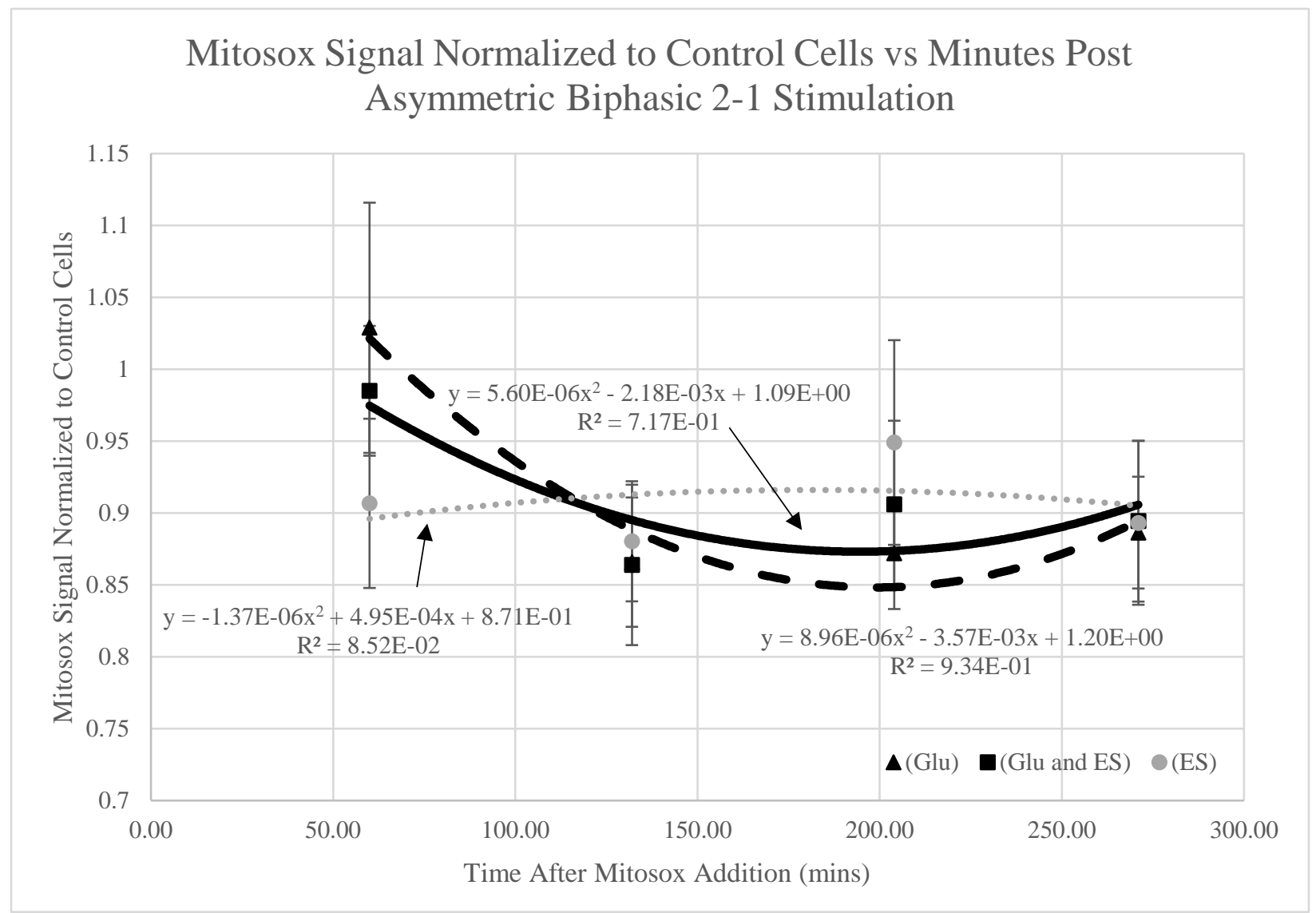

Figure 43 (B): Graphical representation of the normalized Mitosox signal changing with time as a result of asymmetric biphasic 2-1 ES with or without glutamate treatment. Values are mean \pm SD of five readings for $n=4$ independent replicates. 
Symmetric Biphasic Results - The DAF-FM signal following symmetric biphasic waveform treatment is depicted in Figure 44(A,B). Treatment with ES increased the DAF-FM signal by approximately $15 \%$ relative to the no treatment control (Figure 44A). The group that received the glutamate treatment shows an even greater increase in the signal of DAF-FM relative to the no treatment control cells. Treatment with both glutamate and symmetric biphasic ES shows an elevated DAF-FM signal, relative to the no treatment control cells, that falls between the other two groups (Figure 44B). These results indicate that symmetric biphasic stimulation does not have a large impact on the level of NO- in comparison to when added glutamate is present.

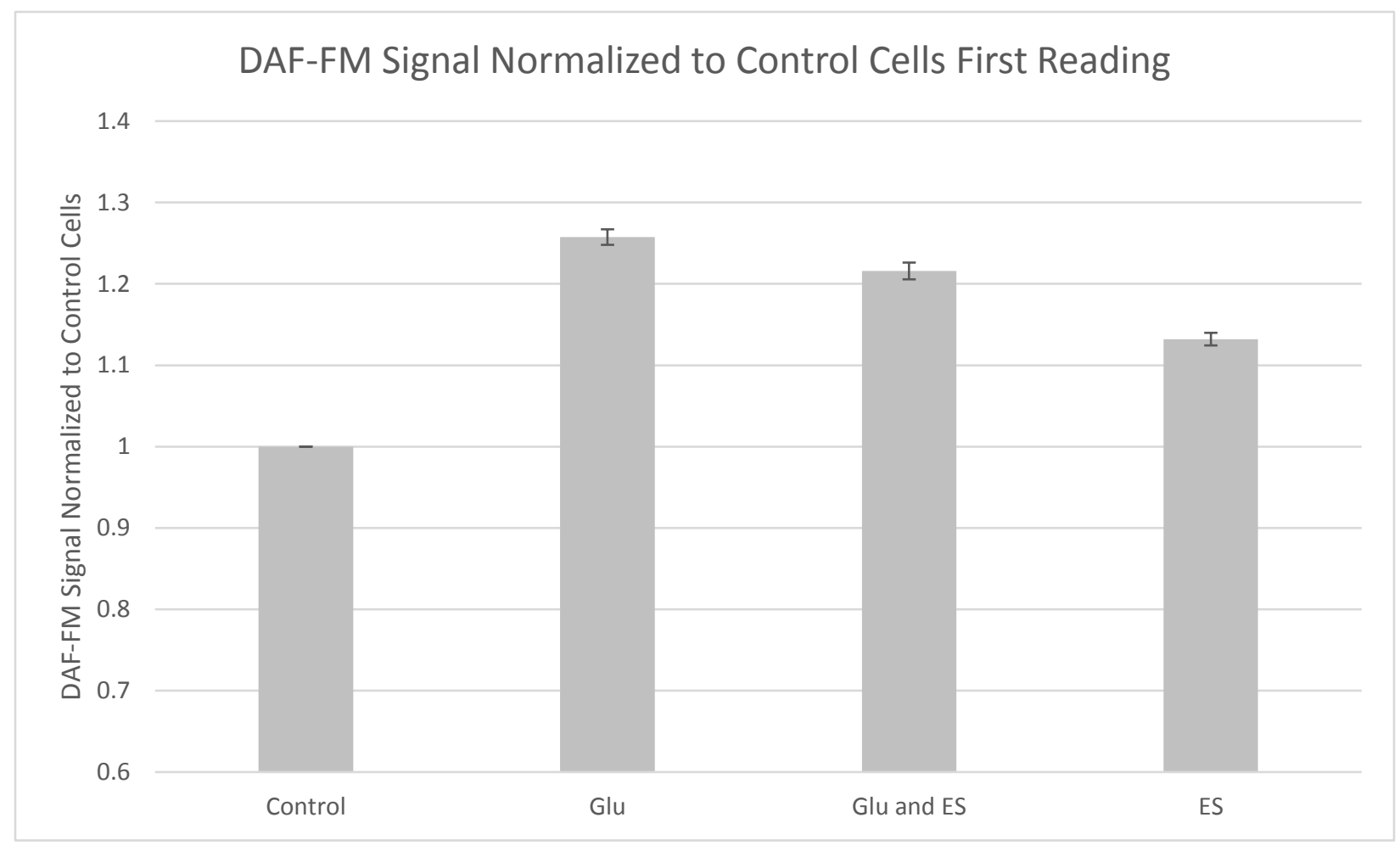

Figure 44 (A): Graphical representation of the normalized DAF-FM signal at the initial reading as a result of symmetric biphasic ES with or without glutamate treatment. Values are mean \pm SD of five readings for $\mathrm{n}=4$ independent replicates. 


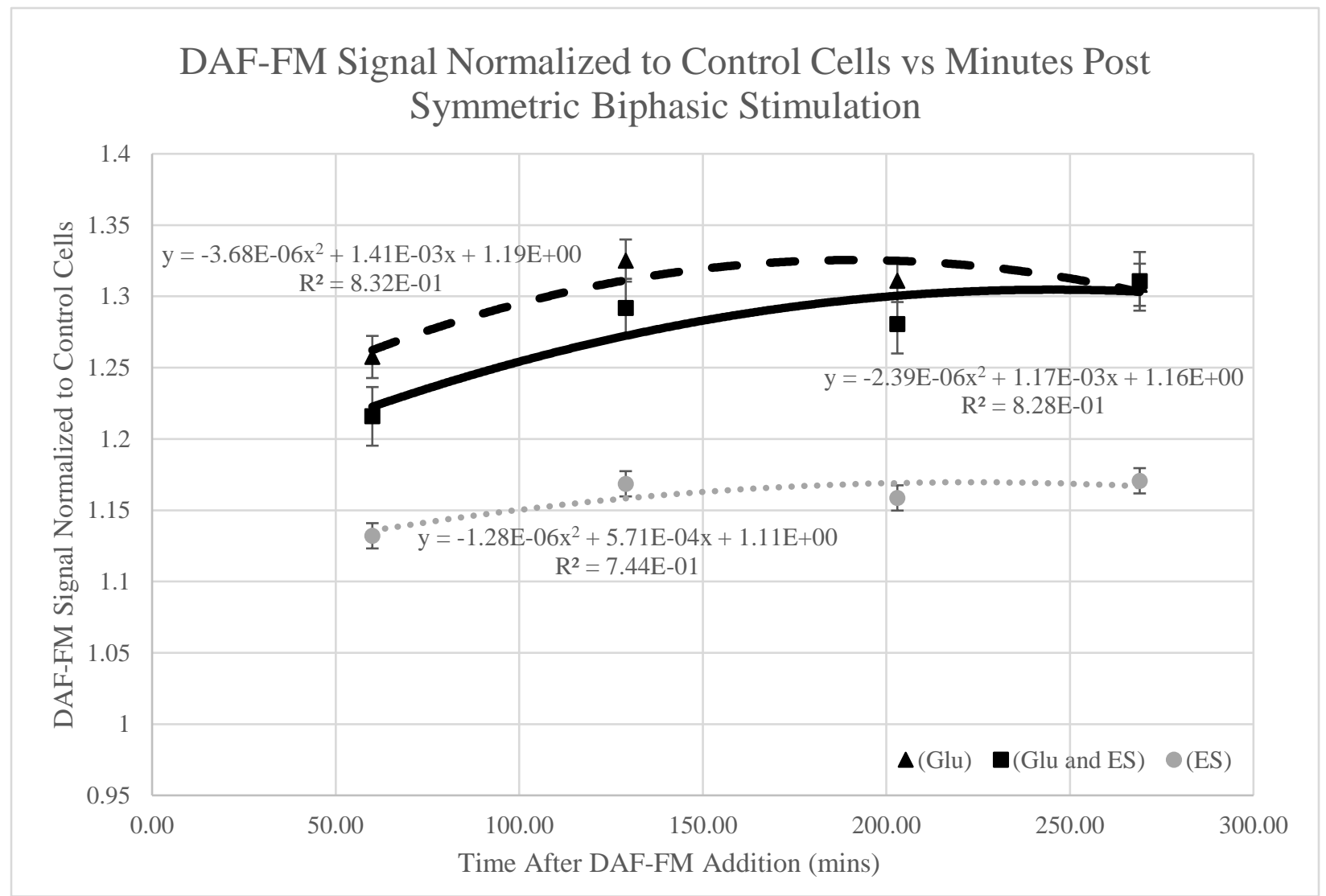

Figure 44 (B): Graphical representation of the normalized DAF-FM signal changing with time as a result of symmetric biphasic ES with or without glutamate treatment. Values are mean \pm SD of five readings for $n=4$ independent replicates. 
Symmetric Biphasic Results cont. - The Mitosox Red Superoxide probe signal for the symmetric biphasic waveform is depicted in Figure 45(A,B). Although there is a large degree of noise in the Mitosox signal, the ES and ES with added glutamate treatment groups are trending up in concert relative to the no treatment control group as incubation progresses (Figure 45B). This result may be indicating an effect of symmetric biphasic ES on increasing the level of superoxide radicals in the glioma cells. The glutamate treatment group has a consistently lower Mitosox signal than the no treatment control cells. The large fluctuations in the Mitosox signals in all the treatment groups prevent this from being a defendable conclusion at the first time point, but last one shows this trend clearly.

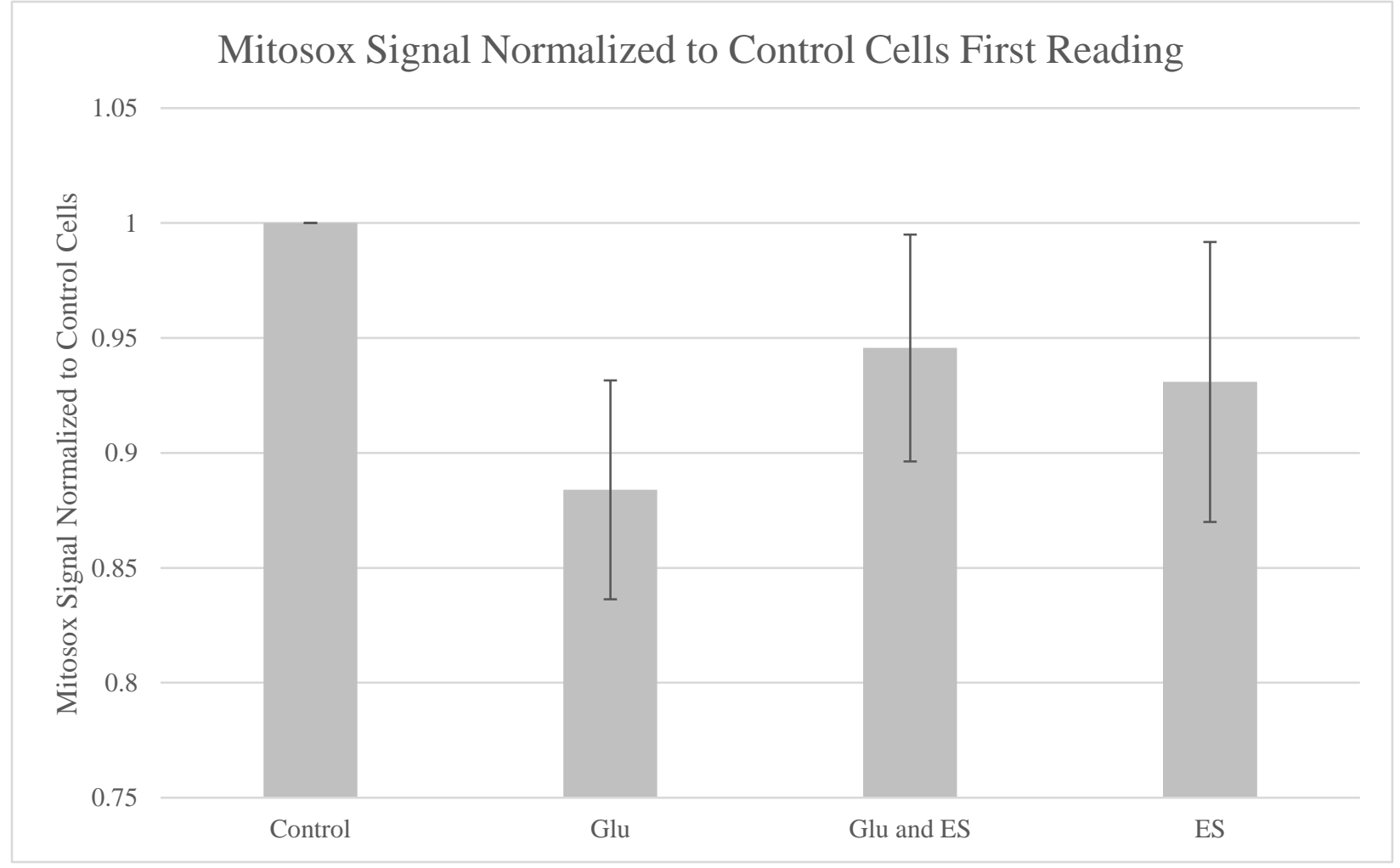

Figure 45 (A): Graphical representation of the normalized Mitosox signal at the initial reading as a result of symmetric biphasic ES with or without glutamate treatment. Values are mean \pm SD of five readings for $n=4$ independent replicates. 


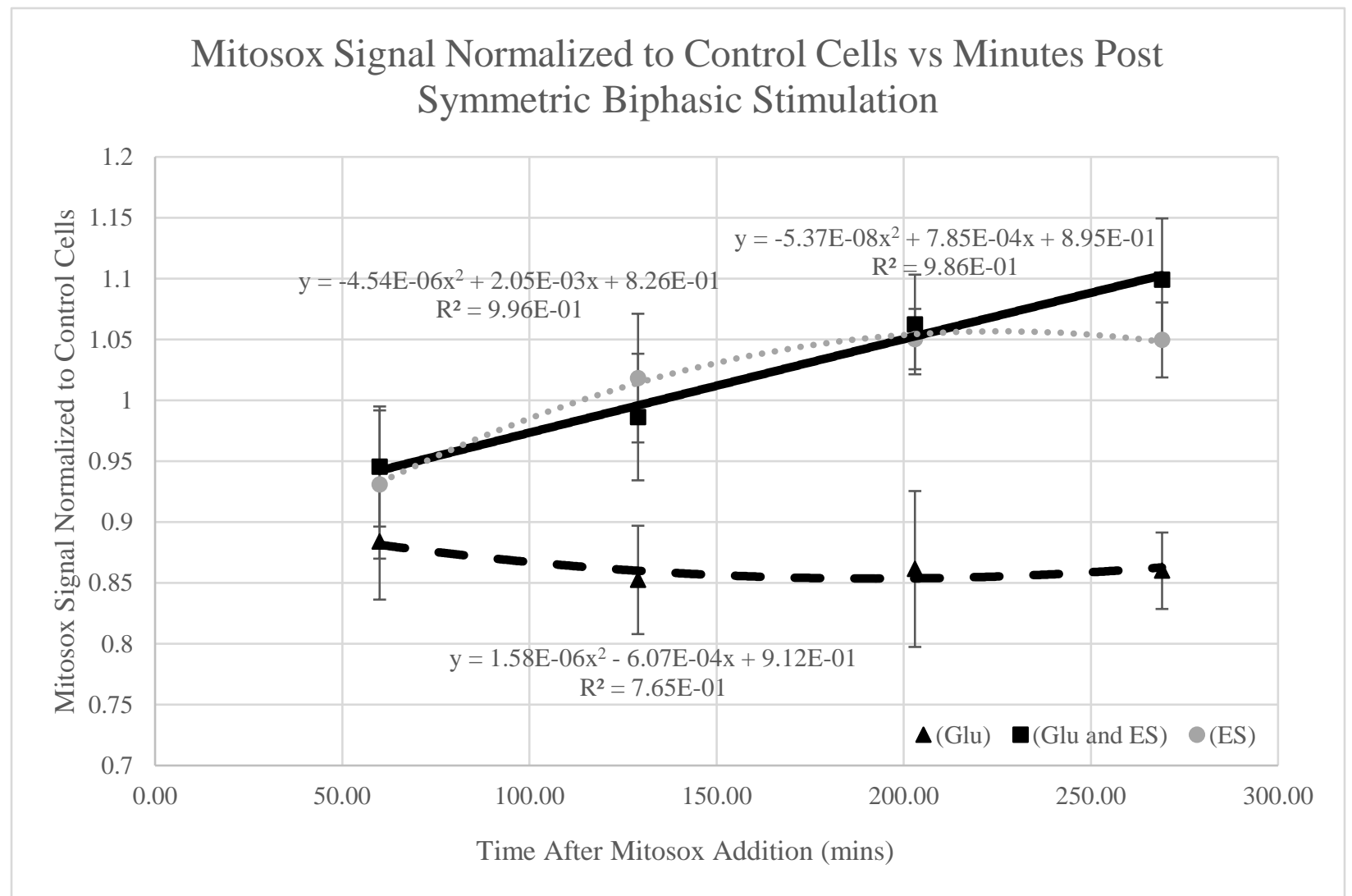

Figure 45 (B): Graphical representation of the normalized Mitosox signal changing with time as a result of symmetric biphasic ES with or without glutamate treatment. Values are mean \pm SD of five readings for $\mathrm{n}=4$ independent replicates. 
Fluorescent Probe Assay Summary - The trends in the fluorescent probe signals measured are summarized in Tables 4 and 5. In Table 4 the arrows indicate increases or decreases in probe signal (at the first time point) relative to control cells for all waveforms used. For six of the seven waveforms there is an increase in signal with added glutamate treatment as well as ES with added glutamate treatment. The ES treatment alone shows mixed results at the first time point. In Table 5 arrows are indicating the direction of the trend between the first and last time points. The two asymmetric biphasic waveforms result in trends that are almost mirror images of one another. Cathodic PR ES, one of the clinically relevant waveforms, results in increasing trends for the DAF-FM probe, but a steady or decreasing signal for the Mitosox probe. Anodic PR ES, the most impactful waveform on the genes tested in the QPCR experiments, results in opposing trends for the two probes with added glutamate. Cathodic monophasic results in opposing trends for the two probes in the absence of added glutamate. Anodic monophasic results in an increase in the trend of the DAF-FM probe in the presence of added glutamate. Symmetric biphasic ES results in an increase in the trend of the Mitosox probe in the absence or presence of glutamate. 
Table 4: Tabulated summary of the fluorescent probe trend results at the first time point. Arrows ( $\uparrow)$ indicate the direction of the change in signal relative to the signal of the normalized control cells. Hyphens (-) indicate no change in signal relative to the signal of the normalized control cells.

\begin{tabular}{|c|c|c|c|}
\hline & \multicolumn{3}{|c|}{ DAF-FM Signal } \\
\hline Waveform & ES & Glu & Glu + ES \\
\hline Cathodic & $\uparrow$ & $\uparrow$ & $\uparrow$ \\
\hline Anodic & - & $\uparrow$ & $\uparrow$ \\
\hline SymBi & $\uparrow$ & $\uparrow$ & $\uparrow$ \\
\hline AsymBi 2-1 & $\downarrow$ & $\uparrow$ & $\uparrow$ \\
\hline AsymBi 1-2 & $\uparrow$ & $\uparrow$ & $\downarrow$ \\
\hline Cathodic PR & $\downarrow$ & $\downarrow$ & $\uparrow$ \\
\hline Anodic PR & - & $\uparrow$ & \\
\hline
\end{tabular}

Table 5: Tabulated summary of the fluorescent probe trend results. Bolded arrows ( $)$ ) indicate the direction of the change in trend of the normalized probe signal over the course of the experiment. Hyphens (-) indicate a normalized probe signal that was stable with time over the course of the experiment.

\begin{tabular}{|c|c|c|c|c|c|c|c|}
\hline & \multicolumn{3}{|c}{ DAF-FM } & \multicolumn{2}{c|}{ Mitosox } & $\begin{array}{c}\text { \# of } \\
\text { Relative } \\
\text { Changes }\end{array}$ \\
\hline Waveform & ES & Glu & $\begin{array}{c}\text { ES and } \\
\text { Glu }\end{array}$ & ES & Glu & $\begin{array}{c}\text { ES and } \\
\text { Glu }\end{array}$ & \\
\hline Cathodic & $\uparrow$ & $\downarrow$ & $\uparrow$ & $\downarrow$ & - & - & 4 \\
\hline Anodic & - & - & $\uparrow$ & - & - & - & 1 \\
\hline $\begin{array}{c}\text { SymBi } \\
\text { AsymBi } \\
2-1\end{array}$ & - & - & - & $\uparrow$ & - & $\uparrow$ & 2 \\
\hline $\begin{array}{c}\text { AsymBi } \\
1-2\end{array}$ & $\uparrow$ & $\downarrow$ & $\downarrow$ & - & $\downarrow$ & $\downarrow$ & 5 \\
\hline $\begin{array}{c}\text { Cathodic } \\
\text { PR }\end{array}$ & $\uparrow$ & $\uparrow$ & $\uparrow$ & - & $\uparrow$ & $\uparrow$ & 5 \\
\hline $\begin{array}{c}\text { Anodic } \\
\text { PR }\end{array}$ & - & $\downarrow$ & $\downarrow$ & - & $\downarrow$ & - & 4 \\
\hline
\end{tabular}




\section{CHAPTER IV: CONCLUSION}

Conclusions - Glial cells, a primary component of the central nervous system, have a diverse set of functions. Recently, cells of this type have been implicated in the development of chronic pain in animal model systems (Vallejo et al., 2016). The progression of this pathology is poorly understood, but there is evidence that oxidative stress, pertaining to reactive oxygen and reactive nitrogen species, is intimately involved. To treat chronic neuropathic pain in the clinic, medical professionals utilize many treatment strategies, including electrical stimulation. From a mechanistic stand point, the effectiveness of ES treatments are in need of description. With the goal of developing a non-animal model system to test the mechanism(s) of action of the electrical stimulation treatments, experiments were designed to test electrically stimulated cells in culture for changes in gene expression, ROS, and RNS.

As evidenced by the tabulated summaries, the changes measured in gene expression and ROS and RNS levels varied widely. There are a couple of trends that seem promising, however. The anodic PR waveform was especially interesting since six of the eight genes tested showed increases in expression levels relative to the control groups, even with the conservative criteria used here. Additionally, the NO- probe experiment suggest this waveform may be counter-acting the effect of glutamate on the glioma cells' RNS levels. The cathodic monophasic waveform elicited an effect on five of the eight genes tested in the QPCR analysis and was consistent in decreasing the expression levels. The fluorescent probe studies for cathodic monophasic also gave intriguing results where the NO- probe trends inverted in response to glutamate and cathodic monophasic stimulation as incubation times increased. Anodic monophasic and asymmetric biphasic 2-1 showed changes in two of eight genes tested, but not in the same two genes. Symmetric biphasic altered expression of only one gene tested, and this was decreased. 
Asymmetric biphasic 1-2 showed no change in normalized gene expression for any of the eight genes tested. Yet all waveforms result in one or more relative changes in ROS or RNS signals.

It is worth noting that exclusion criteria for the gene expression study were intentionally broad, encompassing the mean and standard deviation of all the control groups for all the waveforms. This was done to account for the plate to plate variability introduced by the differences in the cell population that were potentially changing over time. As a result of this, there were a number experimental conditions that were very near the cut-off region. These sets of conditions may lead to significant changes in gene expression, but are obscured by our conservative criteria leaving only some changes in expression to be considered as significant.

The most significant conclusion to be drawn from these results is that the glioma cell culture method developed in this thesis is capable of monitoring differential gene expression and perturbations in ROS and RNS probe signals as a result of applied ES with or without glutamate. This glial cell model system can thus be utilized to investigate the effects of different waveforms of ES and various effector compounds on cultured glioma cells for a myriad of different parameters. 


\section{CHAPTER V: FUTURE WORK}

Mitosox Optimization - During the course of the experiments the fluorescence signal of the Mitosox probe has shown a wide degree of variation. At this time, this fluctuation is attributed to an improper concentration of Mitosox relative to the population of glioma cells. To improve signal of this probe an optimization experiment should be conducted using a serial dilution of Mitosox.

Temperature Effects Experiment - The effect of temperature was poorly controlled during the course of our ES experiments and remains a potential source of error that may be obscuring trends in the results. The stimulation step of the experiments was performed at room temperature due to instrumental limitations. To better account for the effect temperature has on this system, the fluorescent probe experiments should be conducted using a slide warmer apparatus to help maintain $37^{\circ} \mathrm{C}$ during the stimulation step of the experiment. If there is a large

effect on ROS or RNS probe signals due to temperature fluctuations, this experiment may help to improve our controls on this system.

Dimethylfumarate Experiment - A compound, dimethylfumarate (DMF), currently undergoing clinical trials for treatment of multiple sclerosis, is reported to elicit effects on ROS and RNS balance in the neurological system by acting as an enzyme inhibitor. To test whether or not this compound is affecting the ROS and RNS balance of glial cells, and if ES is impactful on this process, DMF should also be tested as the cellular perturbant, in place of glutamate, in the fluorescent probe experiments. 


\section{WORKS CITED}

Arndt, V., Dick, N., Tawo, R., Dreiseidler, M., Wenzel, D., Hesse, M., \& Höhfeld, J. (2010). Chaperone-Assisted Selective Autophagy Is Essential for Muscle Maintenance. Current Biology, 20(2), 143-148. https://doi.org/10.1016/j.cub.2009.11.022

Bridges, R. J., Natale, N. R., \& Patel, S. A. (2012). System xc- cystine/glutamate antiporter: an update on molecular pharmacology and roles within the CNS. British Journal of Pharmacology, 165(1), 20-34. https://doi.org/10.1111/j.1476-5381.2011.01480.x

Deponte, M. (2013). Glutathione catalysis and the reaction mechanisms of glutathione-dependent enzymes. Biochimica et Biophysica Acta (BBA) - General Subjects, 1830(5), 3217-3266. https://doi.org/10.1016/j.bbagen.2012.09.018

Grace, P. M., Gaudet, A. D., Staikopoulos, V., Maier, S. F., Hutchinson, M. R., Salvemini, D., \& Watkins, L. R. (2016). Nitroxidative signaling mechanisms in pathological pain. Trends in Neurosciences, 39(12), 862-879. https://doi.org/10.1016/j.tins.2016.10.003

Grubbs, F. E. (1950). Sample Criteria for Testing Outlying Observations. The Annals of Mathematical Statistics, 21(1), 27-58. https://doi.org/10.1214/aoms/1177729885

Helfman, D. M., Kim, E. J., Lukanidin, E., \& Grigorian, M. (2005). The metastasis associated protein S100A4: role in tumour progression and metastasis. British Journal of Cancer, 92(11), 1955-1958. https://doi.org/10.1038/sj.bjc.6602613

Kung, L.-H., Gong, K., Adedoyin, M., Ng, J., Bhargava, A., Ohara, P. T., \& Jasmin, L. (2013). Evidence for Glutamate as a Neuroglial Transmitter within Sensory Ganglia. PLoS ONE, 8(7), e68312. https://doi.org/10.1371/journal.pone.0068312 
Ling, X.-B., Wei, H.-W., Wang, J., Kong, Y.-Q., Wu, Y.-Y., Guo, J.-L., \& Li, J.-K. (2016). Mammalian Metallothionein-2A and Oxidative Stress. International Journal of Molecular Sciences, 17(9). https://doi.org/10.3390/ijms17091483

Liu, H.-T., Akita, T., Shimizu, T., Sabirov, R. Z., \& Okada, Y. (2009). Bradykinin-induced astrocyte-neuron signalling: glutamate release is mediated by ROS-activated volumesensitive outwardly rectifying anion channels: Anion channels mediate astrocyte-neuron signalling. The Journal of Physiology, 587(10), 2197-2209. https://doi.org/10.1113/jphysiol.2008.165084

Loboda, A., Damulewicz, M., Pyza, E., Jozkowicz, A., \& Dulak, J. (2016). Role of Nrf2/HO-1 system in development, oxidative stress response and diseases: an evolutionarily conserved mechanism. Cellular and Molecular Life Sciences, 73, 3221-3247. https://doi.org/10.1007/s00018-016-2223-0

Matés, J. M., Segura, J. A., Alonso, F. J., \& Márquez, J. (2006). Pathways from glutamine to apoptosis. Frontiers in Bioscience: A Journal and Virtual Library, 11, 3164-3180.

Milligan, E. D., \& Watkins, L. R. (2009). Pathological and protective roles of glia in chronic pain. Nature Reviews Neuroscience, 10(1), 23-36. https://doi.org/10.1038/nrn2533

Mori, R., Wang, Q., Danenberg, K. D., Pinski, J. K., \& Danenberg, P. V. (2008). Both $\beta$-actin and GAPDH are useful reference genes for normalization of quantitative RT-PCR in human FFPE tissue samples of prostate cancer. The Prostate, 68(14), 1555-1560. https://doi.org/10.1002/pros.20815

Niu, X., Zheng, S., Liu, H., \& Li, S. (2018). Protective effects of taurine against inflammation, apoptosis, and oxidative stress in brain injury. Molecular Medicine Reports, 18(5), 45164522. https://doi.org/10.3892/mmr.2018.9465 
Robinson, K. M., Janes, M. S., Pehar, M., Monette, J. S., Ross, M. F., Hagen, T. M., \& Beckman, J. S. (2006). Selective fluorescent imaging of superoxide in vivo using ethidium-based probes. Proceedings of the National Academy of Sciences of the United States of America, 103(41), 15038-15043. https://doi.org/10.1073/pnas.0601945103

Salvemini, D., Little, J. W., Doyle, T., \& Neumann, W. L. (2011). Roles of Reactive Oxygen and Nitrogen Species in Pain. Free Radical Biology \& Medicine, 51(5), 951-966. https://doi.org/10.1016/j.freeradbiomed.2011.01.026

Sdrulla, A. D., Guan, Y., \& Raja, S. N. (2018). Spinal Cord Stimulation: Clinical Efficacy and Potential Mechanisms. Pain Practice, 18(8), 1048-1067. https://doi.org/10.1111/papr.12692

Tiburcio-Félix, R., Escalante-López, M., López-Bayghen, B., Martínez, D., Hernández-Kelly, L. C., Zinker, S., \& Ortega, A. (2018). Glutamate-Dependent Translational Control of Glutamine Synthetase in Bergmann Glia Cells. Molecular Neurobiology, 55(6), 52025209. https://doi.org/10.1007/s12035-017-0756-3

Tiede, J., Brown, L., Gekht, G., Vallejo, R., Yearwood, T., \& Morgan, D. (2013). Novel Spinal Cord Stimulation Parameters in Patients with Predominant Back Pain: Novel Spinal Cord Stimulation. Neuromodulation: Technology at the Neural Interface, 16(4), 370-375. https://doi.org/10.1111/ner.12032

Tjalkens, R. B., Carbone, D. L., \& Wu, G. (2011). Detection of Nitric Oxide Formation in Primary Neural Cells and Tissues. Methods in Molecular Biology (Clifton, N.J.), 758, 267-277. https://doi.org/10.1007/978-1-61779-170-3_18 
Vallejo, R., Tilley, D. M., Cedeño, D. L., Kelley, C. A., DeMaegd, M., \& Benyamin, R. (2016). Genomics of the Effect of Spinal Cord Stimulation on an Animal Model of Neuropathic Pain. Neuromodulation: Technology at the Neural Interface, 19(6), 576-586. https://doi.org/10.1111/ner.12465

Verkhratsky, A., \& Kirchhoff, F. (2007a). Glutamate-mediated neuronal-glial transmission. Journal of Anatomy, 210(6), 651-660. https://doi.org/10.1111/j.1469-7580.2007.00734.x

Verkhratsky, A., \& Kirchhoff, F. (2007b). NMDA Receptors in Glia. The Neuroscientist, 13(1), 28-37. https://doi.org/10.1177/1073858406294270

Verkhratsky, A., \& Kettenmann, H. (1996). Calcium signalling in glial cells. Trends in Neurosciences, 19(8), 346-352. https://doi.org/10.1016/0166-2236(96)10048-5

Weinstein, D. E. (1991). Suppression by antisense mRNA demonstrates a requirement for the glial fibrillary acidic protein in the formation of stable astrocytic processes in response to neurons. The Journal of Cell Biology, 112(6), 1205-1213.

https://doi.org/10.1083/jcb.112.6.1205 


\section{APPENDIX A: SUPPLIMENTRY MATERIALS}

Modified Dulbecco's Modified Eagle's Medium Formulation - $\mathrm{CaCl}_{2}$ (anhydrous) - 0.2000

$\mathrm{g} / \mathrm{L} ; \mathrm{Fe}\left(\mathrm{NO}_{3}\right)_{3} \cdot 9 \mathrm{H} 2 \mathrm{O}-0.0001 \mathrm{~g} / \mathrm{L} ; \mathrm{MgSO}_{4}$ (anhydrous) - $0.09770 \mathrm{~g} / \mathrm{L} ; \mathrm{KCl}-0.4000 \mathrm{~g} / \mathrm{L} ;$

$\mathrm{NaHCO}_{3}-1.5000 \mathrm{~g} / \mathrm{L} ; \mathrm{NaCl} 6.4000 \mathrm{~g} / \mathrm{L} ; \mathrm{NaH}_{2} \mathrm{PO}_{4} \cdot \mathrm{H}_{2} \mathrm{O}-0.1250 \mathrm{~g} / \mathrm{L} ; \mathrm{D}-\mathrm{Glucose}-4.5000 \mathrm{~g} / \mathrm{L}$;

Sodium Pyruvate $-0.1100 \mathrm{~g} / \mathrm{L}$. The $\mathrm{pH}$ was adjusted to 7.3 prior to filter sterilization. 